\title{
Patrícia Baldasso
}

\section{Análise comparativa da dinâmica das ondas de Rossby a partir de anomalias da altura da superficie do mar obtidas por satélite e modelos numéricos}

Dissertação apresentada ao Instituto Oceanográfico da Universidade de São Paulo, como parte dos requisitos para obtenção do título de Mestre em Ciências, Programa de Oceanografia Física.

Orientador: Prof. Dr. Paulo Simionatto Polito 


\section{Análise comparativa da dinâmica das ondas de Rossby a partir de anomalias da altura da superficie do mar obtidas por satélite e modelos numéricos}

\section{Patrícia Baldasso}

Dissertação apresentada ao Instituto Oceanográfico da Universidade de São Paulo, como parte dos requisitos para obtenção do título de Mestre em Ciências, Programa de Oceanografia Física.

Versão corrigida

Julgada em por 


\section{Agradecimentos}

Primeiramente gostaria de agradecer ao meu orientador Professor Paulo Simionatto Polito que me aceitou como aluna. Muito obrigada por compartilhar o seu conhecimento ao longo desses últimos anos, por sempre estar disponível para esclarecer qualquer dúvida a respeito de qualquer assunto, por me incentivar nos momentos de desânimo, por me acalmar nos momentos de desespero e principalmente por confiar em mim e em minha capacidade como aluna. Gostaria de agradecer também ao Guilherme Castelão, grande amigo, que além de sugerir o tema dessa dissertação de mestrado me ajudou imensamente em todos os momentos que precisei.

Também agradeço ao Instituto Oceanográfico da Universidade de São Paulo (IOUSP) e todos os professores e funcionários que contribuíram para a minha formação. Em especial ao Professor Ilson da Silveira, que soube entender as minhas particularidades e não mediu esforços para que eu aproveitasse suas aulas da melhor forma possível. Por me oferecer um emprego, compartilhar todo o seu conhecimento e experiência, além do incentivo e compreensão com o meu cansaço e estresse nas semanas anteriores ao depósito deste trabalho. Sou imensamente grata por tudo.

À Coordenação de Aperfeiçoamento de Pessoal de Nível Superior - CAPES pelo apoio financeiro para realização da presente dissertação.

À todos os amigos do Laboratório de Oceanografia por Satélite que compartilharam inúmeros momentos. Principalmente ao Wandrey Watanabe pelas explicações durante a disciplina de Dinâmica de Fluídos Geofísicos II, à Ana Beatriz M. Villas Bôas por todo incentivo, ajuda nos estudos de cálculo para ingressar no mestrado e depois nas intermináveis listas de exercícios e ao Márcio Borges Ferreira por compartilhar toda a sua experiência dentro e fora da vida acadêmica e por me lembrar como é bom estar no mar.

Ao amigos e companheiros de trabalho do Laboratório de Dinâmica Oceânica pelos inúmeros cafés, conversas, companhia, paciência e principalmente pelas risadas diárias. Em especial ao Dante Campagnoli Napolitano e Iury T. Simões de Souza que não mediram esforços para me ajudar com os mínimos detalhes deste trabalho.

Aos meus pais, José Felicio Baldasso e Clarinda G. Baldasso, que sempre foram meus maiores incentivadores e nunca questionaram minha escolhas, nem mesmo quando uma dessas me levou para $1500 \mathrm{~km}$ de distância, aos 17 anos. Aos meus irmãos Priscila Baldasso e Wilian Baldasso pela amizade mais linda que existe. Sem o apoio de todos vocês eu não seria nada.

Por último, a pessoa que esteve ao meu lado em absolutamente todos os dias, que ouviu todos os meus medos, incertezas e me ajudou a superar cada um deles. Muito obrigada Gilberto Akio Oliveira Watanabe por ser meu parceiro na vida. 


\section{Resumo}

Dados de altura da superfície do mar medidos a partir de satélites altimétricos e saídas de dois modelos de circulação geral dos oceanos (OGCM for the Earth Simulator - OFES e Community Earth System Model - CESM) foram utilizados com o objetivo de verificar se modelos numéricos climáticos reproduzem ondas de Rossby de forma similar à observada em dados altimétricos no Atlântico Sul. Os modelos diferem quanto à forçante, o modelo OFES é forçado com dados do NECP-NCAR enquanto que o modelo CESM é acoplado com modelo atmosférico, de gelo e terrestre. Uma vez que essas ondas dependem da estrutura interna de densidade e da forçante do vento, podemos fazer inferências sobre a adequação desses dois fatores nos modelos à realidade observada pelo altímetro. Uma série de filtros de resposta impulsiva finita 2D (FIR-2D) foi aplicada aos dados de anomalia da altura da superfície do mar com o propósito de detectar as ondas de Rossby e as componentes de onda encontradas nos dados dos modelos foram comparadas com as do altímetro. Os dois modelos são capazes de reproduzir ondas de Rossby e apresentam melhores resultados em baixas latitudes. Porém o modelo OFES apresentou mais dificuldades para reproduzir os parâmetros de onda encontrados no altímetro apresentando diferenças médias de até $68 \%$ para a amplitude, $34 \%$ para o comprimento de onda e $38 \%$ para a velocidade de fase. Em contrapartida as maiores diferenças médias entre os parâmetros de onda calculados a partir dos dados altimétricos e do modelo CESM foram de 32\% para a amplitude, $20 \%$ para o comprimento de onda e $20 \%$ para a velocidade de fase. Além disso, o modelo CESM foi capaz de reproduzir o sinal sazonal com uma correlação média de aproximadamente 0,7 com o sinal sazonal encontrado pelo altímetro em toda a bacia do oceano Atlântico Sul enquanto que o sinal sazonal do modelo OFES apresentou uma correlação média de 0,4 com o sinal encontrado pelo satélite. Estes resultados mostram que os dois modelos reproduzem o fenômeno satisfatoriamente, sendo o CESM melhor que o OFES. A diferença dos resultados deve estar ligada aos aspectos supracitados, especificamente à forçante atmosférica e estrutura de densidade na coluna d'água nas latitudes ao sul de $20^{\circ} \mathrm{S}$. 


\section{Abstract}

Sea surface height data measured from altimetry satellites and outputs of two ocean general circulation models (OGCM for the Earth Simulator - OFES and Community Earth System Model - CESM) were used to determine whether climate numerical models reproduce the Rossby waves in a manner similar to those observed in altimetry record in the South Atlantic. The models differs in the forcing, OFES is forced with NCEP-NCAR data while CESM is coupled with atmospheric model, ice and land model. Because these waves depend on the internal density structure and wind forcing, we can make inferences about the suitability of these two factors in the models in comparison with the altimetry data used as a reference. A series of finite impulse response band-pass filters (FIR-2D) was applied to isolate the westward propagating signals corresponding to Rossby waves in the altimeter. Both models are able to reproduce Rossby waves and show better results in low latitudes. However, the OFES model presented more difficulty to reproduce the wave parameters found in altimeter with differences of up to $68 \%$ for amplitude, $34 \%$ for the wavelength and $38 \%$ for phase velocity. By contrast the greatest differences between the wave parameters computed from the altimeter data and the CESM model were $32 \%$ for amplitude, $20 \%$ for the wavelength and $20 \%$ for phase velocity. Furthermore, the CESM model was capable of reproducing the seasonal signal correlation with an average of approximately 0.7 with altimeter's seasonal signal found throughout the South Atlantic basin, while the OFES's seasonal signal showed an average correlation 0.4 with the signal found by the satellite. These results indicate that both models can reproduce the phenomenon satisfactorily, the CESM better than OFES. The difference between the results should be related with the aspects cited above, specifically with the atmospheric forcing and the density structure in the water column in latitudes southern then $20^{\circ} \mathrm{S}$.

Key-words: Rossby wave, remote sensing, numerical model, OFES, CESM 
"Não há nada que não possa fazer se focar nos seus objetivos." Filme "Love, Rosie" 


\section{Sumário}

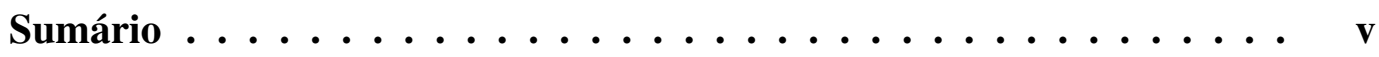

Lista de figuras ............................. vi

Lista de tabelas ...................... ix

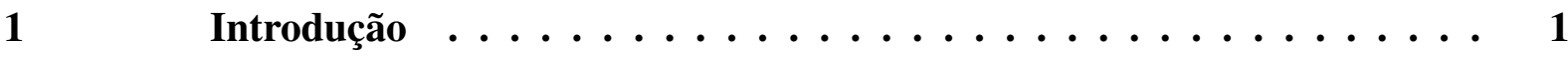

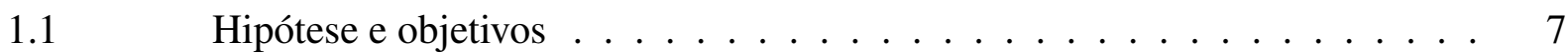

$2 \quad$ Área de Estudo $\ldots \ldots \ldots \ldots \ldots \ldots \ldots$

3 Conjunto de dados $\ldots \ldots \ldots \ldots \ldots \ldots \ldots$

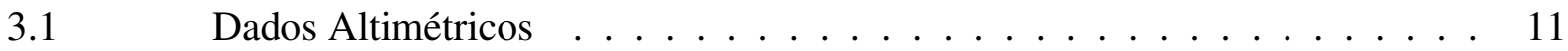

$3.2 \quad$ Saídas de modelo . . . . . . . . . . . . . . . . . . 14

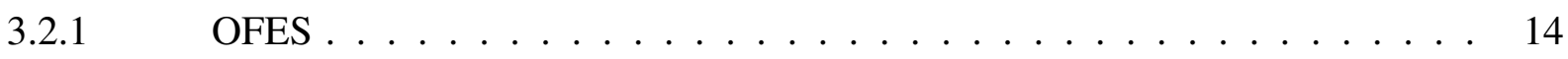

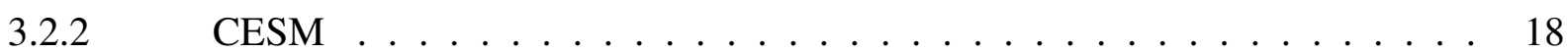

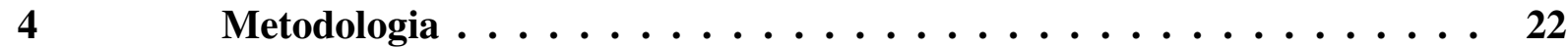

$4.1 \quad$ Pré-processamento dos dados . . . . . . . . . . . . . 22

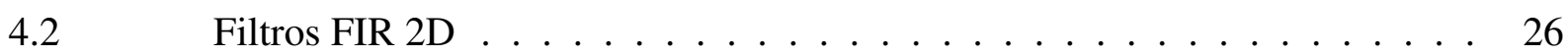

$4.3 \quad$ Transformada de Radon . . . . . . . . . . . . . . . . . 28

$4.4 \quad$ Comparação modelo-altímetro . . . . . . . . . . . . . . . 30

$5 \quad$ Resultados e discussão $\ldots \ldots \ldots \ldots \ldots \ldots$

5.1 Distribuição de potência de ondas de Rossby observada e modelada . . . . . 34

5.1.1 Comparação com o modelo OFES . . . . . . . . . . . . . . . . . . . . . 34

5.1.2 Comparação com o modelo CESM . . . . . . . . . . . . . . 42

5.2 Comparação entre médias zonais dos parâmetros de onda . . . . . . . . 50

$5.2 .1 \quad$ Modelo OFES . . . . . . . . . . . . . . . . . 50

$5.2 .2 \quad$ Modelo CESM . . . . . . . . . . . . . . . . 55

5.3 Correlações com atraso de fase entre observações e simulações . . . . . . . 60

$5.3 .1 \quad$ Modelo OFES . . . . . . . . . . . . . . . . . . . . 60

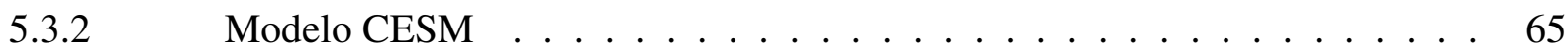

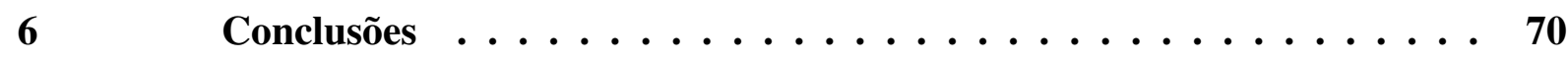

$7 \quad$ Trabalhos futuros $\ldots \ldots \ldots \ldots \ldots \ldots \ldots \ldots$

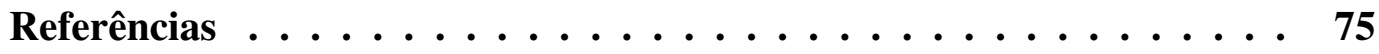




\section{Lista de figuras}

Figura 1 - Representação esquemática média das correntes de superfície do oceano Atlântico Sul. As setas pretas representam as correntes e as respectivas direções dos fluxos. Os tons de cinza indicam a profundidade média da coluna de água, em metros, onde o branco representa o oceano aberto e o cinza escuro os continentes (figura modificada de Talley et al. (2011)).

Figura 2 - Apresentação da área de estudo do presente trabalho no oceano Atlântico Sul entre as latitudes de $10^{\circ} \mathrm{S}$ e $40^{\circ} \mathrm{S}$, sob batimetria ETOPO1 .

Figura 3 - Convenção de nomenclatura das alturas altimétricas. SSH: altura da superfície do mar; SLA: anomalia da altura da superfície do mar; MSS: média da superfície do mar; MDT: topografia dinâmica média; ADT: topografia dinâmica absoluta. De Duacs/AVISO (2014) . . . . . . . . . . . . . . . .

Figura 4 - Anomalia da superfície do mar, em milímetros, no dia 01 de Janeiro de 1993, para o oceano Atlântico Sul entre as latitudes de 10 e $40^{\circ} \mathrm{S}$, fornecido pelo

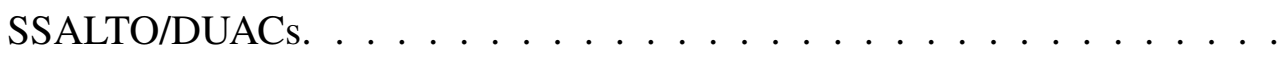

Figura 5 - Altura da superfície do mar simulada pelo modelo OFES, em milímetros, no oceano Atlântico Sul entre as latitudes de $10^{\circ}$ e $40^{\circ} \mathrm{S}$, com resolução horizontal de $1 / 10^{\circ}$, para o dia 01 de Janeiro de 1993 . . . . . . . . . . . . .

Figura 6 - Altura da superfície do mar simulada pelo modelo CESM, em milímetros, no oceano Atlântico Sul entre as latitudes de $10^{\circ}$ e $40^{\circ} \mathrm{S}$, com resolução horizontal de $1 / 10^{\circ}$, para o dia 17 de Fevereiro do ano 45 da simulação.

Figura 7 - Diagrama zonal-temporal de anomalia da altura da superfície do mar, em milímetros, obtido no oceano Atlântico para a latitude de $10,125^{\circ} \mathrm{S}$, com o dados de altímetro.

Figura 8 - Diagramas zonais-temporais de anomalia da altura da superfície do mar, em milímetros, obtidos com os dados altimétricos (à esquerda) e através das saídas do modelo CESM (à direita), para a latitude de $10,125^{\circ} \mathrm{S}$ no oceano Atlântico.

Figura 9 - À esquerda, diagrama zonal-temporal de anomalia da altura da superfície do mar em milímetros, obtido a partir dos dados altimétricos, referente ao período escolhido para comparação com o modelo. À direita, diagrama zonaltemporal de anomalia da altura da superfície do mar, obtido através das saídas do modelo CESM. Ambos para a latitude de $10,125^{\circ} \mathrm{S}$ do oceano Atlântico. 26 
Figura 10 - Decomposição do sinal original de anomalia da superfície do mar $\left(\eta_{o}\right)$ no somatório das componentes propagantes $\left(\eta_{s}\right)$, no resíduo $\left(\eta_{r}\right)$, no sinal nãopropagante $\left(\eta_{t}\right)$, nas componentes da onda de Rossby do primeiro modo baroclínico $\left(\eta_{24}\right.$ até $\left.\eta_{1}\right)$ e na componente de meso-escala $\left(\eta_{E}\right)$, para o oceano Atlântico na latitude de $10,125^{\circ} \mathrm{S}$.

Figura 11 - Espectrogramas médios (média na longitude) do sinal original do altímetro e do modelo OFES para a latitude de $10^{\circ} \mathrm{S} \ldots \ldots$. . . . . . . . . . 37

Figura 12 - Similar à Figura 11 para a latitude de $15,5^{\circ}$ S . . . . . . . . . . . . . 38

Figura 13 - Similar à Figura 11 para a latitude de $28^{\circ} \mathrm{S} \ldots \ldots \ldots$. . . . . . . . . . 40

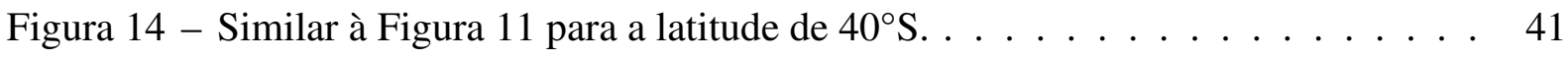

Figura 15 - Similar à Figura 11 para o modelo CESM. . . . . . . . . . . . . . . . . . 43

Figura 16 - Similar à Figura 12 para o modelo CESM. . . . . . . . . . . . . . . . . . 45

Figura 17 - Similar à Figura 13 para o modelo CESM. . . . . . . . . . . . . . . . . 47

Figura 18 - Similar à Figura 14 para o modelo CESM. . . . . . . . . . . . . . . . . . . 49

Figura 19 - Comparação entre as médias das amplitudes calculadas pelo dados do altímetro (linha escura azul) e pelo modelo OFES (linha escura vermelha) mais os respectivos desvios padrão (faixa azul claro para o desvio padrão do altímetro e vermelho claro para o desvio padrão do modelo), na banda anual (quadro a) e semianual (quadro b), ao longo das latitudes de $10^{\circ} \mathrm{S}$ e $40^{\circ} \mathrm{S}$. . . 51

Figura 20 - Similar à Figura 19, mas para o comprimento de onda. . . . . . . . . . . . 52

Figura 21 - Similar à Figura 19, mas para velocidade de fase. . . . . . . . . . . . . 53

Figura 22 - Similar à Figura 19, mas para período de onda. . . . . . . . . . . . . . . 54

Figura 23 - Similar à Figura 19 para o modelo acoplado CESM. . . . . . . . . . . . . . 56

Figura 24 - Similar à Figura 20 para o modelo acoplado CESM. . . . . . . . . . . . . 57

Figura 25 - Similar à Figura 21 para o modelo acoplado CESM. . . . . . . . . . . . . 58

Figura 26 - Similar à Figura 22 para o modelo acoplado CESM. . . . . . . . . . . . . . 59

Figura 27 - Mapa de correlação em lag zero entre a anomalia da altura do nível do mar calculada através dos dados do modelo OFES e do altímetro, para a componente sazonal (painel à esquerda). Média latitudinal do coeficiente de correlação (painel à direita).

Figura 28 - Mapa dos máximos coeficientes de correlação cruzada entre a anomalia da altura do nível do mar calculada através dos dados do modelo OFES e do altímetro, para a componente anual (painel a). Média latitudinal dos coeficientes de correlação (painel b). Mapa dos lags associados aos máximos coeficientes de correlação (painel c). Gráfico dos coeficientes de correlação ao longo de todas as longitudes da área de estudo nas latitudes de $10^{\circ} \mathrm{S}$ (roxo), $15,5^{\circ} \mathrm{S}$ (azul), $28^{\circ} \mathrm{S}$ (vermelho) e $40^{\circ} \mathrm{S}$ (cinza)(painel d). . . . . . . . . . 62 
Figura 29 - Mapa dos máximos coeficientes de correlação cruzada entre a anomalia da altura do nível do mar calculada através dos dados do modelo OFES e do altímetro, para a componente semianual (painel a). Média latitudinal dos coeficientes de correlação (painel b). Mapa dos lags associados aos máximos coeficientes de correlação (painel c). Gráfico dos coeficientes de correlação ao longo de todas as longitudes da área de estudo nas latitudes de $10^{\circ} \mathrm{S}$ (roxo), $15,5^{\circ} \mathrm{S}$ (azul) e $28^{\circ} \mathrm{S}$ (vermelho) (painel d). . . . . . . . . . . . 64

Figura 30 - Similar à Figura 27 para o modelo CESM. . . . . . . . . . . . . . . . 65

Figura 31 - Similar à Figura 28 para o modelo CESM. . . . . . . . . . . . . . . . . . 67

Figura 32 - Similar à Figura 29 para o modelo CESM. . . . . . . . . . . . . . . . . . . 69 


\section{Lista de tabelas}

Tabela 1 - Resumo das características dos modelos OFES e CESM.

Tabela 2 - Comparação entre as amplitudes (A) do sinal original $\left(\eta_{o}\right)$, do sinal não propagante $\left(\eta_{t}\right)$, do sinal de meso escala $\left(\eta_{E}\right)$, do resíduo $\left(\eta_{r}\right)$ e das componentes de onda bianual $\left(\eta_{24}\right)$, anual $\left(\eta_{12}\right)$, semianual $\left(\eta_{6}\right)$, trimestral $\left(\eta_{3}\right)$ e sesquimensal $\left(\eta_{1}\right)$, em milímetros, calculadas através dos dados altimétricos e do modelo OFES, no oceano Atlântico Sul na latitude de $10^{\circ} \mathrm{S}$. v representa a variância explicada de cada componente em relação à componente original. $\Delta$ representa a diferença entre as estimativas dos parâmetros através dos dados altimétricos e os das saídas do modelo. . . . . . . . . . . . 36

Tabela 3 - Similar à Tabela 2 para a latitude de $15,5^{\circ}$ S. . . . . . . . . . . . . . . . . . . 37

Tabela 4 - Similar à Tabela 2 para a latitude de $28^{\circ}$ S. . . . . . . . . . . . . . 39

Tabela 5 - Similar à Tabela 2 para a latitude de $40^{\circ} \mathrm{S} \ldots \ldots$. . . . . . . . . 40

Tabela 6 - Similar à Tabela 2, para o modelo CESM. . . . . . . . . . . . . . 43

Tabela 7 - Similar à Tabela 6 para a latitude de $15,5^{\circ}$ S. . . . . . . . . . . . . . 44

Tabela 8 - Similar à Tabela 6 para a latitude de $28^{\circ} \mathrm{S} \ldots \ldots \ldots$. . . . . . . . . 46

Tabela 9 - Similar à Tabela 6 para a latitude de $40^{\circ}$ S. . . . . . . . . . . . . 48 


\section{Introdução}

Ondas de Rossby pertencem a uma categoria especial de ondas planetárias sub-inerciais de larga escala, cuja existência tanto no oceano como na atmosfera está associada à forma esférica e à rotação da Terra. Estas ondas planetárias são observadas na forma de oscilações notadas, por exemplo, na estratificação de temperatura (Kang and Magaard, 1979), nas anomalias de altura (Polito and Cornillon, 1997), do calor armazenado (Polito and Sato, 2003), da clorofila (Cipollini et al., 2001) e da temperatura superficial (Hill et al., 2000). Seu mecanismo restaurador é a conservação de vorticidade potencial, mais especificamente, vorticidade planetária, estando assim sujeitas a uma variação latitudinal do parâmetro de Coriolis (Rossby et al., 1939). As ondas de Rossby longas do primeiro modo baroclínico no oceano são oscilações verticais da interface entre a camada acima da termoclina e a camada abaixo, com propagação para oeste, comprimento de onda da ordem de centenas a milhares de quilômetros e levam de meses a anos para atravessar uma bacia oceânica.

Estas ondas são centrais para todas as teorias modernas de circulação oceânica de larga escala (Chelton and Schlax, 1996). Elas são responsáveis por estabelecer a característica mais importante desta circulação: a intensificação (Anderson and Gill, 1975; Anderson and Killworth, 1977; Deser et al., 1999) e o posicionamento (Taguchi et al., 2005) das correntes de contorno oeste, que por sua vez, controlam uma parcela significativa do fluxo meridional de calor (Sato and Rossby, 2000) e apresentam uma forte influência no clima de grandes áreas (Jacobs et al., 1994). Através deste mecanismo elas conectam a variabilidade do oceano interno com os fluxos médios nas bordas (Gangopadhyay et al., 1992) e transmitem informação do oceano tropical para o interior dos oceanos de médias e altas latitudes (McCreary, 1976). Do ponto de vista do fluxo vertical de momentum na interface, elas são o mecanismo dinâmico de ajuste do oceano às mudanças de larga escala na forçante atmosférica.

Desde os anos 1970, oceanógrafos têm analisados dados in-situ com a intenção de verificar a existência de ondas planetárias oceânicas (Bernstein and White, 1974; Stumpf and Legeckis, 1977; Bernstein and White, 1981; White, 1982, 1983). Entretanto, tais estudos foram dificultados devido às características dessas ondas. Segundo Gill (1982), considerando o primeiro modo baroclínico, as variações na altura da superfície do mar espelham as variações na profundidade da termoclina com sinal oposto e com amplitude de aproximadamente três ordens de grandeza menor. A grande diferença entre as escalas horizontal e vertical faz com que a identificação destas ondas planetárias na superfície seja difícil, pois além da variação na superfície do mar ser da ordem de $5 \mathrm{~cm}$ para variações de $50 \mathrm{~m}$ na termoclina, o comprimento destas ondas é da ordem de centenas a milhares de quilômetros e períodos de meses a anos. Sendo assim, a observação de ondas de Rossby com técnicas in situ é difícil e restrita a regiões específicas. Cabe notar que o período mais comumente observado dessas ondas é o anual. Dados pontuais 
isolados não permitem a distinção entre sinais de ondas de Rossby anuais e a flutuação sazonal.

Com o advento dos satélites altimétricos, nosso conhecimento sobre as características da dinâmica oceânica de meso e larga escala aumentou drasticamente e, com isso, o conhecimento sobre ondas de Rossby (Killworth et al., 2004). Evidências da propagação de ondas planetárias baroclínicas aparecem em diagramas zonais-temporais (Hovmöller) como alinhamentos diagonais de cristas e cavados se movendo para oeste com o tempo (Matthews et al., 1992; Le Traon and Minster, 1993). Polito and Cornillon (1997) mostraram que a propagação dessas ondas é predominantemente zonal o que justifica o uso de diagramas de Hovmöller e a análise apenas na dimensão zonal. Sendo assim, é possível observar a assinatura dessas ondas nos dados de anomalias da altura do nível do mar (SLA) (Chelton and Schlax, 1996; Polito and Cornillon, 1997; Cipollini et al., 1997; Polito and Liu, 2003). As primeiras detecções de ondas de Rossby baroclínicas usando altimetria foram realizadas com os dados do satélite Geosat (Jacobs et al., 1993; Le Traon and Minster, 1993). No entanto, a componente lunar principal da maré $M_{2}$ se tornou um sinal fictício com propriedades propagantes similares ao primeiro modo baroclínico das ondas de Rossby, devido à sub-amostragem temporal por causa do período de repetição exata da órbita do Geosat. Segundo Schlax and Chelton (1994), os dados dos ERS-1/2 e TOPEX/POSEIDON estão totalmente livres dos problemas com o aliasing de maré. Sem a interferência da maré, as primeiras observações de ondas planetárias através de altímetros apresentam a progressão das mesmas através das bacias oceânicas e quantificam principalmente a velocidade de fase em médias latitudes (Chelton and Schlax, 1996; Polito and Cornillon, 1997; Cipollini et al., 1997; Killworth et al., 1997; Polito and Liu, 2003). Observações de satélites altimétricos mostraram também que, como diz a teoria clássica, ondas de Rossby tem velocidades de fase mais rápidas na porção oeste dos oceanos onde a termoclina é mais profunda, se comparada com a porção leste do mesmo oceano e na mesma latitude (Cipollini et al., 1996; Chelton and Schlax, 1996; Polito and Liu, 2003).

Além do campo de anomalia da altura da superfície do mar, é possível se observar ondas de Rossby em dados de temperatura da superfície do mar (SST) (Cipollini et al., 1997; Hill et al., 2000; Oliveira and Polito, 2013), em variações da profundidade da isoterma de $20^{\circ} \mathrm{C}$ (White, 1977), em perfis de temperatura subsuperficial (Chu et al., 2007) ou através da concentração de clorofila (Machu et al., 1999; Cipollini et al., 2001; Uz et al., 2001; Kawamiya and Oschlies, 2001; Ryan et al., 2002; Killworth et al., 2004) com resultados bastante convincentes e correlacionados (Quartly et al., 2003). Mais recentemente, Menezes et al. (2014) observou a assinatura de ondas planetárias na salinidade de superfície do oceano Índico Sul, utilizando os dois primeiros anos de dados do satélite Aquarius/SAC-D. Apesar dos dados de satélite serem de grande utilidade, por estarem disponíveis apenas há pouco mais de duas décadas, afirmações sobre tendências decadais do nível do mar, bem como o papel das ondas de Rossby no ajuste dos giros se mostram complicados (Sasaki et al., 2008).

Com as limitações do tamanho da série temporal dos satélites e a capacidade de obter 
informações diretas apenas da superfície dos oceanos, outras ferramentas vêm sendo utilizadas para complementar essas informações e aprofundar o nosso conhecimento em relação à dinâmica dos oceanos. Modelos de circulação geral oceânica (Ocean General Circulation Models OGCMs) são uma dessas ferramentas e têm sido cada vez mais utilizados para estudos de circulação dos oceanos, sistemas climáticos e suas variações espaciais e temporais em diferentes escalas (Masumoto et al., 2004).

De acordo com Maltrud and McClean (2005), a capacidade dos OGCMs reproduzirem a realidade aumentou significativamente na última década. Esta melhora se deve principalmente aos avanços na tecnologia de supercomputadores, que permitem que esses modelos sejam executados em grades que resolvem a física dos vórtices (eddy-resolving), pois a veracidade das simulações é minada por falta de representações e representações inadequadas dos processos entre as componentes atmosférica e oceânica do modelo (Large and Danabasoglu, 2006). Historicamente, a melhor formar de diminuir os erros dos modelos relacionados a uma simulação pobre da dinâmica de fluidos é aumentando a resolução espacial dos componentes do modelo de forma que a maior parte dos processos dinâmicos sejam resolvidos explicitamente e que cada vez menos processos sejam parametrizados (McClean et al., 2011).

Semtner and Chervin (1992) foram os pioneiros em avaliar o impacto de uma simulação eddy-permitting no domínio global. Smith et al. (2000) mostraram que o modelo deve ter uma resolução da ordem de $1 / 10^{\circ}$ ou menos para reproduzir quantitativamente o desvio padrão da anomalia da altura da superfície do mar no Atlântico Norte, utilizando um modelo eddyresolving desenvolvido durante o projeto World Ocean Circulation Experiment (WOCE) para o oceano Atlântico Norte. Seguindo esse esforço de simulações oceânicas em alta resolução, um grande número de estudos usando diferentes modelos oceânicos foi conduzido na década passada com resoluções entre $1 / 10^{\circ}$ e $1 / 16^{\circ}$, principalmente no oceano Atlântico Norte (Webb, 2000; Smith et al., 2000; McClean et al., 2002; Hurlburt and Hogan, 2000; Chassignet and Garraffo, 2001). A partir desses resultados, concluiu-se que a resolução espacial horizontal dos OGCMs deve ser de no mínimo $1 / 10^{\circ}$ para simular adequadamente a variabilidade de meso escala e os fluxos médios, bem como as correntes de contorno oeste (Maltrud and McClean, 2005).

Simulações globais de alta resolução revelaram processos que não eram vistos em seus homólogos de baixa resolução. McClean et al. (2011) mostrou exemplos de ciclones tropicais induzindo rastros frios na superfície do oceano que potencialmente podem afetar a força das tempestades, principalmente as que se movem lentamente. Vórtices oceânicos são parte significante do transporte de calor no oceano e são melhor representados nessas simulações (McClean et al., 2011). Alguns dos vieses de longa data de SST nas regiões de contorno leste são reduzidos devido aos ventos costeiros melhorados e, consequentemente, correntes de superfície e ressurgência oceânica são representadas de forma mais realistas (Gent et al., 2010). Apesar dos avanços feitos por causa da alta resolução nos modelos globais, alguns problemas perma- 
necem ou são exacerbados por essas resoluções. Por exemplo, a ITCZ na classe dos modelos CESM (Community Earth System Model) fica mais intensa que o observado. Algumas simulações apresentam um grande aquecimento ou arrefecimento com um efeito notável sobre as regiões polares, onde o gelo oceânico pode ser muito fino e limitado em área (Kirtman et al., 2012) ou muito grosso e extenso (McClean et al., 2011), respectivamente.

O desenvolvimento de modelos oceânicos progressivamente mais realísticos irá incrementar o nosso entendimento à respeito da circulação oceânica e nos permitirá fazer previsões mais acuradas sobre a resposta dos oceanos às mudanças nas condições climáticas (Cipollini et al., 2000). Um dos principais assuntos nos estudos de mudanças climáticas é a variação do nível do mar. Isso se deve ao esperado aumento do nível do mar (ANM) em uma situação de aquecimento global (Slangen et al., 2012). O ANM trará sérias implicações socioeconômicas para populações que vivem próximas ao nível do mar (Nicholls and Cazenave, 2010), pois está intimamente ligada a vários perigos costeiros, incluindo tempestades, inundações de áreas baixas, erosão de praia, e danos a infra-estruturas e ecossistemas (Nicholls et al., 2007).

Em resposta a uma mudança climática, o ANM não será uniforme espacialmente, mas apresentará formas complexas, tal como indicado por medições disponíveis (Douglas, 2001; Bindoff et al., 2007). Como resultado, algumas regiões podem experimentar um aumento do nível do mar maior e mais rápido do que a média global, enquanto outros locais podem ter um ANM menor do que a média global ou mesmo negativo. Apesar do padrão de ANM ser muito importante, por muito tempo ele foi atribuído apenas a processos geológicos naturais. Com o recente progresso neste campo, uma melhor compreensão dos padrões de ANM e seus mecanismos subjacente foram identificados como alvo de pesquisas com alta prioridade na próxima década (Milne et al., 2009).

A tendência interanual local do ANM foi analisada e quantificada através de dados altimétricos por Polito and Sato (2008). Nesse trabalho eles confirmaram que as tendências são espacialmente heterogêneas, sendo maiores no oceano Índico, seguido pelo Atlântico e Pacífico e mostram-se mais intensas na borda oeste desses oceanos, região onde se localizam as correntes de contorno oeste. Mais especificamente, há tendências estatisticamente significativas e relativamente altas, porém de sinais opostos separadas por poucas centenas de km. Isto é uma indicação de intensificação e, possivelmente, de uma mudança meridional na posição média das correntes com os seus meandros e vórtices.

Qiu and Chen (2006) obtiveram resultados sugerindo que muitas feições de larga escala, tanto decadais quanto multidecadais, nas tendências do nível do mar no Pacífico podem ser explicadas em termos da resposta do oceano às variações do bombeamento de Ekman e da propagação de ondas de Rossby oceânicas. O aumento da concentração de gases de efeito estufa altera a temperatura da superfície do mar, gerando anomalias no padrão da tensão de cisalhamento do vento de longo termo nos oceanos tropicais. Essa variação na tensão de cisalhamento do vento é responsável por alterar o bombeamento de Ekman, a propagação de calor de Ekman 
(Sato et al., 2002; Sato and Polito, 2005) e a propagação de ondas de Rossby, que por sua vez resultarão em variações na profundidade da termoclina e no nível do mar (Gill, 1980).

É necessário que os modelos consigam reproduzir de forma acurada as ondas de Rossby, para conseguir reproduzir de forma realística a tendência do nível do mar, a circulação dos oceanos e as variações sazonais. Estas ondas transportam informação de um lado da bacia oceânica para outro e a velocidade de fase dessas ondas define o tempo de resposta dos giros oceânicos a mudanças na forçante atmosférica. Dessa forma, dentro de um cenário hipotético de mudanças climáticas que contemple mudanças no espectro integrado do campo de ventos, uma variação na intensidade e no tempo de ajuste dos giros oceânicos pode ocorrer. Para que os modelos climáticos consigam representar corretamente mudanças no transporte dos giros subtropicais é necessário que o processo de transmissão via ondas de Rossby esteja corretamente resolvido.

Hughes (1995) foi um dos pioneiros na tentativa de verificar a fidedignidade das ondas de Rossby simuladas por modelos numéricos comparando-as com as observadas por altímetro. Em seu trabalho ele encontra ondas de Rossby advectadas pela corrente no oceano Antártico em simulações do modelo Fine Resolution Antartic Model (FRAM) e procura essas mesmas feições nos dados altimétricos, encontrando-as no setor do oceano Pacífico Sul. Incertezas no fluxo médio da corrente Circumpolar o impediram de usar as relações de dispersão para confirmar a identidade das ondas, embora o período e comprimento de onda encontrados sejam plausíveis para ondas de Rossby nessa região.

Polito et al. (2008) compararam e validaram o sinal de SLA obtido do modelo de circulação geral oceânica Model for interdisciplinary Research on Climate (MIROC) com observações do satélite altimétrico TOPEX/POSEIDON. A comparação focou em diversas bandas espectrais que correspondem ao (i) sinal sazonal e interanual não propagante e (ii) ondas de Rossby do primeiro modo baroclínico. Ondas de Rossby com um período de aproximadamente 3 meses foram subestimadas pelo modelo, enquanto ondas com períodos de aproximadamente 6, 12 ou 24 meses foram reproduzidas com velocidade de fase não mais do que $30 \%$ diferentes das encontradas em observações de satélite. Este é um importante resultado, uma vez que essas ondas são um elemento chave na dinâmica e termodinâmica que governam a circulação de larga escala.

Lecointre et al. (2008) antes de investigar e descrever a estrutura vertical dos fenômenos propagantes para oeste no modelo CLIPPER ATL6, validou a capacidade do modelo de simular a velocidade e amplitude das feições que se propagam para oeste comparando-as com as observadas por altímetro no oceano Atlântico Norte Subtropical. As regiões que apresentaram a maior amplitude de onda correspondem as regiões de maior energia cinética turbulenta - EKE (corrente do Golfo e corrente dos Açores). Como esperado da teoria e mostrado por vários autores (Polito and Cornillon, 1997; Osychny and Cornillon, 2004) a velocidade de fase aumenta em direção ao equador e, em menor ordem, em direção a oeste. Essa feição é bem representada pelo modelo, atingindo uma velocidade de fase de $13 \mathrm{~cm} / \mathrm{s}$ no limite sul do domínio. A maior 
diferença (i.e. 2 a 3cm/s) entre modelo e observação deu-se na região da corrente do Golfo, entorno de $10^{\circ} \mathrm{N}$ e próximo ao contorno do domínio, tornando-se negligenciável na corrente de Açores.

Além da SLA, Subrahmanyam et al. (2009) utilizaram dados de sensoriamento remoto de temperatura da superfície do mar (SST) e observações de clorofila-a (chl-a) através da cor do mar, no período de 2003 a 2006, para detectar ondas de Rossby baroclínicas do $1^{\circ}$ modo no oceano Índico. E as compararam com os parâmetros derivados de simulações do modelo HYbrid Coordinate Ocean Model (HYCOM), com resolução de 1/12 ${ }^{\circ}$. Eles encontraram propagação de ondas de Rossby nos Hovmöllers de $10^{\circ}$ e $20^{\circ}$ S das simulações de SLA, SST e SSS (salinidade da superfície do mar) e nas observações dos satélites altimétricos, de SST e chl-a. Em $10^{\circ} \mathrm{S}$, o sinal de onda de Rossby anual pode ser observado em todos os parâmetros. Com exceção da cor do mar, todos os parâmetros aparentaram estar em fase, onde a propagação de uma anomalia alta de SSH, correspondeu com uma alta na SST e SSS (tanto no modelo quanto nas observações). A cor do mar, no entanto, aparentou estar exatamente $180^{\circ}$ fora de fase.

Ondas de Rossby não são um código explícito nesses modelos; elas são apenas uma série de soluções para as equações do movimento em uma superfície girante com uma forçante variando na superfície. Sendo assim, a comparação das ondas de Rossby simuladas nos modelos com as observações é um bom teste de quão bem a dinâmica de larga escala dos modelos está simulando a realidade. Quando modelos e observações não concordam, o código do modelo não requer um ajuste específico do "parâmetro onda de Rossby", mas sim requer um esforço para resolver o problema subjacente. Por exemplo, mistura vertical fraca ou um modelo construído com poucas camadas resultam em uma representação fraca da estratificação e consequentemente do cisalhamento vertical (Cipollini et al., 2000).

A simples comparação da velocidade de fase das ondas planetárias em dados de altímetros e as obtidas pelas simulações do modelo providenciam meios de documentar os problemas na dinâmica com respeito à reprodução de ondas planetárias nos modelos climáticos globais. Em ondas não-dispersivas, a velocidade de fase determina o tempo que um sinal demora para atravessar a bacia oceânica e portanto configura a escala temporal de fenômenos como ENSO (Holton et al., 1989), ou o dipolo no oceano Índico (Vaid et al., 2007). Além disso, a velocidade de fase é uma função do raio de deformação de Rossby, que depende da estrutura vertical de densidade. Sendo assim, discrepâncias significativas na velocidade de fase entre o modelo e observações revelam um potencial problema com a estrutura vertical de densidade. As amplitudes medem o quanto de energia potencial as ondas carregam para a direção oeste e transferem para os fluxos médios nas bordas oestes (Anderson and Gill, 1975). Portanto, é plausível que discrepâncias nas amplitudes das ondas de Rossby no modelo podem ser a causa final de possíveis problemas com a intensidade das correntes de borda oeste. Outra forma de olhar para esse problema é considerar que o deslocamento vertical da termoclina está associado com as anomalias no armazenamento de calor nos oceanos. Por exemplo, na região equatorial as ondas de Rossby 
de baixa frequência tem uma escala espacial da ordem de $10^{4} \mathrm{~km}$ e portanto carregam uma quantidade significativa de calor. Quando ocorre troca com a atmosfera, esse calor pode mudar a distribuição de momentum e umidade na região. Sendo assim, se o modelo apresenta problemas na reprodução da amplitudes das ondas, podemos esperar um impacto direto na progressão dos padrões sinóticos e climáticos que dependem da interação ar-mar.

Os trabalhos comparando ondas de Rossby simuladas por modelos numéricos com dados altimétricos realizados até o momento foram executados com modelos de baixa resolução, como por exemplo o modelo ATL6-ERS26 no trabalho de Lecointre et al. (2008) e modelo MIROC no trabalho de Polito et al. (2008). Além desses modelos não apresentarem uma boa resolução espacial a maior parte dessas comparações foram feitas para o hemisfério norte, ou no caso do MIROC, a comparação foi melhor no Pacífico Norte, sugerindo que o modelo foi ajustado de forma a reproduzir satisfatoriamente este hemisfério.

\subsection{Hipótese e objetivos}

A ideia que queremos testar neste trabalho é que os modelos climáticos reproduzem ondas de Rossby semelhantes às observações em termos de velocidade de fase, fase e amplitude pelo menos para ondas anuais e semianuais no Atlântico Sul em latitudes médias.

\section{Objetivos}

O objetivo geral deste trabalho é verificar se dois modelos numéricos climáticos de características diferentes reproduzem a dinâmica de ondas de Rossby de forma similar à observada em dados altimétricos. Uma vez que essas ondas dependem da estrutura interna de densidade e da forçante do vento, podemos fazer inferências sobre a adequação desses dois fatores nos modelos à realidade observada pelo altímetro. Mais especificamente, pretende-se:

- Filtrar os dados dos modelos e do altímetro de forma a decompor os sinais originais em componentes que nos permitam tratar separadamente as ondas de Rossby e as demais formas de variabilidade;

- Obter velocidade de fase, fase, amplitude e frequência de ondas de Rossby anuais e semianuais para todos os conjuntos de dados na região de estudo;

- Verificar em quais regiões os resultados relativos à caracterização do campo de ondas de Rossby planetárias do $1^{\circ}$ modo baroclínico dos modelos coincidem com as observações;

- Discutir possíveis responsáveis (forçante ou estrutura interna do modelo) por eventuais divergências nos resultados. 


\section{2 Área de Estudo}

Todas as bacias oceânicas apresentam um mesmo padrão de circulação superficial que é caracterizado pela presença dos grandes giros. Esses giros são anti-ciclônicos e assimétricos, apresentando correntes mais intensas e estreitas nos contornos oeste das bacias oceânicas e são impulsionados pelo rotacional da tensão de cisalhamento do vento. $\mathrm{O}$ regime de ventos na região tropical, $30^{\circ} \mathrm{N}$ e $30^{\circ} \mathrm{S}$, é predominante de leste, enquanto que nos subtrópicos, entre $30^{\circ} \mathrm{e}$ $60^{\circ}$, tanto no hemisfério sul quanto no norte, os ventos são de oeste (Talley et al., 2011).

De acordo com Sverdrup (1947) a circulação da camada superior de todos os oceanos está relacionada com o rotacional da tensão de cisalhamento do vento e com a força de Coriolis que varia em função da latitude, o chamado efeito $\beta$. Em 1948 Stommel demostrou que o efeito $\beta$ também é responsável pela assimetria dos grandes giros oceânicos. Por fim, Munk em 1950 incorpora os efeitos da viscosidade turbulenta para o cálculo da circulação da camada superior dos oceanos (Stommel, 1948; Munk, 1950).

Apesar do padrão de circulação superficial de todas as bacias oceânicas serem iguais a grosso modo, algumas características topográficas distinguem o oceano Atlântico do Pacífico e do Índico. O oceano Atlântico é uma bacia oceânica meridionalmente extensa e longitudinalmente estreita que se estende até as regiões Ártica e Antártica. Possui o maior número de mares adjacentes que influenciam as características de suas águas, como por exemplo o mar Mediterrâneo. Além disso, o oceano Atlântico é dividido quase que igualmente em uma série de bacias à leste e à oeste da Cordilheira Meso Atlântica, diminuindo a profundidade local para $2000 \mathrm{~m}$, e alcançando em algumas regiões profundidades de apenas $1000 \mathrm{~m}$, apresentando um forte impacto na circulação das camadas mais profundas. (Talley et al., 2011).

A circulação de larga escala do oceano Atlântico Sul próxima da superfície pode ser representada como na Figura 1. Nessa representação, ela é dominada pelo giro subtropical. Esse giro é formado pela corrente de Benguela, o ramo mais ao sul da corrente Sul Equatorial (CSE), a corrente do Brasil (CB) e a corrente do Atlântico Sul (CAS). A CSE flui em direção oeste, e ao alcançar o continente sul-americano bifurca-se em dois ramos. Um ramo segue em direção ao equador alimentando a corrente Norte do Brasil (CNB) e o outro ramo forma a CB ao sul de $10^{\circ} \mathrm{S}$ a partir do ramo mais ao sul da CSE. A CB é a corrente de contorno oeste que flui em direção ao polo, margeando o continente sul-americano até a região de aproximadamente 36-38 ${ }^{\circ}$ S. Nessa região a CB encontra a corrente das Malvinas (CM), que flui para o equador carregando água da corrente Circumpolar Antártica (CCA), formando a confluência BrasilMalvinas, onde ambas são defletidas afastando-se da costa originando posteriormente a CAS próximo a $45^{\circ} \mathrm{S}$. A CAS flui para leste, em direção ao Continente Africano, paralelamente à CCA, no limite sul do giro. Esse é referido na literatura como sendo a Frente ou convergência 
Subtropical do Atlântico Sul. No lado leste da bacia, a retroflexão da corrente das Agulhas (CA) contribui com água do oceano Índico através de seus anéis alimentando a corrente de Benguela. A corrente de Benguela é a corrente de contorno leste que flui em direção ao equador ao longo da costa sudoeste da África e separa-se da costa entre 24-30 ${ }^{\circ} \mathrm{S}$ alimentando a CSE. (Campos et al., 1999; Stramma and Peterson, 1990; Peterson and Stramma, 1991).

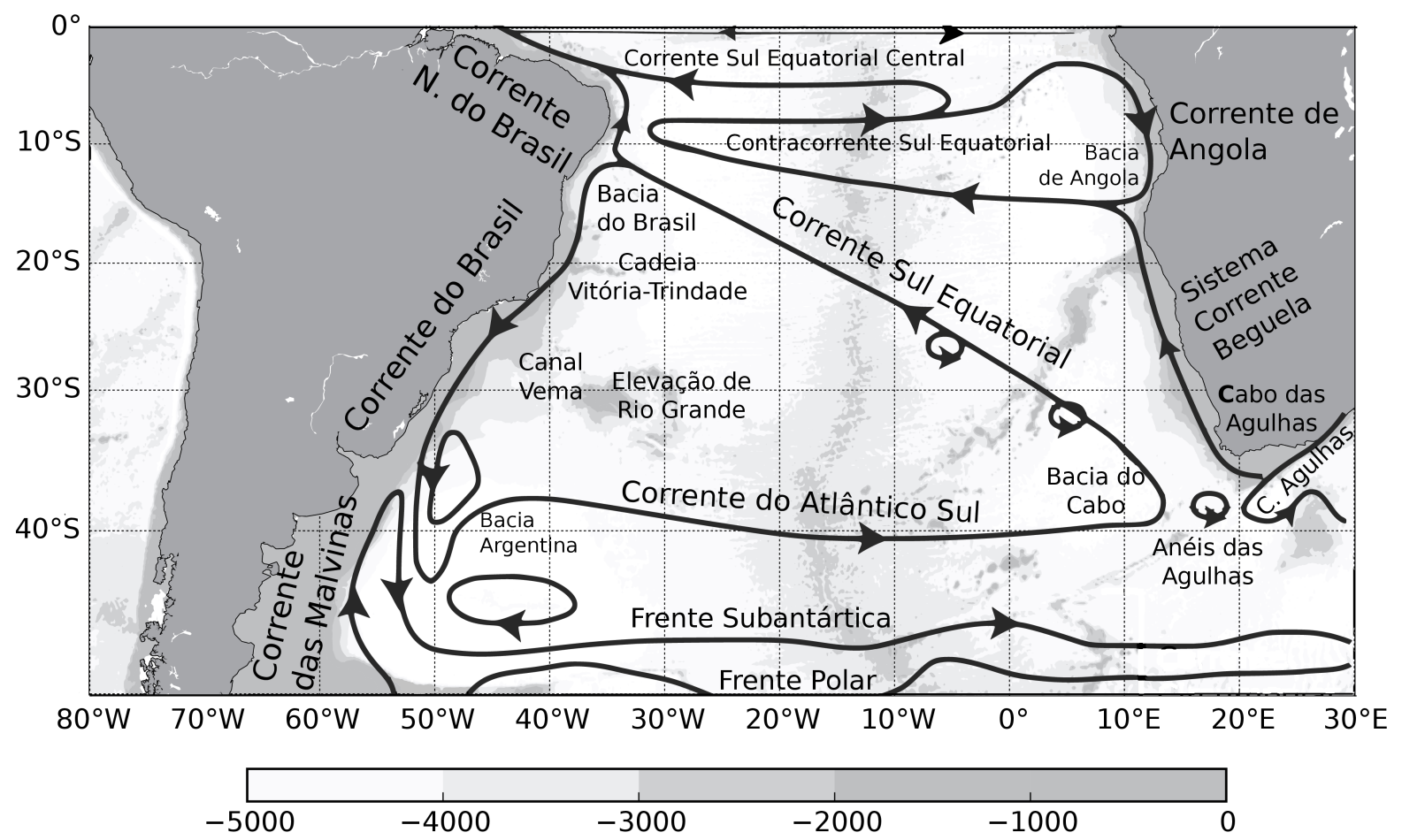

Figura 1 - Representação esquemática média das correntes de superfície do oceano Atlântico Sul. As setas pretas representam as correntes e as respectivas direções dos fluxos. Os tons de cinza indicam a profundidade média da coluna de água, em metros, onde o branco representa o oceano aberto e o cinza escuro os continentes (figura modificada de Talley et al. (2011)).

Este estudo se restringe a ondas de Rossby fora da banda tropical entre $10^{\circ} \mathrm{N} \mathrm{e} 10^{\circ} \mathrm{S}$, referidas como ondas de Rossby extra-tropicais. Alguns dos motivos para não incluirmos a região tropical neste estudo foram: (i) Dinâmica diferenciada uma vez que o parâmetro de Coriolis é aproximadamente zero; (ii) grande interação térmica ar-mar o que acarretaria uma maior dependência do modelo atmosférico ou dos input de dados atmosféricos; (iii) limite da resolução temporal do altímetro para detectar ondas com velocidade de fase maiores, consequentemente, erros maiores; (iv) presença de ondas de instabilidade tropical. 
Dessa forma, a área de estudo deste trabalho abrange o oceano Atlântico Sul Subtropical, entre $10^{\circ} \mathrm{S}$ e $40^{\circ} \mathrm{S}$. O limite sul foi escolhido de forma a cobrir as regiões do oceano definidas por Oliveira and Polito (2013) como sendo dominadas por ondas de Rossby (entre $10^{\circ} \mathrm{e} 25,5^{\circ} \mathrm{S}$ ), transição entre ondas de Rossby e vórtices de mesoescala (entre $25,5^{\circ} \mathrm{e} 34,5^{\circ} \mathrm{S}$ ) e a região dominada por vórtices (ao sul de $34,5^{\circ} \mathrm{S}$ ). Na figura 2 é apresentada a área de estudo sobre a batimetria ETOPO1 (Amante and Eakins, 2009), que ilustra o relevo da superfície da Terra, integrando a topografia do terreno com a batimetria oceânica. As linhas vermelhas indicam as latitudes que serão utilizadas na metodologia descrita na próxima seção.

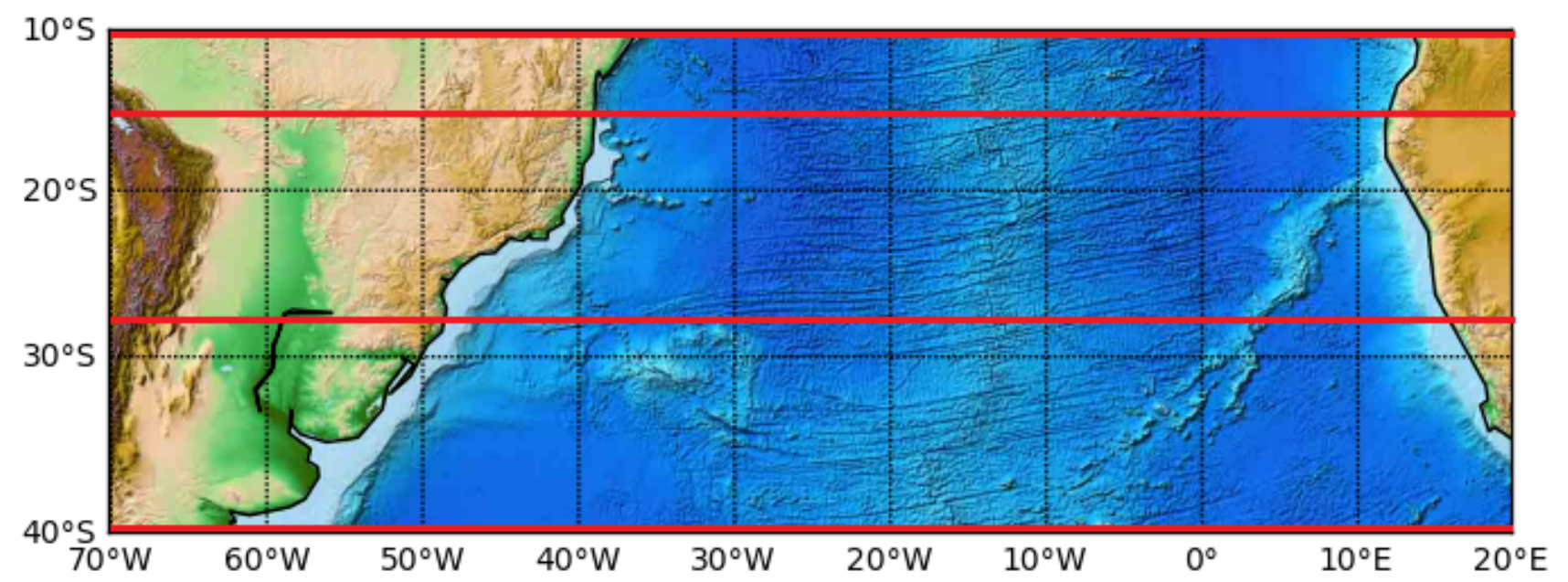

Figura 2 - Apresentação da área de estudo do presente trabalho no oceano Atlântico Sul entre as latitudes de $10^{\circ} \mathrm{S}$ e $40^{\circ} \mathrm{S}$, sob batimetria ETOPO1 . 


\section{Conjunto de dados}

No presente trabalho foram analisadas ondas de Rossby anuais e semianuais representadas por dois modelos climáticos globais (OGCM for the Earth Simulator - OFES e Community Earth System Model - CESM), de alta resolução temporal e espacial, através de suas saídas de altura da superfície do mar. Esses resultados foram comparados com dados de anomalia da superfície do mar obtidos por satélites altimétricos. A seguir estão descritas as principais características de cada conjunto de dados.

\subsection{Dados Altimétricos}

Satélites altimétricos estimam a distância entre o satélite e uma superfície específica através do tempo de retorno $(\Delta t)$ de um pulso de radar, emitido na direção Nadir, perpendicular à superfície. Superfícies não homogêneas, que contém descontinuidades ou grande inclinações, como gelo, rios e os continentes, fornecem estimativas com nível de ruído relativamente alto. Os melhores resultados são obtidos sobre os oceanos. Em primeira aproximação, a distância $(d)$ entre o altímetro e a superfície do mar pode ser obtida por $d=c \Delta t$, sabendo que $c$ é a velocidade da luz, na qual o pulso viaja. O elipsóide de referência é ajustado a altura média da superfície do planeta; a altura da superfície do mar (SSH) é dada pela diferença entre a altura do satélite a partir do elipsóide de referência e a distância $d$ medida pelo altímetro. Desde 1985 vários satélites equipados com altímetros foram lançados no espaço, o que permite uma observação periódica da SSH com uma resolução espaço-temporal sem precedentes.

Como ilustrado na Figura 3, a anomalia da altura da superfície do mar (SLA, Sea Level Anomaly) representa as variações da altura da superfície do mar (SSH - Sea Surface Height) relativas a uma média da superfície do mar (MSS - mean sea surface). A MSS é representativa de um período particular de tempo, chamado de período de referência. Os produtos de anomalia da altura da superfície do mar da SSALTO/DUACs (Segment Sol multimissions d'ALTimétrie, d'Orbitographie et de localisation précise/Data Unification and Altimeter Combination System), têm sido referenciados por um período de 7 anos (1993-1999) desde 2001, quando a MSS CLS01 foi calculada. Entretanto, com uma série temporal de 20 anos de medidas altimétricas, o período de referência foi alterado para 20 anos (1993-2012). A mudança no período de referência de 7 para 20 anos integra a evolução do nível do mar em termos de tendência, e também, em termos de sinais interanuais em pequenas e grandes escalas (e.g. El Niño/ La Niña) nos últimos 13 anos (Duacs/AVISO, 2014). Além disso, essa mudança induz as variações globais e regionais no nível médio do mar. A MDT é a topografia dinâmica média, e também é referenciada pela média dos 20 anos de dados. Esta variável é conhecida também como geóide marinho por ser uma superfície média do mar que se soma ao geóide no cálculo da anomalia da altura. A 


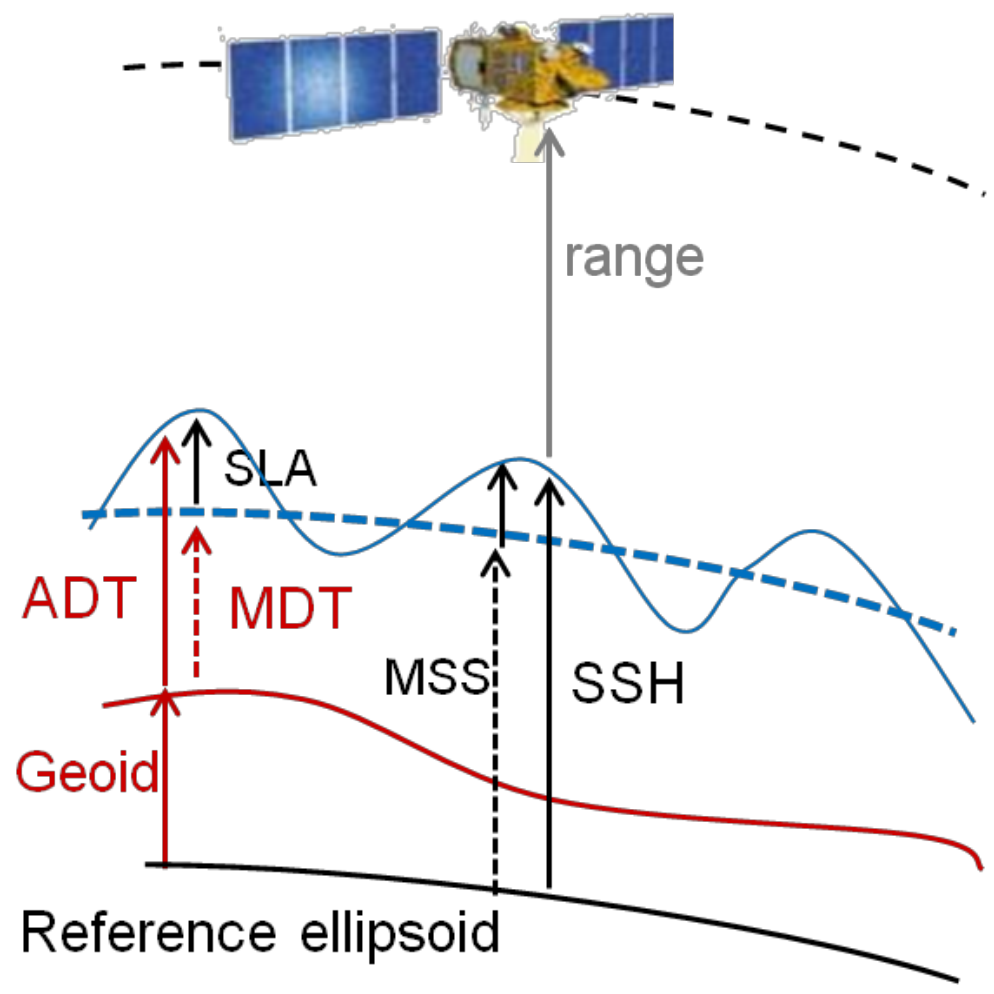

Figura 3 - Convenção de nomenclatura das alturas altimétricas. SSH: altura da superfície do mar; SLA: anomalia da altura da superfície do mar; MSS: média da superfície do mar; MDT: topografia dinâmica média; ADT: topografia dinâmica absoluta. De Duacs/AVISO (2014)

topografia dinâmica absoluta (ADT) é o somatório da anomalia da altura da superfície do mar e da topografia dinâmica média. O geóide é limitado por uma superfície equipotencial do campo de gravidade da Terra e é a altura utilizada como referência para o cálculo geostrófico absoluto. Por esta razão tanto ADT como a MDT são calculadas em relação ao geóide.

Devido à influência da atmosfera e ao deslocamento da superfície em reação à antena, são necessárias correções nas distâncias calculadas. Estas são:

- remoção da altura do geóide, onde o resíduo é uma primeira estimativa da SSH;

- correções atmosféricas que incluem a influência do ar seco, umidade e atraso da radiação eletromagnética ao atravessar a ionosfera, por causa dos elétrons livres;

- correção do geóide marinho através da remoção da média de longo termo da SSH;

- remoção do sinal das marés oceânicas, da Terra sólida, oscilação dos pólos e peso da atmosfera. Maiores informações sobre as correções podem ser encontradas em Benada (1997).

Levando em consideração as correções feitas, o erro nominal dos dados pontuais obtidos por um único satélite é de $2 \mathrm{~cm}$. As principais limitações dos dados altimétricos são a 
dificuldade de medição do nível do mar em regiões costeiras devido à influência da maré; o cálculo apenas da componente geostrófica das correntes verticalmente integradas; e a suavização das correntes médias devido à baixa resolução espacial do geóide. Em contrapartida, os altímetros são capazes de realizar medições globais sinóticas do sinal superficial de fenômenos que efetivamente ocorrem em subsuperfície, permitindo, portanto, a observação de ondas de Rossby.

No presente trabalho foram utilizados 18 anos (1993-2010), da versão 2014 de dados de SLA do produto 'gridded multimission' processado pelo Ssalto/Duacs, distribuídos pelo Archiving, Validation and Interpretation of Satellite Ocean data (AVISO) (http://www. aviso. oceanobs.com/duacs/). Este conjunto de dados é obtido através da combinação de duas missões de satélites simultâneas com o mesmo 'groundtrack', sendo uma européia e uma americana. As missões européias (ERS-1, ERS-2, Envisat, Cryosat-2 e Altika) tem ciclos de 35 dias e separação equatorial de passagens de $\sim 85 \mathrm{~km}$ e as americanas (TOPEX, Jason-1 e Jason-2) de $\approx 10$ dias e $315 \approx \mathrm{km}$, resultando em um conjunto de dados estatisticamente mais homogêneos que o produto alternativo da AVISO que usa todos os satélites disponíveis na época.

Nesta versão, os dados são interpolados (3D) no espaço e no tempo com uma resolução temporal diária e resolução espacial cartesiana de $1 / 4^{\circ}$. Além disso, em relação às versões pré-2014, um novo processamento foi aplicado, em termos de filtro e sub-amostragem, resultando em uma menor suavização em baixas latitudes e um conjunto de dados mais denso. A Figura 4 é um exemplo das medidas de anomalia da superfície do mar estimada pelo altímetro, em milímetros, para o dia 01 de janeiro de 1993, primeiro dia da série temporal utilizada neste trabalho. Este exemplo ilustra a escala mínima de variabilidade espacial que estes dados altimétricos contém, bem como a distribuição espacial da anomalia da altura.

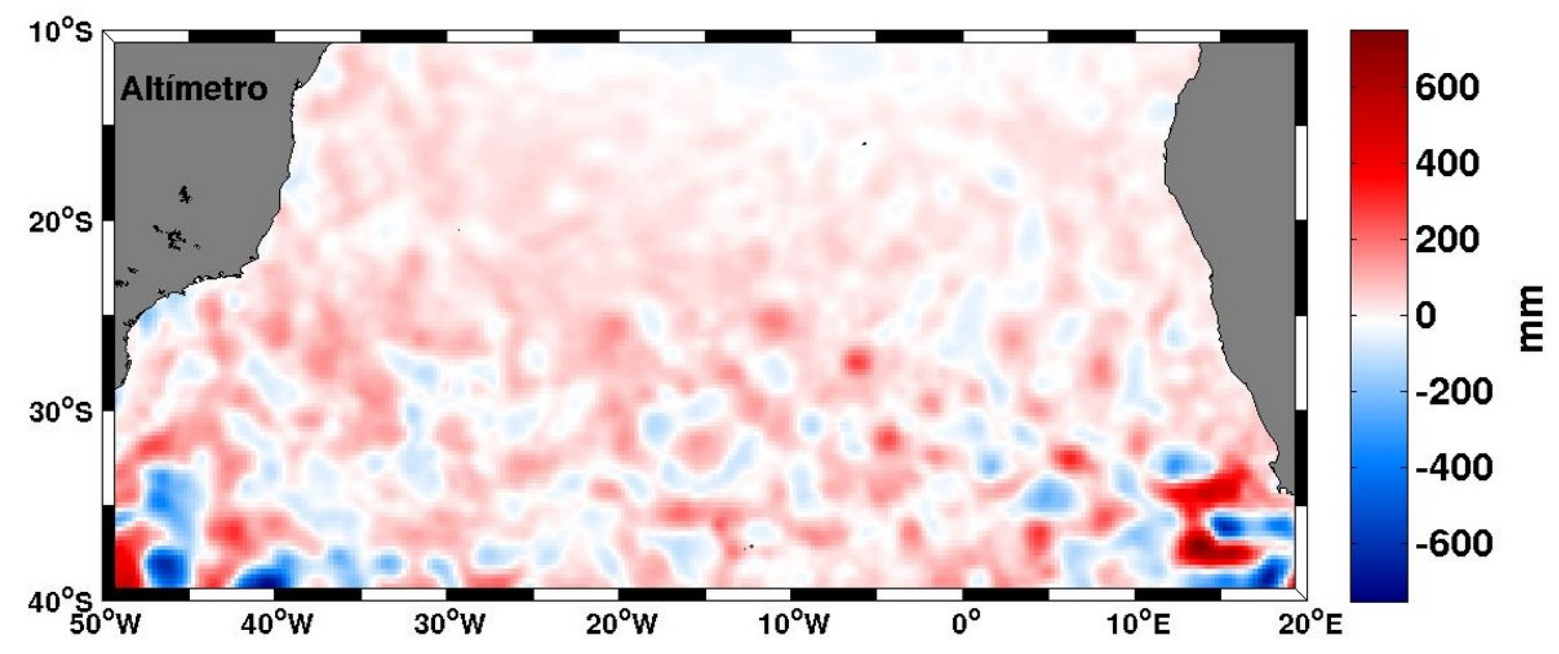

Figura 4 - Anomalia da superfície do mar, em milímetros, no dia 01 de Janeiro de 1993, para o oceano Atlântico Sul entre as latitudes de 10 e $40^{\circ} \mathrm{S}$, fornecido pelo SSALTO/DUACs. 


\subsection{Saídas de modelo}

\subsubsection{OFES}

OFES é um modelo oceânico de alta resolução desenvolvido pelo Geophysical Fluid Dynamics Laboratory (GFDL/NOAA). Este modelo é simulado no Earth Simulator (ES) e é baseado no Modular Ocean Model (MOM3) (Pacanowski and Griffies, 2000). O MOM é uma solução por diferenças finitas das equações diferenciais completas ou primitivas do oceano, que descrevem com excelente aproximação a circulação oceânica de larga escala. Como descritas por Bryan (1969), as equações consistem em Navier-Stokes aplicada com as aproximações de Boussinesq, hidrostática e conservação de massa.

A aproximação de Boussinesq é justificada para simulações oceânicas de larga escala com base na pequena variação relativa da densidade em relação à média do oceano (Gill, 1982). O perfil médio de densidade do oceano $\rho_{0}(z)$ varia tipicamente não mais do que $2 \%$ do seu valor médio $\rho_{0}=1,035 \mathrm{gcm}^{-3}$. A aproximação de Boussinesq consiste em substituir $\rho_{0}(z)$ pela sua média vertical $\rho_{0}$. Entretanto, a fim de considerar as variações de densidade afetando o termo de empuxo na equação de Navier-Stokes, a aproximação de Boussinesq mantém o prognóstico de densidade completa $\rho=\rho(\lambda, \phi, z, t)$ quando multiplicada pela constante de aceleração gravitacional. Equivalentemente, a escala vertical das variações na velocidade vertical é muito menor do que a escala vertical das variações na $\rho_{o}(z)$, e flutuações da densidade devido a variações de pressão locais são negligenciáveis. A última consideração é que o fluido pode ser tratado como incompressível.

Além da aproximação de Boussinesq, Bryan (1969) impôs a aproximação hidrostática, que implica que o gradiente vertical de pressão é devido apenas à densidade. Quando escalas horizontais são muito maiores do que escalas verticais, a aproximação hidrostática é justificada e, na verdade, é idêntica à aproximação de ondas longas para um fluido continuamente estratificado. De acordo com Gill (1982), o oceano pode ser pensado como sendo composto por finas camadas de fluido, de forma que a extensão horizontal é muito maior do que a vertical. Sendo assim, a energia cinética é amplamente dominada por movimentos horizontais. Essa característica do modelo é consistente com a mecânica de ondas de Rossby longas.

Consistente com a aproximação acima, Bryan (1969) também utilizou a aproximação da calota esférica, pois a profundidade do oceano é muito menor do que o raio médio da Terra. Esta aproximação permite substituir a coordenada radial de uma parcela de fluido pelo raio médio da Terra, a menos que esta coordenada seja diferenciada. Os termos da componente de Coriolis e viscosidade envolvendo a velocidade vertical nas equações do movimento horizontal são ignoradas baseadas em análises de escala levando em consideração as aproximações citadas 
acima.

As equações resolvidas pelo MOM são dadas por:

$$
\begin{gathered}
\frac{\partial u}{\partial t}=-\underbrace{\nabla \cdot(u \mathbf{u})+\left(\frac{v u \tan \phi}{a}\right)}_{1}+\underbrace{v f}_{2}-\underbrace{\frac{1}{a \rho_{0} \cos \phi} \frac{\partial p}{\partial \lambda}}_{3}+\underbrace{\left(F_{H x}(u, v)\right.}_{4}+\underbrace{F_{V}(u)}_{5} \\
\frac{\partial v}{\partial t}=-\underbrace{\nabla \cdot(v \mathbf{u})+\left(\frac{u^{2} \tan \phi}{a}\right)}_{1}-\underbrace{u f}_{2}-\underbrace{\left(\frac{1}{a \rho_{0}}\right) \frac{\partial p}{\partial \phi}}_{3}+\underbrace{\left(F_{H y}(u, v)\right.}_{4}+\underbrace{F_{V}(v)}_{5} \\
\frac{\partial w}{\partial z}=-\left(\frac{\partial u}{\partial \lambda}+\frac{\partial v}{\partial \phi}\right) \\
\frac{\partial p}{\partial z}=-\rho g \\
\frac{\partial \theta}{\partial t}=-\nabla \cdot[\mathbf{u} \theta+\mathbf{F}(\theta)] \\
\frac{\partial s}{\partial t}=-\nabla \cdot[\mathbf{u} s+\mathbf{F}(s)] \\
\rho=\rho(\theta, s, z) .
\end{gathered}
$$

onde a coordenada $\phi$ é latitude, que aumenta em direção ao norte e é zero no equador. Portanto temos aqui o efeito $\beta$ completo, não se trata de plano- $f$ onde as ondas de Rossby são suprimidas, ou do plano- $\beta$ onde temos ondas de Rossby, mas a distribuição meridional de vorticidade de background é simplificada. Nos modelos de plano- $\beta$ as inferências sobre velocidade de fase são limitadas a faixas de latitude estreitas ao redor de uma latitude de referência; neste aqui, não. $\lambda$ é a longitude, que aumenta em direção a leste. $z$ é a coordenada vertical, positiva para cima com o zero na superfície em um oceano em repouso. As constantes básicas e parâmetros são: densidade, dada por $\rho_{0}=1,035 \times 10^{3} \mathrm{kgm}^{-3}$; aceleração média da gravidade $g=9,8 \mathrm{~ms}^{-2}$; raio médio da terra $a=6371 \times 10^{3} \mathrm{~m}$; parâmetro de Coriolis, dado por $f=2 \Omega \sin \phi$, onde a velocidade angular da terra $\Omega=7,292 \times 10^{-5} s^{-1}$.

As equações (3.1) e (3.2) são as componentes horizontais da equação do movimento e são compostas pelos seguintes termos:

1. Advecção

2. Força de Coriolis 
3. Gradiente horizontal de pressão

4. Fricção horizontal

5. Fricção vertical

A velocidade vertical é diagnosticada através da equação da continuidade (3.3). A pressão é estimada através da equação hidrostática (3.4). Temperatura potencial e salinidade são os marcadores ativos ${ }^{1}$ calculados pelas equações (3.5) e (3.6). A equação do estado (3.7), relaciona a densidade com a temperatura potencial, salinidade e pressão, e por sua característica não-linear é capaz de representar importantes aspectos da termodinâmica dos oceanos. Embora fuja ao escopo do presente trabalho, cabe aqui mencionar que este modelo tem uma formulação capaz de reproduzir os aspectos termodinâmicos da propagação de ondas de Rossby (Polito and Liu, 2003).

O sistema de equações (3.1)-(3.7) do modelo contém todos os fatores necessários para o desenvolvimento de ondas de Rossby de forma realística. Mais especificamente, além do efeito beta planetário ele inclui cisalhamento horizontal, topografia, e não-linearidade. Ele é completado por um conjunto de condições de contorno e condições iniciais. A condição de contorno cinemática de fundo define o fundo do oceano através da condição de ausência de fluxo normal ao fundo, ou seja, velocidade perpendicular ao contorno é zero. Além disso, esta condição determina que uma partícula no fundo permanecerá no fundo, de forma que, o fundo mantém sua integridade e não há erosão ou deposição. A condição de contorno cinemática está na superfície livre, que não é impermeável pois existe aporte de água doce. A condição de contorno dinâmica descreve o fluxo de momento através dos contornos laterais, de fundo e superficial. Na superfície o fluxo de momento vem de duas fontes distintas, o stress do vento e o fluxo de água doce na interface ar-mar. O fluxo de momento nos contornos é dado pelas condições de ausência de fluxo perpendicular ao contorno e no-slip. Desta forma, o modelo inclui dois mecanismos não completamente distintos associados à gênese das ondas de Rossby. Um é o bombeamento de Ekman em oceano aberto, pois a dinâmica de Ekman está contida na formulação supracitada. O segundo, é a ressurgência costeira, suportada pelas condições de contorno. O fluxo de marcadores através das laterais e do fundo do oceano são definidos como zero. Já os fluxos através da superfície do oceano, que são mantidos por processos turbulentos não reproduzidos pelo modelo, são parametrizados através dos dados do NCEP, que serão descritos mais à frente. Além disso, a condição de contorno denominada esponja é utilizada, onde os campos ao longo dos contornos são restaurados de tempos em tempos de acordo com um banco de dados. As condições iniciais do modelo foram oceano em repouso e a estrutura de densidade foi especi-

1 Um marcador de fluxo é qualquer propriedade do fluido usada para marcar seu fluxo. A concentração de um componente químico em um fluido pode ser usada como um marcador químico e a temperatura potencial como um marcador físico. Marcadores ativos alteram dinamicamente o fluxo de um fluido através da mudança das suas propriedades presentes na equação do movimento, como por exemplo, densidade ou viscosidade, enquanto que marcadores passivos não influenciam o fluxo. 
ficada com a média anual dos campos de temperatura e salinidade do Wolrd Ocean Atlas 1998 (WOA98) (Pacanowski and Griffies, 2000).

O domínio do modelo é quase global, se estendendo de $75^{\circ} \mathrm{S}$ a $75^{\circ} \mathrm{N}$, exceto pelo oceano Ártico. A simulação utilizada neste trabalho possui resolução temporal de 3 dias, horizontal de $1 / 10^{\circ}$ e 54 níveis verticais, com a distância entre um nível e outro variando de $5 \mathrm{~m}$ na superfície à $330 \mathrm{~m}$ na profundidade máxima, que é de $6065 \mathrm{~m}$. A distribuição dos níveis verticais é feita de forma que seja capaz de reproduzir a estratificação oceânica acima da termoclina média. A topografia foi construída a partir do banco de dados batimétricos criados pelo projeto OCCAM no Southampton Oceanography Center, obtidos através do GDFL/NOAA, com resolução de $1 / 30^{\circ}$. A série temporal utilizada se estende do dia 01 de janeiro de 1993 a 31 de dezembro de 2010.

No modelo, o fluxo de calor na superfície é calculado pela bulk fórmula (Rosati and Miyakoda, 1988) através de variáveis atmosféricas baseadas na reanálise do National Centers for Environmental Prediction-National Center for Atmospheric Research (NCEP-NCAR) (Kalnay et al., 1996). Nesse modelo esse é um processo unidirecional, onde os fluxos atmosféricos impostos pelos dados NCEP-NCAR forçam o modelo oceânico, mas não há mecanismo de feedback. O oceano não tem como forçar a atmosfera. Este ponto é importante na discussão dos resultados, pois é a principal diferença em relação ao modelo CESM que será descrito na subseção a seguir. O fluxo de água doce é calculado através da taxa de precipitação dos dados de reanálise. Adicionalmente a esse fluxo de água doce, a descarga dos rios é incorporada na salinidade da superfície do mar através de uma correção, feita a cada seis dias, entre a salinidade simulada e a média mensal de salinidade do World Ocean Atlas 1998 (WOA98) (Antonov et al., 1998; Boyer et al., 1998). A climatologia é baseada World Ocean Atlas 1998 (WOA98) (Antonov et al., 1998; Boyer et al., 1998). Os campos de temperatura e salinidade nas bordas artificiais norte e sul, localizadas em $75^{\circ} \mathrm{N}$ e $75^{\circ} \mathrm{S}$, também são restaurados para suas médias mensais através do WOA98, com escala temporal de um dia aumentando linear e infinitamente em direção ao interior. Uma descrição mais detalhada dos parâmetros e ajustes do modelo podem ser encontradas no Masumoto et al. (2004); Sasaki et al. (2006).

A partir de uma condição inicial de repouso com campos médios anuais de temperatura e salinidade (WOA98), o modelo foi rodado por 50 anos aplicando uma forçante atmosférica de médias mensais do período de 1950 até 1999 baseado nos dados de reanálise do NCEP-NCAR. Seguindo essa rodada climatológica de 50 anos como período de estabilização (spin up), o modelo foi rodado com forçantes atmosféricas médias diárias da reanálise do NCEP-NCAR de 1950 até 2013 (Nonaka et al., 2006; Taguchi et al., 2007). Um resumo das características do modelo encontra-se no final desta seção na Tabela 1.

A Figura 5 é o campo de altura da superfície do mar do modelo OFES para o oceano Atlântico Sul, para o dia 01 de Janeiro de 1993. É importante ressaltar que a diferença de valores entre essa figura e a Figura 4 se dá pelo fato das saídas do modelo serem altura da 
superfície do mar, enquanto que os dados do altímetro são apenas as anomalias da altura da superfície do mar, por isso as cores diferentes. Uma rápida comparação entre as Figuras 4 e 5 nos permite observar que no modelo o giro subtropical é marcado por maiores profundidades, no altímetro não é possível observar isso pois a circulação média foi retirada. Outra diferença entre os dados é que devido à maior resolução espacial do modelo e ao fato da simulação produzir campos verdadeiramente sinóticos, enquanto que o campo de SLA do altímetro (Figura 4) é um produto interpolado com base em dados de aproximadamente \pm 35 dias em relação à data de referência, portanto não exatamente sinótico, o resultado são vórtices com simetria mais próxima da circular na Figura 5 em relação à Figura 4. Como o modelo OFES é forçado por ventos realísticos esperamos que este seja capaz de reproduzir mais adequadamente os eventos sinóticos observados pelo altímetro.

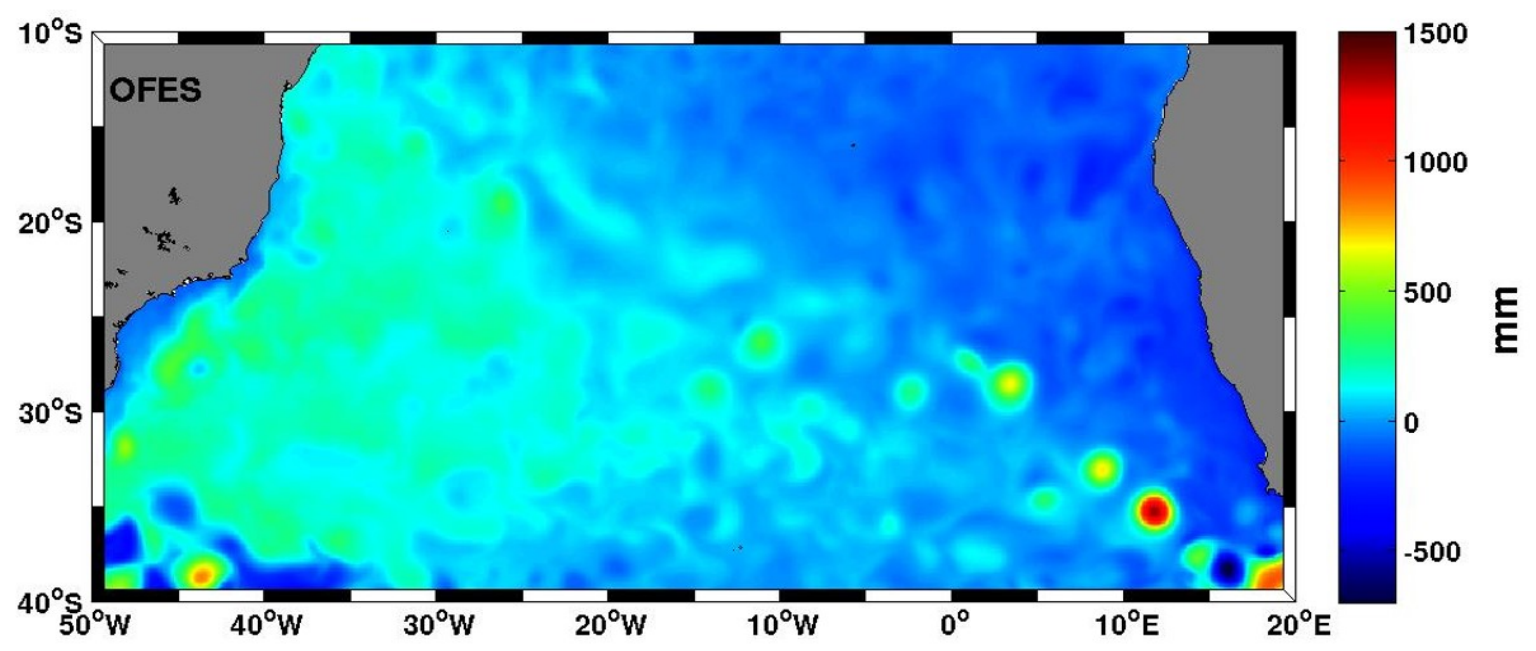

Figura 5 - Altura da superfície do mar simulada pelo modelo OFES, em milímetros, no oceano Atlântico Sul entre as latitudes de $10^{\circ}$ e $40^{\circ} \mathrm{S}$, com resolução horizontal de $1 / 10^{\circ}$, para o dia 01 de Janeiro de 1993.

\subsubsection{CESM}

O Community Earth System Model (CESM) (Hurrell et al., 2013), é um modelo climático acoplado de alta resolução que sucede o Community Climate System Model versão 4 (Gent et al., 2011). A configuração do modelo aqui usada apresenta o Community Atmosphere Model (CAM5) (Neale et al., 2010) como componente atmosférica; a componente de gelo marinho é o Community Ice Code (CICE) versão 4 (Hunke and Lipscomb, 2008); o Parallel Ocean Program versão 2 (POP2) (Smith et al., 2010) e o Community Land Model (CLM) versão 4 (Lawrence et al., 2011) são as componentes oceânica e terrestre, respectivamente.

O modelo POP2, assim como o MOM3, é um modelo descendente da classe de modelos Bryan-Cox-Semtner (Semtner Jr., 1986). Sua dinâmica oceânica também é descrita pe- 
las equações primitivas para um fluido estratificado, fino, utilizando as aproximações hidrostática e de Boussinesq (equações (3.1) a (3.7)). Pelos mesmos argumentos apresentados na subseção precedente, esse modelo também tem uma formulação suficiente para reproduzir ondas de Rossby baroclínicas de forma realística. A resolução espacial é de $0,1^{\circ}$ (11 km no equador diminuindo para 2,5 $\mathrm{km}$ em altas latitudes) em uma grade tripolo com os polos na América do Norte e na Ásia. As configurações são similares às usadas por McClean et al. (2011) e Kirtman et al. (2012), exceto pelo número de níveis verticais que aumentou de 42 para 62 com uma maior concentração de níveis na termoclina. A topografia oceânica interpolada na grade foi construída através de uma combinação dos conjuntos de dados batimétricos do ETOPO2 (http://www.ngdc.noaa.gov/mgg/fliers/01mgg04.html) e do BEDMAP (http://www.antarctica.ac.uk//bas_research/data/access/bedmap/).

As condições iniciais do oceano são derivadas da climatologia do WOCE (Gouretski and Koltermann, 2004). Esta compreende campos de temperatura e salinidade otimamente analisados em uma grade de $0,5^{\circ}$. A interpolação ótima foi feita nas superfícies de densidade para evitar a produção de massas de água artificiais nos dados de grade resultando em gradientes horizontais mais nítidos. A estabilidade hidrostática também é imposta nos perfis de densidade climatológica analisados. Um pequeno (1 ano) spin-up foi rodado no modelo de gelo marinho, forçado pelas condições de contorno do protocolo CORE (Coordinated Ocean Reference Experiment) (Large and Yeager, 2009).

As forçantes devido ao estresse do vento, fluxo de calor e água doce são aplicadas como condições de contorno de superfície. As condições de contorno lateral e de fundo, assim como no MOM3, são de fluxo nulo para os marcadores, gradiente normal às bordas nulo, e no-slip para as velocidades, velocidade igual a zero no fundo e nos contornos laterais. Portanto neste caso também estão contemplados os mecanismos geradores de ondas de Rossby associados à dinâmica de Ekman.

A comunicação do oceano com o acoplador acontece a cada 6 horas, promovendo uma atualização dos valores de temperatura da superfície do mar e recebendo atualização dos fluxos pela superfície. Cabe notar que a escala de tempo deste processo de acoplamento é mais do que suficiente para o estudo das ondas de Rossby cuja escala temporal mínima é duas ordens de grandeza mais longa. A comunicação da atmosfera com o acoplador ocorre a cada 10 minutos. Este acoplador computa os fluxos na interface ar-mar usando o esquema de camada superficial de Large and Yeager (2009). Os modelos atmosférico e terrestre foram rodados com resolução horizontal de $0,25^{\circ}$ enquanto que o de gelo marinho assim como o oceânico foram rodados com resolução horizontal de $0,1^{\circ}$. O CESM foi executado sob condições de gases do efeito estufa atuais (concentração de $\mathrm{CO}_{2}$ fixa em 367 ppm). Esse valor foi escolhido de forma que comparações diretas pudessem ser feitas com observações recentes de fenômenos de pequena e larga escala.

No presente trabalho utilizamos saídas diárias de altura do nível do mar ( $\eta$ ) do dia 17 
de Fevereiro do ano 45 da simulação até o dia 17 de Setembro do ano 49, totalizando 4 anos e 7 meses de série temporal, disponíveis através do https://www.earthsystemgrid.org/. A figura 6 é o campo de altura do nível do mar calculado pelo modelo CESM, em milímetros, para o dia 17 de Fevereiro do ano 45 da simulação, no oceano Atlântico Sul entre as latitudes de 10 e $40^{\circ} \mathrm{S}$ e longitudes de $50^{\circ} \mathrm{W}$ e $20^{\circ} \mathrm{E}$, com resolução horizontal de $1 / 10^{\circ}$. Comparando as Figura 6 e 4 notamos que assim como o modelo OFES no CESM podemos ver que o giro subtropical é marcado por maiores profundidades. Apesar da resolução espacial dos dois modelos serem a mesma e da resolução temporal do CESM (diária) ser melhor do que a do OFES (3 dias), os vórtices presentes no CESM não apresentam uma simetria próxima da circular. Um outro ponto é que o modelo CESM não é forçado por ventos observados, ou por uma reanálise dos dados observacionais e sim, acoplado com um modelo atmosférico, dessa forma não esperamos uma reprodução de eventos sinóticos neste modelo. Um resumo das características dos dois modelo utilizados nesse trabalho encontra-se na Tabela 1.

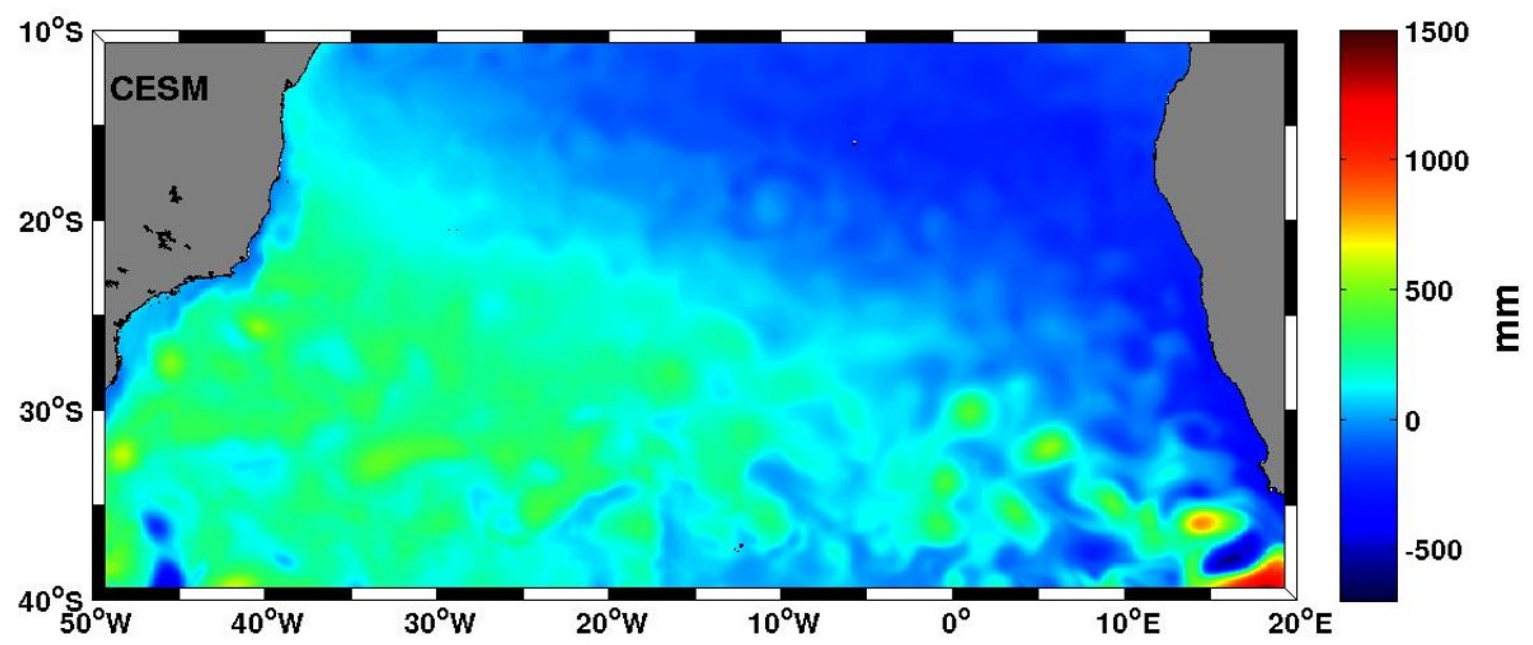

Figura 6 - Altura da superfície do mar simulada pelo modelo CESM, em milímetros, no oceano Atlântico Sul entre as latitudes de $10^{\circ}$ e $40^{\circ} \mathrm{S}$, com resolução horizontal de $1 / 10^{\circ}$, para o dia 17 de Fevereiro do ano 45 da simulação. 
Tabela 1 - Resumo das características dos modelos OFES e CESM.

\begin{tabular}{lll}
\hline & \multicolumn{1}{c}{$\begin{array}{c}\text { Ocean GCM for the Earth Simulator } \\
\text { (OFES) }\end{array}$} & \multicolumn{1}{c}{$\begin{array}{c}\text { Community Earth System Model } \\
\text { (CESM) }\end{array}$} \\
\hline Grupo: & GFDL/NOAA & NCAR/UCAR \\
Baseado no: & MOM3 & POP2 \\
Tipo de modelo: & Equações primitivas & Equações primitivas \\
Condição inicial: & Repouso & Repouso \\
Estrutura densidade: & WOA98 & WOCE \\
Gases efeito estufa: & - & Concentração de $\mathrm{CO}_{2}$ fixa 367 ppm \\
Resolução temporal: & 3 dias & diária \\
Resolução horizontal: & $1 / 10^{\circ}$ & $1 / 10^{\circ}$ \\
Resolução vertical: & 54 níveis & 62 níveis \\
Distância entre as camadas: & $5 \mathrm{~m}$ na superfície até $330 \mathrm{~m}$ na profundidade de $6065 \mathrm{~m}$ & $10 \mathrm{~m}$ na superfície até $250 \mathrm{~m}$ na profundidade de $6000 \mathrm{~m}$ \\
Período: & $1993-2010$ & 4 anos e 7 meses (não datado) \\
Forçante: & reanálise NCEP/NCAR & modelos atmosférico, terrestre e criosférico \\
Saída: & altura da superfície do mar & altura da superfície do mar \\
\hline
\end{tabular}




\section{Metodologia}

\subsection{Pré-processamento dos dados}

Inicialmente, foram calculadas as anomalias da altura da superfície do mar a partir dos dados de altura da superfície do mar dos modelo OFES e CESM. A anomalia foi calculada como o desvio do valor observado com respeito à média da série temporal. Dessa forma, a partir daqui, os três conjuntos de dados se referem a anomalia da altura da superfície do mar. Foram portanto excluídas as anomalias espaciais da altura decorrentes das correntes médias efetivamente presentes em cada conjunto de dados. Esse procedimento é justificado pelo fato de estarmos interessados em processos oscilatórios. Por essa perspectiva, mesmo que a circulação média seja diferente em cada conjunto de dados, ela é irrelevante para a obtenção do campo de ondas.

As saídas do modelo OFES apresentam resolução espacial de $1 / 10^{\circ}$ e temporal de 3 dias, enquanto que os dados altimétricos utilizados neste trabalho apresentam resolução espacial de $1 / 4^{\circ}$ e temporal diária. Diferenças nas resoluções espacial e temporal podem causar impacto na estimativa da velocidade de fase e influenciar a comparação estatística entre os conjuntos de dados. Assim sendo, padronizamos a resolução entre estes dois conjuntos de dados em $1 / 4^{\circ} \mathrm{e}$ 3 dias, subamostrando os dados altimétricos de 3 em 3 dias e e as saídas do OFES em 1/4 , através de um esquema de interpolação por curvatura contínua em tensão variável (Smith and Wessel, 1990). Neste processo não há perda de informação relevante, uma vez que as resoluções espacial e temporal superam por uma ordem de grandeza ou mais os valores co-intervalos de Nyquist associados às ondas de menor período e comprimento.

Este método consiste em dividir a série de dados em subconjuntos e utiliza polinômios de pequena ordem para cada subconjunto (spline). A junção destes subconjuntos é que forma interpolação sobre todo o domínio (Emery and Thomson, 2001). O ajuste de tensão permite controlar a contribuição do termo harmônico relativo à superfície de mínima curvatura (tensão zero). Curvas suaves são geradas preservando a fidelidade dos dados coletados. A interpolação de curvatura mínima com tensão variável gera uma superfície que interpola todas as observações disponíveis através da solução da equação diferencial modificada bi-harmônica com tensão (Smith and Wessel, 1990):

$$
(1-T) \nabla^{2}\left(\nabla^{2} z\right)+T \nabla^{2} z=0
$$

onde $z$ é a variável a ser interpolada, T é o parâmetro adimensional de tensão para o contorno que varia entre 0 e 1 . No caso extremo de $\mathrm{T}=0$ a solução de mínima curvatura (spline) prevalece e no caso de $\mathrm{T}=1$, a solução de curvatura zero (linear) prevalece. No presente estudo foram 
utilizados para o parâmetro de tensão $T$, os valores de 0,25 no interior do domínio e 0,75 nos contornos (Wessel and Bercovici, 1998). Estes valores foram aplicados para suavizar os contornos continentais. As séries temporais vão do dia 01 de janeiro de 1993 até o dia 31 de dezembro de 2010. A padronização entre as resoluções do CESM (1/10 ${ }^{\circ}$ diária) e do satélite altimétrico ( $1 / 4^{\circ}$ diária) foi feita da mesma forma, subamostrando as saídas numéricas em $1 / 4^{\circ}$.

Após a padronização das resoluções dos dados de SLA, estes foram convertidos em diagramas zonais-temporais $(x, t)$, conhecidos como Hovmöller, como mostra a Figura 7, para cada latitude da área de estudo. Estes diagramas são utilizados para analisar a evolução de fenômenos propagantes com diferentes características. De acordo com Matthews et al. (1992) e Le Traon and Minster (1993), evidências de propagação de ondas de Rossby baroclínicas aparecem nesses diagramas como alinhamentos diagonais de cristas e cavados se movendo para oeste com o tempo. A presença de padrões listrados horizontalmente indica que a superfície subiu ou desceu simultaneamente para todas as longitudes. Como na Figura 7 o período é anual, este sinal é associado à sazonalidade.

Vórtices de mesoescala como o que está centrado em $11^{\circ} \mathrm{E}$ e $35^{\circ} \mathrm{S}$ na Figura 5 se propagam com velocidade similar à das ondas de Rossby (McWilliams and Flierl, 1976) e por vezes junto com elas (Polito and Sato, 2015). A distinção, neste caso se dá pela direção de propagação e pelo número de cristas e cavados. Um vórtice é uma feição isolada e cuja velocidade de propagação é geralmente inclinada (Chelton et al., 2011), cruzando uma latitude por um curto período de tempo. Na Figura 7, os vórtices são pequenos traços inclinados e isolados; as ondas são linhas longas, inclinadas e flanqueadas por outras linhas paralelas.

Antes de calcularmos as características dos fenômenos propagantes presentes nos diagramas de Hovmöllers, padronizamos o comprimento das séries temporais entre AVISO (18 anos de medições) e CESM (4 anos e 7 meses de saídas numéricas) (Figura 8),para que ambos conjuntos de dados apresentem as mesmas características temporais. O CESM é um modelo acoplado, não datado, dessa forma não existe correspondência a priori entre suas séries temporais e as do altímetro. $\mathrm{O}$ que se pode esperar dessa classe de modelos é que reproduzam fenômenos de meso e larga escala compatíveis com a resolução espaço-temporal, por terem a formulação física completa. A parte forçada por transferência radiativa é sazonal, portanto periódica. A resposta linear da altura do oceano deve contemplar um ciclo anual. Os demais sinais não são necessariamente periódicos e dependem da dinâmica interna das componentes (atmosfera, oceano, gelo) do modelo.

Sendo assim, para trabalhar com o período em que o modelo mais se assemelha com os dados observados calculamos a correlação, através das equações 4.2 e 4.3 , entre $\eta_{m}(x, t)$ do modelo CESM e $\eta_{o}(x, t)$ da AVISO. A correlação entre duas séries temporais estima o grau de dependência linear existente entre as mesmas, com possibilidade de deslocamento no tempo $\tau$, sendo esta última variável o "atraso"ou "lag". 


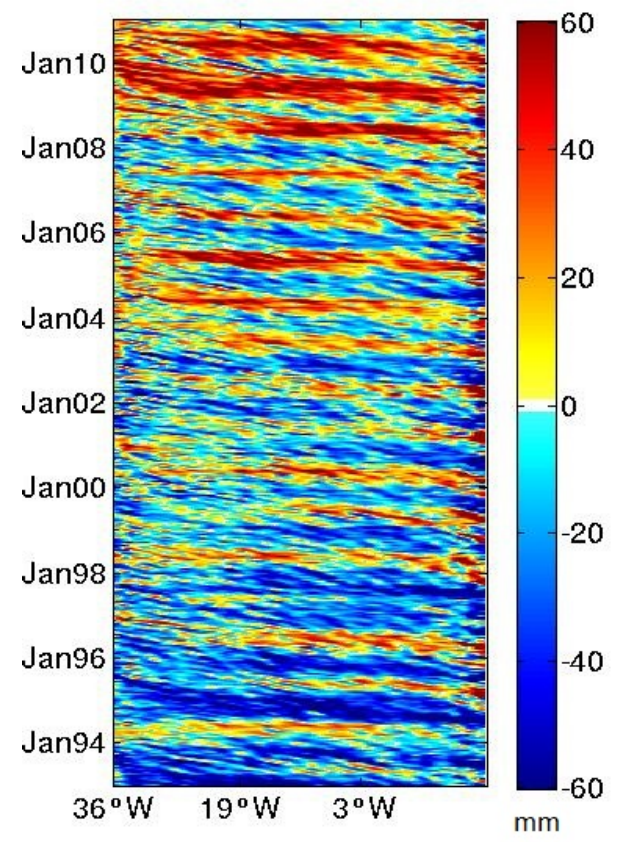

Figura 7 - Diagrama zonal-temporal de anomalia da altura da superfície do mar, em milímetros, obtido no oceano Atlântico para a latitude de $10,125^{\circ} \mathrm{S}$, com o dados de altímetro.

Como o comprimento das séries temporais é diferente, a correlação no lag zero foi calculada entre o diagrama zonal-temporal das saídas do modelo CESM e pedaços do diagrama zonal-temporal das observações altimétricas. O primeiro pedaço recortado dos dados da AVISO vai do dia 01 de janeiro de 1993 até 01 de agosto de 1997, apresentando o mesmo comprimento que a série temporal do modelo. O segundo pedaço vai do dia 02 de janeiro de 1993 até dia 02 de agosto de 1997, o terceiro do dia 03 de janeiro de 1993 até 03 de agosto de 1997, e assim sucessivamente até que a série temporal do modelo tenha sido correlacionada com toda a série temporal do altímetro.

$$
C_{x y}(\tau)=\frac{1}{N-\tau} \sum_{i=1}^{N-\tau}\left[y_{i}-\bar{y}\right]\left[x_{i+\tau}-\bar{x}\right]
$$

e normalizando

$$
r_{x y}(\tau)=\frac{C_{x y}(\tau)}{\sigma_{x} \sigma_{y}}
$$

onde $x_{i}$ e $y_{i}$ são as séries temporais a serem correlacionadas; $\bar{x}$ e $\bar{y}$ são as médias das séries, $\sigma_{x}$ e $\sigma_{y}$ são os desvios padrão das séries; $\mathrm{N}$ é o comprimento da série temporal e $\tau$ é o incremento no tempo ou lag. O coeficiente de correlação cruzada $\left(r_{x y}\right)$ varia entre -1 e 1 . Nesses limites, as séries são totalmente correlacionadas; caso o valor seja zero, não há correlação entre as séries. 

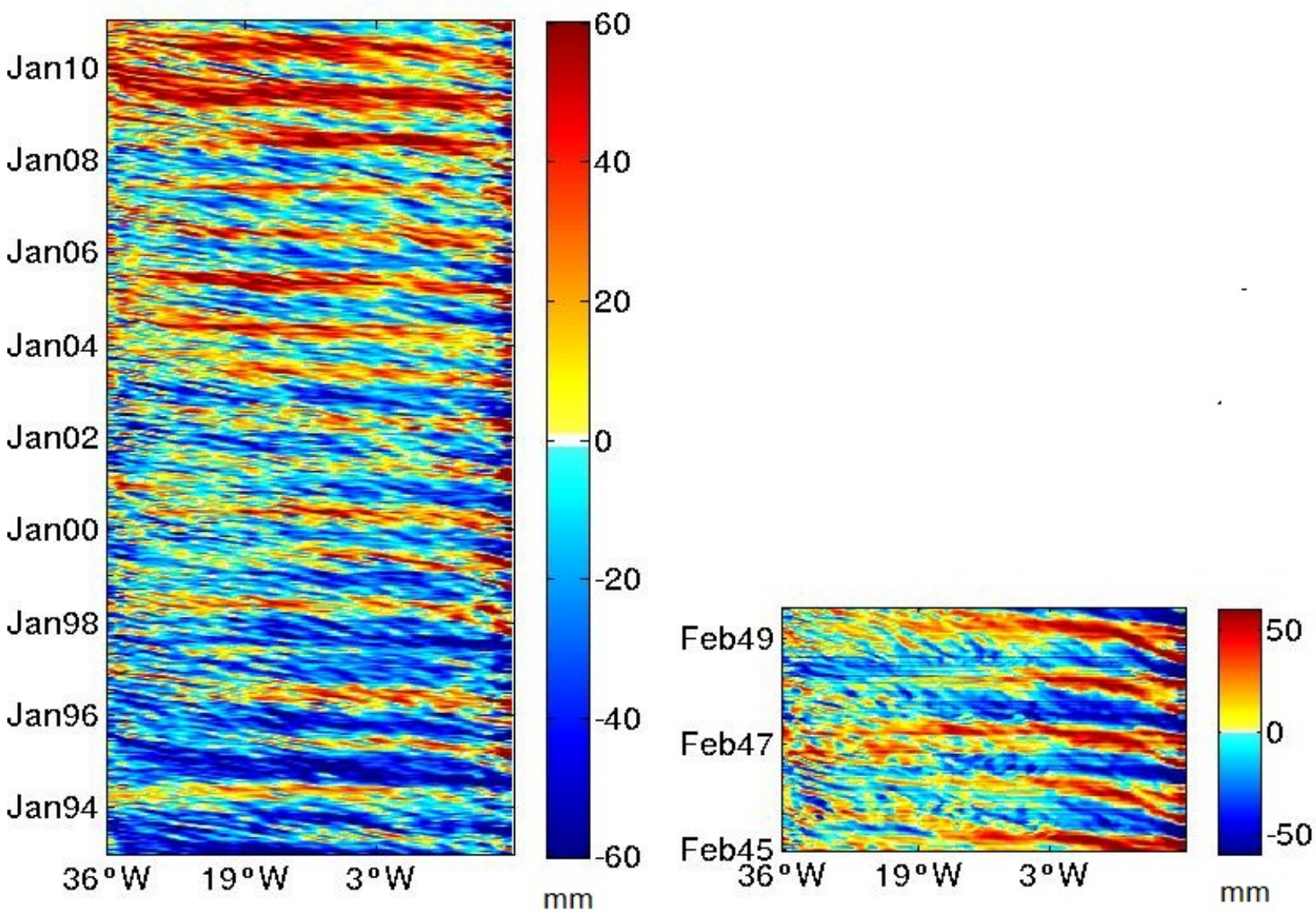

Figura 8 - Diagramas zonais-temporais de anomalia da altura da superfície do mar, em milímetros, obtidos com os dados altimétricos (à esquerda) e através das saídas do modelo CESM (à direita), para a latitude de $10,125^{\circ} \mathrm{S}$ no oceano Atlântico.

Estas correlações foram feitas para 4 latitudes que examinaremos mais detalhadamente, que são $10^{\circ}, 15,5^{\circ}, 28^{\circ}$ e $40^{\circ} \mathrm{S}$. O período da série temporal do altímetro que apresentou o maior coeficiente de correlação com as saídas do modelo nessas quatro latitudes foi recortado, como mostra a Figura 9, e utilizado nos cálculos a seguir. 

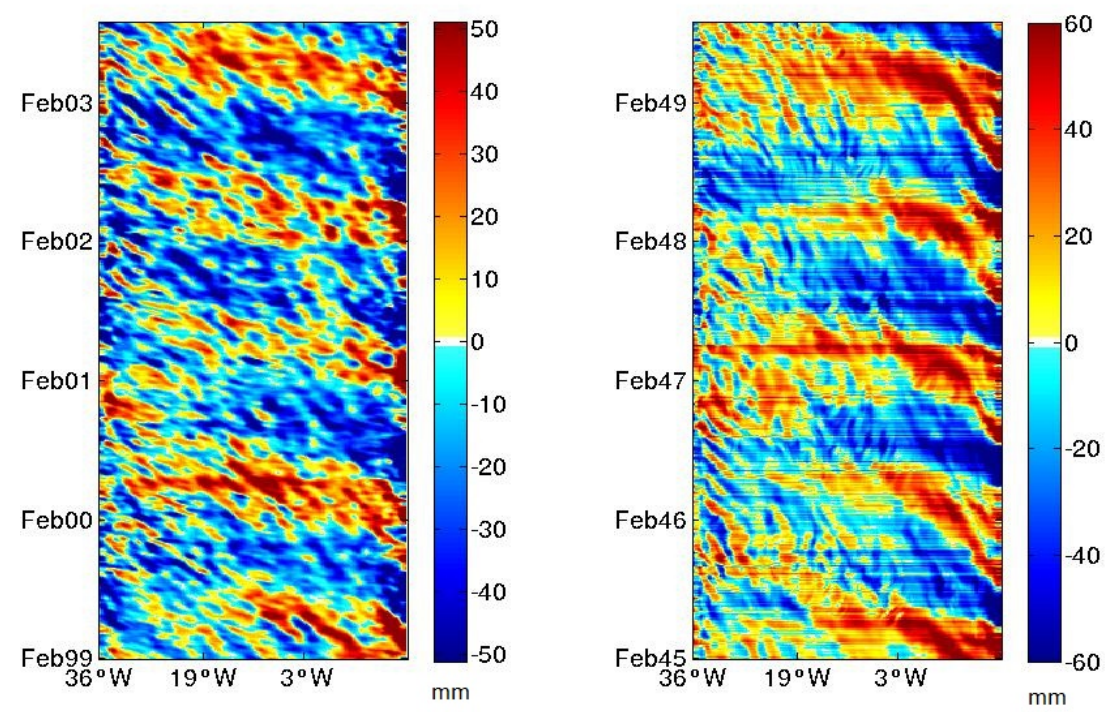

Figura 9 - À esquerda, diagrama zonal-temporal de anomalia da altura da superfície do mar em milímetros, obtido a partir dos dados altimétricos, referente ao período escolhido para comparação com o modelo. À direita, diagrama zonal-temporal de anomalia da altura da superfície do mar, obtido através das saídas do modelo CESM. Ambos para a latitude de $10,125^{\circ} \mathrm{S}$ do oceano Atlântico.

Esta parte da metodologia estabeleceu um método para compatibilização das resoluções espaço-temporal e um critério objetivo para a escolha do período a ser analisado. Com as resoluções e o tamanho das séries temporais semelhantes, a metodologia descrita a seguir foi aplicada separadamente nos quatro conjuntos de dados, sendo estes: i) modelo OFES; ii) dados do altímetro com resolução semelhante ao modelo OFES; iii) modelo CESM; iv) dados altimétricos com resolução semelhante ao modelo CESM. Nos casos ii e iv o intervalo de tempo difere por causa da saída dos modelos numéricos.

\subsection{Filtros FIR 2D}

A partir das feições diagonais presentes nos diagramas zonais-temporais é possível estimar manualmente a velocidade de propagação zonal através da inclinação das cristas e cavados. Estas estimativas podem ser feitas através de duas técnicas de processamento, a transformada de Radon 2-D e a transformada de Fourier 2-D. Neste trabalho utilizamos a primeira. Antes de aplicarmos este método para obter as características da onda, separamos as componentes presentes no diagrama de Hovmöller. Utilizaremos um conjunto de filtros de resposta impulsiva finita 2D (FIR-2D), que são baseados na convolução de duas matrizes no domínio do espaçotempo, onde uma corresponde ao dado geofísico de interesse e a outra à própria matriz filtro. 
Considerando que a SLA é representada por $\eta(x, t)$ e a matriz filtro por $\psi(i, j)$, tem-se que:

$$
\eta_{\psi}(x, t)=\sum_{i=-m}^{m} \sum_{j=-n}^{n} \eta(x+i, t+j) \psi(i, j),
$$

onde $\eta_{\psi}$ é a matriz filtrada. A quantidade de filtros utilizados varia de acordo com o número de bandas espectrais que serão analisadas. A vantagem dos filtros bidimensionais é que cada componente é filtrada em $x$ e $t$ simultaneamente garantindo que o processo de filtragem seja seletivo também em relação à direção de propagação.

Seguindo a metodologia proposta por Polito and Cornillon (1997), foi construído um conjunto de filtros FIR para separar a porção não-propagante contida nos dados. A forma funcional dos filtros para as componentes não-propagantes (sinal não-propagante de larga escala que inclui variabilidade sazonal $\left(\eta_{t}\right)$ e sinal de meso-escala $\left(\eta_{E}\right)$ ) é de uma função Gaussiana bidimensional. Ela decai de 1 no centro a 0 nas bordas e normalizada pelo somatório total dos seus elementos, para que tenha integral unitária, preservando a amplitude, ou seja:

$$
\psi(i, j)=\frac{e^{\frac{-1}{2}\left[\left(\frac{\pi i}{m}\right)^{2}+\left(\frac{\pi j}{n}\right)^{2}\right]}}{\sum_{i=-m}^{m} \sum_{j=-n}^{n} \psi(i, j)} .
$$

A escala adotada é o próprio comprimento da bacia oceânica e o período de decorrelação foi fixado em 183 dias ( 6 meses) para $\eta_{t}$ e $500 \mathrm{~km}$ e 50 dias para $\eta_{E}$, de acordo com a metodologia dePolito and Liu (2003). Daqui em diante, $\eta_{t}$ será referido no texto apenas como sinal sazonal, porém este se refere ao sinal não propagante de larga escala, com período de 12 meses. No caso das porções propagantes, o formato do filtro é o de um cosseno com decaimento exponencial e bidimensional de padrão inclinado, ou seja:

$$
\begin{aligned}
& f(i, j)=\frac{e^{-\frac{1}{2}\left(\left(\frac{\pi i}{m}\right)^{2}+\left(\frac{\pi j}{n}\right)^{2}\right)}}{N} \cos \left(\frac{2 \pi i}{L}-\frac{2 \pi j}{T}\right)+M, \\
& \text { com M e N tal que }\left\{\begin{array}{l}
\sum_{i=-m}^{m} \sum_{j=-n}^{n}|f(i, j)|=1, \\
\sum_{i=-m}^{m} \sum_{j=-n}^{n} f(i, j)=0,
\end{array}\right.
\end{aligned}
$$

as dimensões dos filtros são baseadas em estimativas do comprimento de onda $(\lambda)$ baseadas em estimativas prévias da velocidade de fase das ondas e períodos fixos que são harmônicos e 
subharmônicos do período anual. Em seguida, os filtros foram ajustados para decompor o sinal original de $\eta_{o}(x, t)$ em diagramas zonais-temporais das seguintes componentes espectrais:

$$
\eta_{s}=\eta_{24}+\eta_{12}+\eta_{6}+\eta_{3}+\eta_{1}
$$

onde $\eta_{x} \operatorname{com} x=24,12,6,3,1$ são as ondas de Rossby propagantes para oeste com períodos de aproximadamente 24,12 , 6, 3 e 11/2 meses; $\eta_{s}$ é o somatório de todos os sinais propagantes para oeste sugeridos como ondas de Rossby do primeiro modo baroclínico (Polito and Liu, 2003). Ao final da aplicação dos filtros FIR-2D temos o sinal original decomposto em sinal não propagante de larga escala, somatório dos sinais considerados ondas de Rossby e os sinais não propagantes de meso-escala, como mostrado na equação a seguir:

$$
\eta_{o}=\eta_{t}+\eta_{s}+\eta_{E}
$$

A diferença entre o sinal original e todas as componentes filtradas é o resíduo da decomposição contendo sinais não-propagantes de pequena escala, interpretados como resíduo $\left(\eta_{r}\right)$. Na Figura 10 são apresentados os Hovmöllers das componentes filtradas:

$$
\eta_{r}=\eta_{o}-\left(\eta_{t}+\eta_{s}+\eta_{E}\right)
$$

Os períodos de onda que podem ocorrer em determinadas latitudes são inferidos a partir do cálculo da latitude crítica. Desta forma, os períodos são fixados para cada latitude e o comprimento de onda é estimado através de $\lambda=c_{p} P$. De acordo com a teoria linear (Gill, 1982; Pedlosky, 1987), $c_{p}$ possui uma forte dependência com a latitude, desta forma podemos assumir inicialmente que $c_{p} \propto \frac{\cos \phi}{\sin ^{2} \phi}$. Após a aplicação de cada filtro um novo valor de $c_{p}$ é recalculado e o processo é sistematicamente repetido até que este valor de $c_{p}$ convirja para um valor estável. Os filtros são concebidos para uma transição suave entre as bandas, permitindo uma cobertura do espectro todo, com um mínimo de sobreposição entre bandas.

Posteriormente ao processo de filtragem, a amplitude do sinal de cada componente foi estimada através de $\sqrt{2} \sigma\left(\eta_{x}\right)$, onde $\sigma$ representa o desvio padrão e $\eta_{x}$ a componente espectral " $x$ "da SLA. O fator $\sqrt{2}$ converte o desvio padrão em amplitude, assumindo uma onda senoidal.

\subsection{Transformada de Radon}

Além do $c_{p}$ médio calculado através da teoria linear, utilizado apenas como valor inicial nas iterações que levam ao ajuste automático do filtro, a velocidade de fase final é calculada 


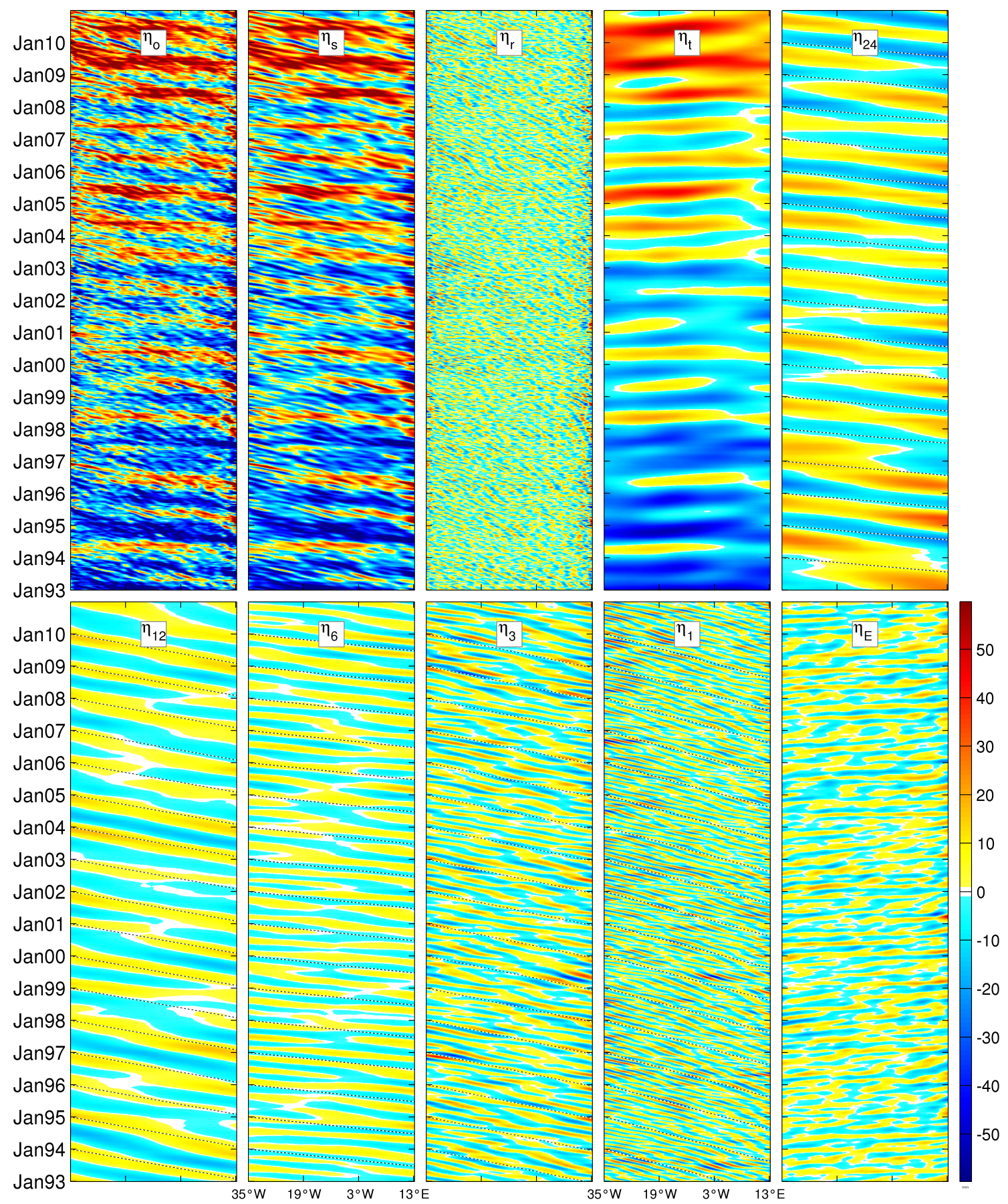

Figura 10 - Decomposição do sinal original de anomalia da superfície do mar $\left(\eta_{o}\right)$ no somatório das componentes propagantes $\left(\eta_{s}\right)$, no resíduo $\left(\eta_{r}\right)$, no sinal não-propagante $\left(\eta_{t}\right)$, nas componentes da onda de Rossby do primeiro modo baroclínico $\left(\eta_{24}\right.$ até $\left.\eta_{1}\right)$ e na componente de meso-escala $\left(\eta_{E}\right)$, para o oceano Atlântico na latitude de $10,125^{\circ} \mathrm{S}$. 
novamente junto com os outros parâmetros de onda, a fim de caracterizar essas ondas. Para isso todas as componentes de onda dos dados filtrados $\left(\eta_{24}(x, t), \eta_{12}(x, t), \ldots, \eta_{1}(x, t)\right)$ são divididas em blocos de tamanho $2 \lambda \times 2 P$, e a autocorrelação $c\left(x_{l}, t_{l}\right)$ de $\eta_{o}(x, t)$ é calculada para cada um desses blocos como uma função dos lags zonal e meridional $x_{l}$ e $y_{l}$. A vantagem de utilizar a autocorrelação ao invés da altura do mar propriamente dita é que a autocorrelação apresenta a mesma informação espectral, porém, os erros randômicos são consideravelmente menores e acumulados na origem, o que reduz muito a interferência no cálculo da velocidade de fase.

Na matriz de autocorrelação $X_{c}$ é aplicada a transformada de Radon modificada para estimar o ângulo das inclinações e posteriormente a velocidade de fase das ondas de Rossby, baseada no método de Lim (1990). Este método consiste em rotacionar o sistema de coordenadas da matriz de autocorrelação de cada bloco até que os padrões se alinhem com o eixo vertical. Esse alinhamento é ótimo quando a variabilidade projetada no eixo horizontal for maximizada. Uma vez que $c_{p}=\lambda / P$, a velocidade de fase é a tangente do ângulo de rotação $(\theta)$ que maximiza a variabilidade da projeção.

Estimativas de P e $\lambda$ são baseadas no método de mínimos quadrados com ajuste de uma função senoidal à matriz de autocorrelação. Novamente a amplitude A é estimada por $\sqrt{2} \sigma\left(\eta_{x}\right)$, onde $\sigma$ representa o desvio padrão e $\eta_{x}$ a componente espectral " $x$ "da SLA. Porém desta vez a amplitude, assim como os outros parâmetros de onda, é estimada para cada bloco da matriz de autocorrelação. Sendo assim, temos um conjunto de diferentes valores de $c_{p}, \lambda, P$ e $A$ por latitude.

Inicialmente, foi calculada a média da amplitude para cada uma das latitudes e os blocos com a amplitude menor que a média foram descartados. Esse critério foi estabelecido para que apenas os sinais de amplitude relativamente grande fossem considerados para as estimativas de $\lambda$ e $P$. Em seguida, foi calculada a média e o desvio-padrão da velocidade de fase e os valores de $c_{p}$ que estiverem acima do limite de 1 desvio-padrão da média são eliminados. Os respectivos valores de $\lambda$ e $P$ relativos a estes valores de $c_{p}$ também são eliminados. Por fim, uma nova média é calculada para $\lambda, P, A$ e $c_{p}$. Os valores finais de $c_{p}$ são dados em $\mathrm{km} / \mathrm{dia}, \lambda \mathrm{em} \mathrm{km}, \mathrm{P}$ em dias e A em mm.

\subsection{Comparação modelo-altímetro}

Nesta seção mostramos as diferentes formas utilizadas para comparar os parâmetros das ondas de Rossby planetárias do $1^{\circ}$ modo baroclínico obtidas a partir de uma mesma metodologia aplicada aos campos de SLA do altímetro e dos modelos OFES e CESM.

Esta metodologia tem apenas um parâmetro fixo: o período central de cada banda espectral. A velocidade de fase inicial é mudada durante as iterações e assume o valor medido localmente para cada latitude. O comprimento de onda é calculado com base no período e na velocidade de fase medidos localmente. Portanto espera-se a priori uma similaridade apenas de 
períodos, mas não de velocidade de fase, de comprimento de onda, de fase ou amplitudes.

Além disso, os fenômenos reproduzidos por qualquer modelo dependem da resolução da grade, no caso de ondas planetárias extra-equatoriais o limitante principal é a resolução espacial horizontal. A dinâmica dessas ondas conecta escalas espaciais com as temporais via relação de dispersão. Isso impõe um limite em termos de quais frequências e quais números de onda o modelo - mesmo sendo de equações primitivas - é capaz de reproduzir.

O primeiro método escolhido para comparar os resultados dos modelos com o altímetro foi através da variância explicada $\left(v_{x}\right)$, calculada através da equação (4.10). Este método permite a caracterização relativa da relevância estatística da amplitude de cada componente filtrada em relação a amplitude do sinal total $\left(\eta_{o}\right)$.

$$
v_{x}=1-\frac{\sigma\left(\eta_{o}-\eta_{x}\right)^{2}}{\sigma\left(\eta_{o}\right)^{2}}
$$

onde $\left(\eta_{x}\right)$ é a componente filtrada analisada, $\sigma$ é o desvio padrão e $v$ é expressa em percentual.

Para comparar as amplitudes dos sinais totais $\left(\eta_{o}\right)$, dos sinais filtrados e as variâncias explicadas de cada sinal filtrado em relação ao sinal total entre os modelos e o altímetro utilizamos o cálculo da diferença percentual, estimada por:

$$
\Delta=100 \times \frac{p_{\text {mod }}-p_{\text {alt }}}{p_{\text {alt }}},
$$

com $p_{\text {mod }}$ representando a amplitude do sinal total, do sinal filtrado ou a variância explicada do sinal filtrado estimado pelo modelo e $p_{\text {alt }}$ o mesmo parâmetro calculado a partir dos dados altimétricos. Valores positivos de $\Delta$ indicam uma superestimação dos parâmetros calculados através das saídas do modelo em relação aos obtidos através das observações do satélite e, valores negativos de $\Delta$ indicam uma subestimação desses parâmetros calculados pelas saídas do modelo. Dessa forma conseguimos estimar a diferença entre as ondas de Rossby calculadas através dos modelos e do satélite altimétrico a partir das amplitudes e das variâncias explicadas.

Uma outra forma utilizada para comparar os sinais do altímetro com os dois modelos foi através do espectro médio de Fourier. A análise espectral é utilizada para particionar a variância de uma dada série temporal como função da frequência. Com um conjunto de dados disponível, a contribuição de uma dada frequência é mensurada em termos de densidade de potência espectral, em termos de energia por unidade de tempo (Emery and Thomson, 2001). Ou seja, nos dá uma ideia de energia contida em cada banda de frequência. Dessa forma calculamos a transformada de Fourier para a série temporal de SLA de cada ponto de longitude dos Hovmöllers, em seguida tiramos a média desses espectros para obter o espectro de densidade potencial médio para cada Hovmöller. Os espectros foram limitados nas altas frequências em 1/20 ciclos/dia pois o altímetro de maior resolução completa um ciclo a cada 10 dias, aproximadamente. Os resultados dessas comparações serão mostrados na Seção 5.1 . 
Os valores médios dos parâmetros de onda $\lambda, c_{p}, A$ e $P$ dos modelos foram comparados com os do altímetro através da diferença percentual média. Primeiramente, foi calculada a diferença relativa $(\delta)$ através da seguinte equação:

$$
\delta=2 \frac{\left(p_{\text {alt }}-p_{\text {mod }}\right)}{\left(p_{\text {alt }}+p_{\text {mod }}\right)}
$$

Em seguida, foi calculada a média para intervalos específicos de latitude e apresentada em porcentagens. Os resultados das diferenças médias são apresentados na Seção 5.2.

Para estimar a diferença de fase entre as ondas de Rossby anuais e semianuais detectadas nos modelos e nos dados do altímetro, utilizamos a função de correlação cruzada, mostrada nas equações (4.2) e (4.3). Essa função é utilizada para caracterizar a variabilidade de uma série temporal ou a covariabilidade de duas séries temporais em dois momentos, $t_{1}=t$ e $t_{2}=t+\tau$, onde $\tau$ é o atraso da segunda em relação à primeira. A função foi aplicada para cada ponto de latitude e longitude das séries temporais. Selecionamos os maiores valores de correlação para cada ponto de latitude e longitude e os lags associados a esses coeficientes de correlação. Montamos então, um mapa dos coeficientes de correlação para cada ponto da área de estudo e um mapa dos lags associados a esses coeficientes. Esses mapas serão discutidos na Seção 5.3.

No modelo clássico as ondas de Rossby são geradas na borda leste pelo bombeamento de Ekman. Se os modelos reproduzissem essas ondas corretamente, a máxima correlação nessa região ocorreria em lag zero, ou seja diferença de fase zero. Como as ondas se propagam para oeste, para que a diferença de fase continue zero em toda a extensão da bacia, $c_{p}$ teria que ser reproduzida com precisão pelos modelos. Hipoteticamente, um pequeno erro em $\rho(z)$ do modelo, geraria um erro no raio de deformação de Rossby $\left(R_{d}\right)$; como para ondas longas $c_{p}$ varia com $\beta R_{d}{ }^{2}$, isso resultaria em um grande erro em $c_{p}$. Dessa forma, a fase do modelo andaria em um passo diferente da do altímetro e rapidamente as ondas ficariam fora de fase. Para diminuir a sensibilidade do processo a pequenos erros de $\rho(z)$ do modelo, utilizaremos apenas os máximos da correlação positiva entre $-180^{\circ}$ e $180^{\circ}$ de diferença de fase entre modelo e altímetro.

Outra forma utilizada para analisar os resultados das correlações foi através da média longitudinal dos coeficientes de correlação apresentados em gráficos de coeficientes por graus de latitude. Também avaliamos como os coeficientes de correlação se comportam em uma latitude específica ao longo da bacia, em gráficos de coeficiente de correlação por graus de longitude.

Além das correlações entre as ondas anuais e semianuais, calculamos também a correlação em lag zero entre os sinais sazonais encontrados nos modelos com o encontrado no altímetro. Os coeficientes da correlação também serão apresentados em formato de mapa. Esses resultados foram utilizados como base de comparação, por ser a parte mais determinística do espectro é justo esperar que este seja o limite superior de correlação entre modelo e altímetro. 
A média longitudinal desta correlação também foi calculada. 


\section{Resultados e discussão}

Esta seção foi dividida em três partes. Na primeira, apresentamos quatro conjuntos de resultados que nos permitem ter uma visão quantitativa do desempenho dos modelos do ponto de vista de variância total e repartida entre as bandas espectrais pelo processo de filtragem. $\mathrm{O}$ foco desta primeira parte é a variabilidade estatística e espectral. Na segunda parte, analisamos parâmetros específicos das ondas de Rossby (algo inédito para estes dois tipos de modelo) de forma quantitativa e direta ao longo das latitudes de $10^{\circ}$ a $40^{\circ} \mathrm{S}$. Esses resultados permitem uma análise mais detalhada que o anterior, concentrando nos no principal mecanismo de transmissão de energia de larga escala nos oceanos. O foco, nesta parte, é a dinâmica de um fenômeno específico. Na terceira e última parte, verificamos qualitativamente e quantitativamente a capacidade dos modelos reproduzirem o sinal sazonal e as ondas de Rossby anuais e semianuais ao longo de toda a bacia do oceano Atlântico sul. Essa abordagem permite propor quais podem ser os motivos por trás do desempenho dos modelos.

\subsection{Distribuição de potência de ondas de Rossby observada e modelada}

\subsubsection{Comparação com o modelo OFES}

Comparamos a amplitude do sinal total e dos sinais filtrados, bem como a variância explicada que cada componente apresenta em relação ao sinal total. Essa análise mais detalhada foi feita para quatro latitudes: $10^{\circ}, 15,5^{\circ}, 28^{\circ}$ e $40^{\circ} \mathrm{S}$. Embora não tenhamos feito uma expansão de erros, as incertezas apresentadas por Polito and Liu (2003) foram baseadas em um método muito semelhante ao aqui utilizado e nos permite apresentar A como um número inteiro de milímetro. Além disso, diferentemente de Polito and Liu (2003) que utilizaram apenas os dados do Topex/Poseidon, neste trabalho nós utilizamos os dados Aviso, aumentando a quantidade de amostras independentes por mapa e portanto essa estimativa de erros pode ser considerada conservadora. Nas Tabelas de 2 a 5, são apresentadas comparações entre as componentes de onda, resultantes do Filtro FIR-2D, dos dados do altímetro e do modelo OFES através da amplitude de cada componente e de sua variância explicada em relação ao sinal original, junto com a diferença percentual entre as estimativas. Abaixo das tabelas são apresentados os resultados da análise espectral calculada através da transformada rápida de Fourier (Figuras de 11 a 14) dos sinais originais do altímetro e do modelo. As faixas vermelhas, da mais escura para a mais clara, marcam as bandas do filtro das frequências anual, semestral, trimestral e sesquimensal, respectivamente.

A Tabela 2 é referente a latitude de $10^{\circ} \mathrm{S}$, onde é possível ver que o modelo representa 
de forma satisfatória a amplitude baseada no desvio padrão do sinal não filtrado $\left(\eta_{o}\right)$ presente no local (sinal total), com uma diferença de 5\% em relação aquela observada pelo altímetro. Apesar do modelo subestimar a amplitude no sinal sazonal $\eta_{t}$ em $14 \%$ quando comparado com o satélite, esta continua sendo a componente dominante no sinal total, com uma variância explicada de 43 e $30 \%$ no altímetro e no modelo, respectivamente. Mais a frente iremos abordar o que pode causar uma subestimativa da amplitude do sinal sazonal da altura. Nas ondas sesquimensais e trimestrais o modelo subestima o valor de amplitude em 13 e $15 \%$, quando comparado com os sinais do altímetro. Para as ondas bianuais o modelo representa com exatidão a amplitude: a diferença entre o modelo e altímetro é de menos de $0.5 \%$. As maiores diferenças se encontram nas ondas anuais e semianuais, onde o modelo superestima a amplitude em $78 \%$ para as ondas anuais e 57\% para as ondas semianuais. Além do modelo superestimar a amplitude nessas frequências, ele superestima também a importância dessas componentes no sinal total, pois no altímetro as componente $\eta_{12}$ e $\eta_{6}$ são as duas componentes menos importantes no sinal total, enquanto que no modelo a componente de onda com período anual representa $13 \%$ da variância da componente total e a semianual representa $7 \%$.

Na Figura 11 estão representados os espectrogramas médios do sinal total do altímetro e do modelo OFES para a latitude de $10^{\circ} \mathrm{S}$. Nela podemos ver a existência de dois picos de maior potência, tanto para o altímetro quanto para o modelo, nas frequências anuais e semianuais. A variância total do modelo é de $9,5 \times 10^{2} \mathrm{~mm}^{2}$ enquanto que a do altímetro é de $9 \times 10^{2} \mathrm{~mm}^{2}$. Analisando as duas curvas vemos que nas frequências menores do que a anual os espectros tem a mesma densidade de potência e nas bandas bi, anual e semianual a inclinação do espectro (decaimento) é bastante similar entre altímetro e modelo. A grande diferença ocorre em frequências altas, onde a potência decai muito mais acentuadamente no caso do satélite. Cabe aqui ressaltar que são dados interpolados no espaço e no tempo. A melhor resolução temporal dos dados originais altímetros é a da série TOPEX/Jason com $\sim 10$ dias e a separação entre as passagens vizinhas dos satélites com melhor resolução espacial é da série ERS/Envisat, com $\sim 85 \mathrm{~km}$ no equador. Isso limita o tamanho e a duração dos fenômenos observáveis no registro altimétrico e é indicado como provável causa da diferença de inclinação dos espectros.

Ao interpretar a Tabela 2 e Figura 11 juntas, observamos que existe uma diferença entre os resultados da tabela e da figura. Na tabela vemos que o sinal da onda de Rossby anual do modelo é $78 \%$ maior do que o do altímetro, entretanto no espectrograma o pico anual do modelo apresenta a mesma densidade de potência do que o do altímetro. De forma geral, as diferenças entre os resultados das transformadas rápidas de Fourier (espectrogramas) e dos filtros FIR-2D (tabelas) estão associadas ao fato que os filtros são sensíveis à propagação e capturam especificamente as ondas de Rossby, enquanto as FFTs trabalham apenas no espaço das frequências independentemente da propagação. Portanto, apesar de o sinal da onda anual do modelo OFES ser $78 \%$ maior do que o do altímetro, as densidades de potência nessa frequência são muito parecidas visualmente, pois a FFT não separa os sinais propagantes dos não propagantes. $\mathrm{Ou}$ 
Tabela 2 - Comparação entre as amplitudes (A) do sinal original $\left(\eta_{o}\right)$, do sinal não propagante $\left(\eta_{t}\right)$, do sinal de meso escala $\left(\eta_{E}\right)$, do resíduo $\left(\eta_{r}\right)$ e das componentes de onda bianual $\left(\eta_{24}\right)$, anual $\left(\eta_{12}\right)$, semianual $\left(\eta_{6}\right)$, trimestral $\left(\eta_{3}\right)$ e sesquimensal $\left(\eta_{1}\right)$, em milímetros, calculadas através dos dados altimétricos e do modelo OFES, no oceano Atlântico Sul na latitude de $10^{\circ} \mathrm{S}$. $v$ representa a variância explicada de cada componente em relação à componente original. $\Delta$ representa a diferença entre as estimativas dos parâmetros através dos dados altimétricos e os das saídas do modelo.

\begin{tabular}{ccccc}
\hline Componente & Parâmetro & Altímetro & OFES & $\Delta(\%)$ \\
\hline$\eta_{o}$ & A (mm) & 42 & 44 & 5 \\
$\eta_{t}$ & A (mm) & 28 & 24 & -14 \\
& v (\%) & 43 & 30 & -30 \\
$\eta_{E}$ & A (mm) & 10 & 12 & 20 \\
& $\vee(\%)$ & 5 & 7 & 40 \\
$\eta_{r}$ & A (mm) & 14 & 17 & 21 \\
& v (\%) & 12 & 16 & 33 \\
$\eta_{24}$ & A (mm) & 15 & 15 & 0 \\
& $v(\%)$ & 13 & 13 & 0 \\
$\eta_{12}$ & A (mm) & 9 & 16 & 78 \\
& v (\%) & 4 & 13 & 225 \\
$\eta_{6}$ & A (mm) & 7 & 11 & 57 \\
& v (\%) & 3 & 7 & 133 \\
$\eta_{3}$ & A (mm) & 13 & 11 & -15 \\
& v (\%) & 9 & 7 & -22 \\
$\eta_{1}$ & A (mm) & 15 & 13 & -13 \\
& v (\%) & 12 & 9 & -25 \\
\hline
\end{tabular}

seja, o pico de potência na frequência anual dos espectrogramas se refere à soma do sinal de onda de Rossby anual e do sinal sazonal.

$\mathrm{Na}$ latitude de $15,5^{\circ} \mathrm{S}$ (Tabela 3) a maior parte da variância do sinal total continua sendo explicada pelo sinal sazonal $\left(\eta_{t}\right)$, representando $54 \%$ do sinal do altímetro e $30 \%$ do modelo. A diferença de amplitude do sinal total $\left(\eta_{o}\right)$ entre o modelo e o altímetro é de $17 \%$. Sendo que as maiores diferenças de amplitude entre modelo e altímetro encontram-se no sinal da componente onda de Rossby com período anual (56\%) e no resíduo (91\%). Para facilitar a discussão da performance dos modelos, a partir de agora, usaremos o critério de que uma diferença relativa $\Delta$ de $30 \%$ ou menos seria análoga a menos de um desvio padrão e portanto um resultado aceitável. Enquanto que um $\Delta$ menor que $5 \%$ representaria um resultado estatisticamente idêntico. As componentes $\eta_{24}$ e $\eta_{6}$ contribuem com a mesma porcentagem na variância explicada do sinal total do satélite e do modelo. O sinal considerado resíduo de pequena escala no modelo explica $19 \%$ da variabilidade do sinal total, enquanto que no altímetro este sinal representa apenas $7 \%$ da variância do sinal total. 

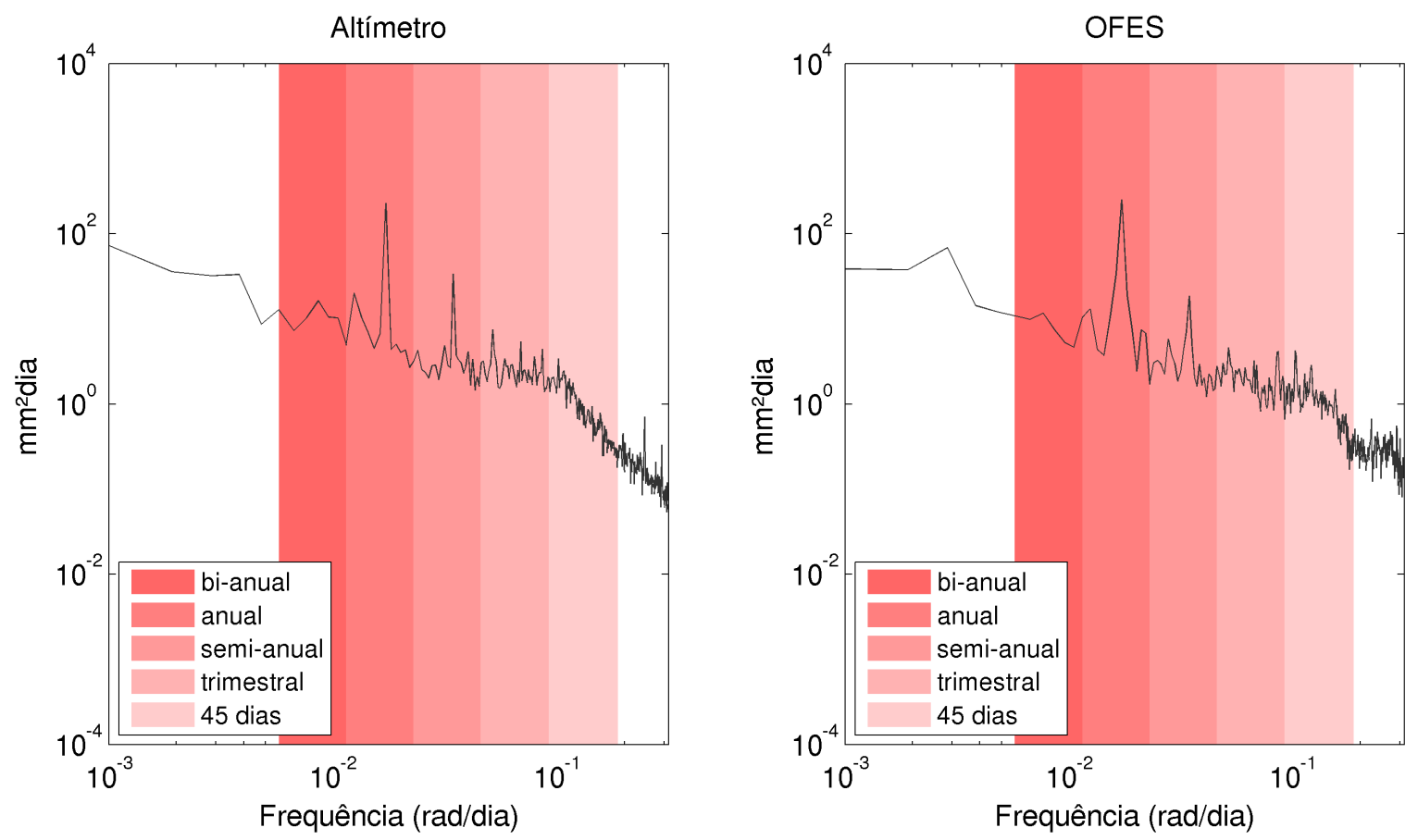

Figura 11 - Espectrogramas médios (média na longitude) do sinal original do altímetro e do modelo OFES para a latitude de $10^{\circ} \mathrm{S}$.

Tabela 3 - Similar à Tabela 2 para a latitude de $15,5^{\circ} \mathrm{S}$.

\begin{tabular}{ccccc}
\hline Componente & Parâmetro & Altímetro & OFES & $\Delta(\%)$ \\
\hline$\eta_{o}$ & A $(\mathrm{mm})$ & 41 & 48 & 17 \\
$\eta_{t}$ & A (mm) & 30 & 26 & -13 \\
& v (\%) & 54 & 30 & -44 \\
$\eta_{E}$ & A (mm) & 10 & 13 & 30 \\
& v (\%) & 6 & 7 & 17 \\
$\eta_{r}$ & A (mm) & 11 & 21 & 91 \\
& v (\%) & 7 & 19 & 171 \\
$\eta_{24}$ & A (mm) & 12 & 14 & 17 \\
& v (\%) & 8 & 8 & 0 \\
$\eta_{12}$ & A (mm) & 9 & 14 & 56 \\
& v (\%) & 5 & 8 & 60 \\
$\eta_{6}$ & A (mm) & 12 & 14 & 17 \\
& v (\%) & 9 & 9 & 0 \\
$\eta_{3}$ & A (mm) & 14 & 20 & 43 \\
& v (\%) & 11 & 18 & 64 \\
\hline
\end{tabular}

A Figura 12 mostra que os períodos anual e semianual continuam sendo os mais energéticos no sinal do altímetro na latitude de $15,5^{\circ} \mathrm{S}$. Entretanto, no sinal do modelo, apenas o período anual aparece como sendo um pico energético no espectrograma. Em ambos os casos os fenômenos com períodos maiores são os mais energéticos, diminuindo a potência espectral 
com a diminuição do período dos fenômenos, sendo que o decaimento da densidade de potência nas altas frequências é muito mais acentuado nos dados do altímetro. A variância total do altímetro é de $8,3 \times 10^{2} \mathrm{~mm}^{2}$ enquanto que a do modelo é de $1,1 \times 10^{3} \mathrm{~mm}^{2}$.
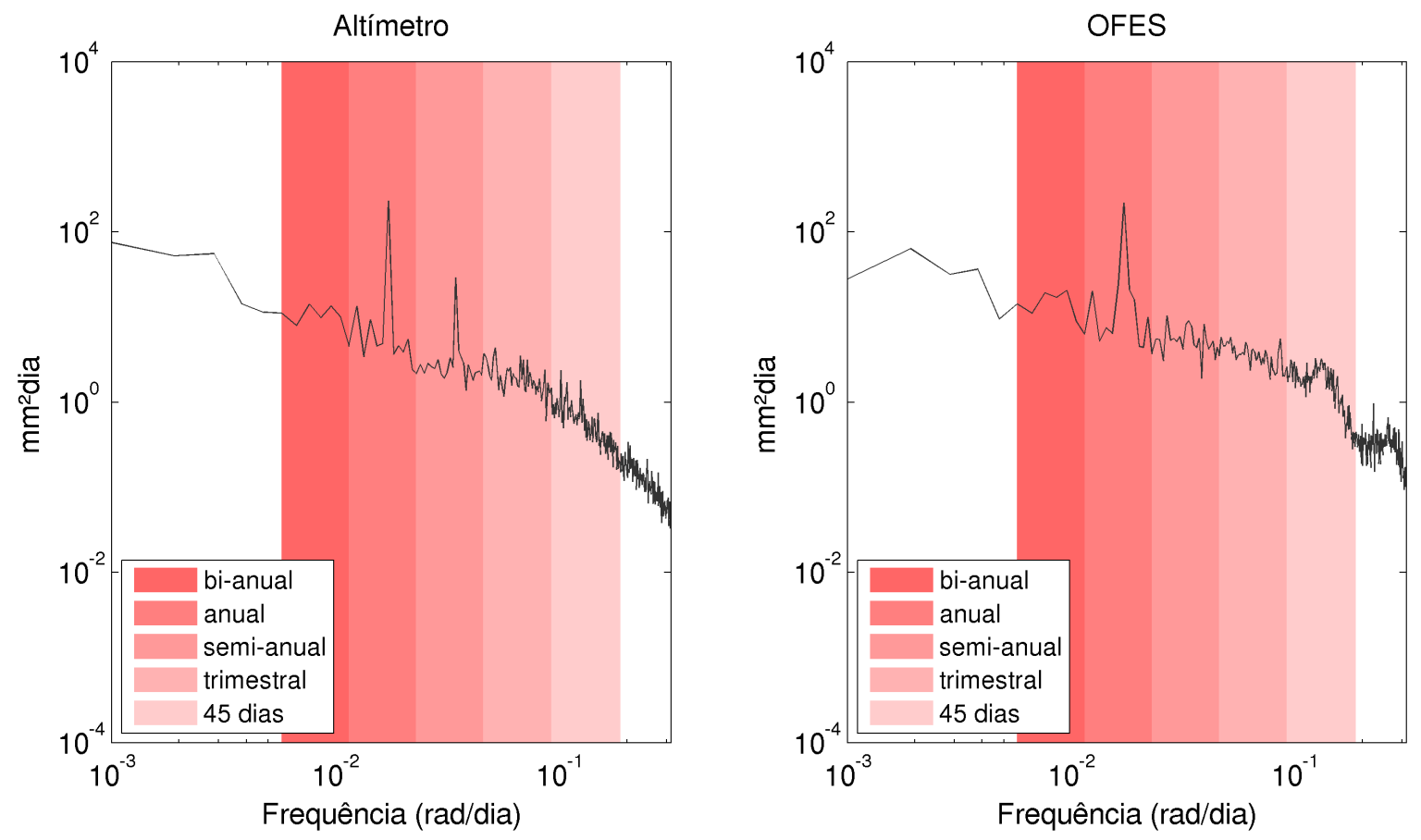

Figura 12 - Similar à Figura 11 para a latitude de $15,5^{\circ} \mathrm{S}$.

Em $28^{\circ} \mathrm{S}$ (Tabela 4), $\eta_{t}$ já não é a componente dominante na constituição do sinal total. Nesta latitude o sinal de onda de Rossby com período semianual $\left(\eta_{6}\right)$ passa a representar a maior parte da variância do sinal total, sendo $30 \%$ do sinal total do altímetro e $22 \%$ do sinal do modelo. A diferença de amplitude do $\eta_{6}$ entre modelo e altímetro é de $-4 \%$, ou seja, estatisticamente as amplitudes do modelo e do altímetro para onda de Rossby semianual são iguais. A maior diferença entre modelo e altímetro se dá na componente resíduo $\left(\eta_{r}\right)$, ou seja, no sinal não propagante de pequena escala que não entra em nenhuma outra componente. No altímetro esta componente apresenta uma amplitude de $16 \mathrm{~mm}$, o que representa apenas $3 \%$ do sinal total enquanto que no modelo a amplitude é de $46 \mathrm{~mm}$ sendo responsável por $19 \%$ da variância do sinal total. Dessa forma, $\eta_{r}$ é a segunda componente mais energética no sinal total do modelo. Já no altímetro esta componente, junto com a componente dos fenômenos de meso escala $\left(\eta_{E}\right)$ são as duas menos energéticas no sinal total. 
Tabela 4 - Similar à Tabela 2 para a latitude de $28^{\circ} \mathrm{S}$.

\begin{tabular}{ccccc}
\hline Componente & Parâmetro & Altímetro & OFES & $\Delta(\%)$ \\
\hline$\eta_{o}$ & A (mm) & 95 & 106 & 12 \\
$\eta_{t}$ & A (mm) & 42 & 45 & 7 \\
& v (\%) & 19 & 18 & -5 \\
$\eta_{E}$ & A (mm) & 14 & 29 & 76 \\
& v (\%) & 3 & 8 & 167 \\
$\eta_{r}$ & A (mm) & 16 & 46 & 187 \\
& v (\%) & 3 & 19 & 533 \\
$\eta_{24}$ & A (mm) & 36 & 27 & -25 \\
& v (\%) & 14 & 7 & -50 \\
$\eta_{12}$ & A (mm) & 34 & 33 & -3 \\
& v (\%) & 13 & 10 & -23 \\
$\eta_{6}$ & A (mm) & 52 & 50 & -4 \\
& v (\%) & 30 & 22 & -27 \\
$\eta_{3}$ & A (mm) & 39 & 45 & 15 \\
& v (\%) & 17 & 18 & 6 \\
\hline
\end{tabular}

A Figura 13 mostra os espectrogramas do altímetro e do modelo para a latitude de $28^{\circ} \mathrm{S}$. Assim como nas latitudes anteriores, em $28^{\circ} \mathrm{S}$ a frequência anual continua sendo a frequência com maior densidade de potência associada. Esse resultado está de acordo com a Tabela 4, onde a soma da variância explicada dos sinais com período anual $\left(\eta_{t}\right.$ e $\left.\eta_{12}\right)$ representam a maior parte da variância total do sinal original $\left(\eta_{o}\right)$. Assim como nas latitudes anteriores, nas frequências menores que a semianual a densidade de potência presente nos espectros é muito semelhante, porém a partir das frequências trimestrais o decaimento da densidade de potência no espectro do altímetro é mais acentuado devido a resolução dos seus dados. A variância total do espectro do modelo é de $5,7 \times 10^{3} \mathrm{~mm}^{2}$ enquanto que a do altímetro é $4,5 \times 10^{3} \mathrm{~mm}^{2}$.

Por fim, em $40^{\circ} \mathrm{S}$ (Tabela 5) grande parte do sinal total é representado pelas componentes $\eta_{r}$ e $\eta_{E}$, somando $65 \%$ da variância do sinal total do altímetro e $74 \%$ do modelo, resultado similar ao encontrado por (Oliveira and Polito, 2013). Em ambas as componentes o modelo reproduz a amplitude com um $\Delta<5 \%$, ou seja, do ponto de vista estatístico o modelo reproduz com exatidão essas amplitudes. A terceira frequência mais presente no sinal total é $\eta_{12}$, representando $20 \%$ do sinal total do altímetro e $13 \%$ do sinal do modelo. Por último, os sinais menos importantes nessa latitude são o $\eta_{24}$ e $\eta_{t}$, cada um representando menos de $10 \%$ do sinal total no altímetro e no modelo.

Observando os espectrogramas para a latitude de $40^{\circ} \mathrm{S}$ (Figura 14) notamos que apesar de ainda haver um pico na frequência anual este não é tão acentuado quanto nas latitudes menores, tanto no altímetro quanto no modelo. No sinal do modelo existe um pico local na frequência trimestral. A latitude de $40^{\circ} \mathrm{S}$ é a latitude crítica para ondas com período de aproximadamente 204 dias, ou seja, o sinal de três meses existente no espectrograma do modelo não é 

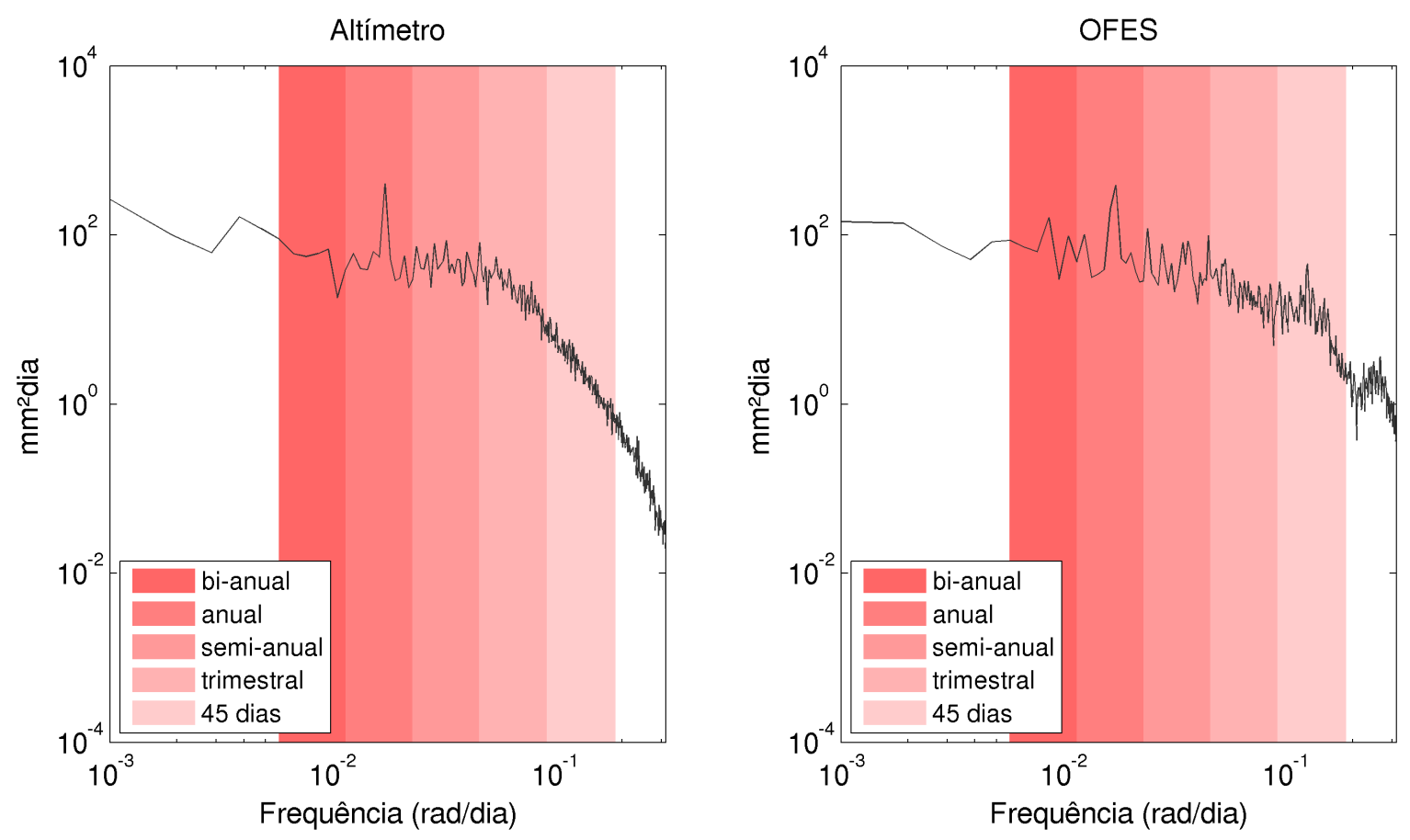

Figura 13 - Similar à Figura 11 para a latitude de $28^{\circ} \mathrm{S}$.

Tabela 5 - Similar à Tabela 2 para a latitude de $40^{\circ} \mathrm{S}$.

\begin{tabular}{ccccc}
\hline Componente & Parâmetro & Altímetro & OFES & $\Delta(\%)$ \\
\hline$\eta_{o}$ & A (mm) & 233 & 221 & -5 \\
$\eta_{t}$ & A (mm) & 67 & 65 & -3 \\
& v (\%) & 8 & 9 & 12 \\
$\eta_{E}$ & A (mm) & 119 & 120 & 1 \\
& v (\%) & 27 & 30 & 11 \\
$\eta_{r}$ & A (mm) & 142 & 146 & 3 \\
& v (\%) & 38 & 44 & 16 \\
$\eta_{24}$ & A (mm) & 67 & 51 & -24 \\
& v (\%) & 8 & 5 & -37 \\
$\eta_{12}$ & A (mm) & 109 & 79 & -28 \\
& v (\%) & 20 & 13 & -35 \\
\hline
\end{tabular}

onda de Rossby trimestral. A densidade de potência presente no sinal, assim como nas latitudes menores, diminui com o aumento da frequência, entretanto esta queda é menor nesta latitude. A variância total do sinal do modelo é de $2,4 \times 10^{4} \mathrm{~mm}^{2}$ e a do altímetro é $2,7 \times 10^{4} \mathrm{~mm}^{2}$.

Analisando as Tabelas 2 a 5 e as Figuras 11 à 14 simultaneamente, notamos alguns padrões nos sinais total, sazonal e nas componentes de ondas de Rossby do altímetro e do modelo analisado. Conforme a latitude aumenta, a energia contida no espectro de potência e, consequentemente, a amplitude do sinal total também aumentam. Já a importância do sinal sazonal na variância do sinal total diminui com o aumento da latitude, tanto no modelo quanto no altímetro. 

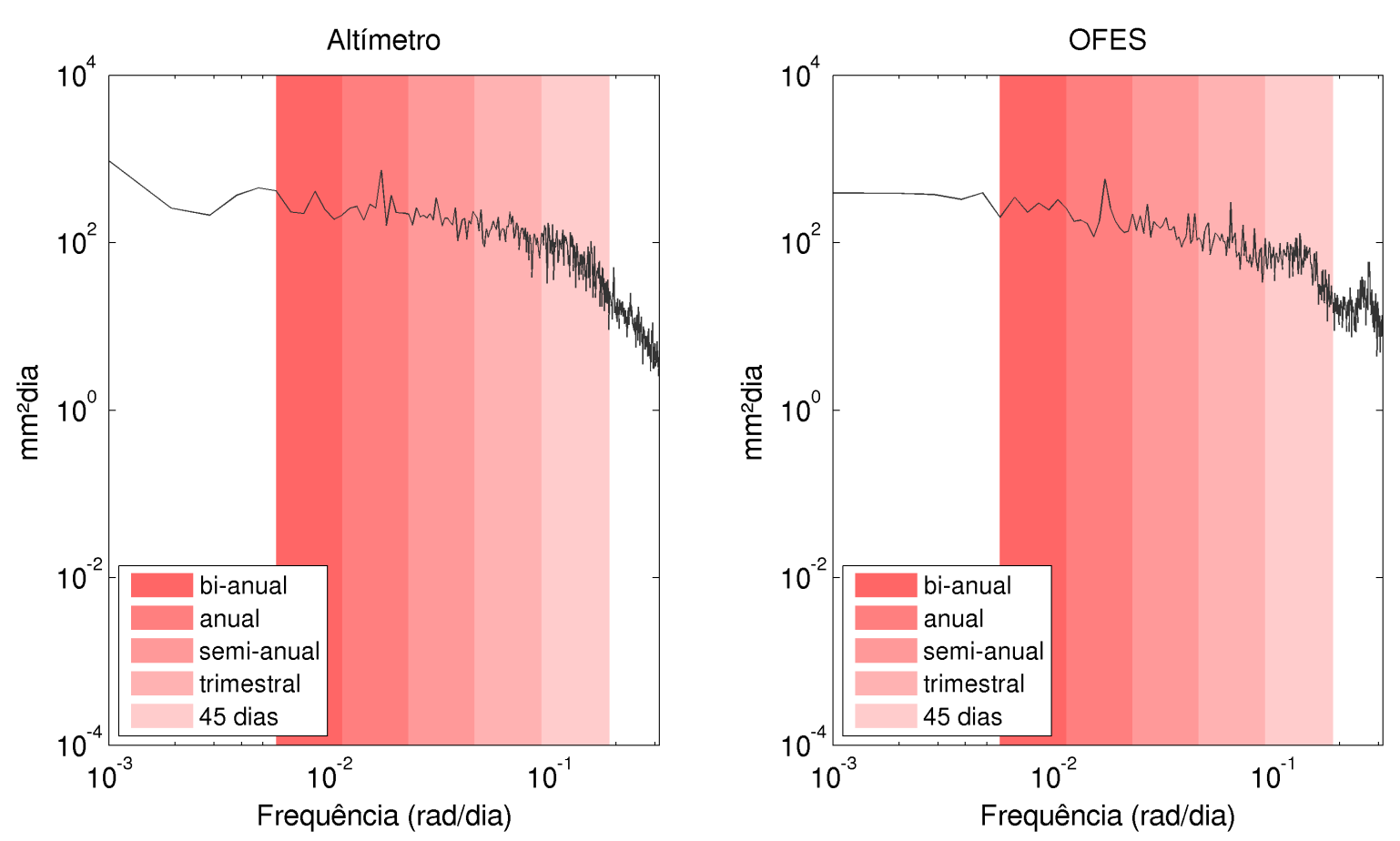

Figura 14 - Similar à Figura 11 para a latitude de $40^{\circ} \mathrm{S}$.

As ondas de Rossby anuais $\left(\eta_{12}\right)$ e semianuais $\left(\eta_{6}\right)$ do modelo e do altímetro apresentam uma maior variância fracional em $\eta_{o}$ conforme aumenta a latitude ao contrário das ondas bianuais $\left(\eta_{24}\right)$ que diminuem a contribuição na variância de $\eta_{o}$ com o aumento da latitude. Entretanto, analisando as ondas de Rossby como um todo, notamos que a importância delas no sinal total aumenta com a latitude até atingir a maior variância explicada do sinal total (74\% altímetro e $57 \%$ modelo) na latitude de $28^{\circ} \mathrm{S}$, sendo que a menor contribuição das ondas para a variabilidade do sinal total ocorre na latitude de $40^{\circ} \mathrm{S}$ ( $28 \%$ altímetro e $18 \%$ modelo). Esse resultado difere do encontrado por Chelton and Schlax (1996) onde ondas de Rossby com período entre 0,5 e 2 ciclos por ano representam mais de $30 \%$ da variância do sinal de SLA em latitudes menores do que $15^{\circ}$ e representam $10 \%$ ou menos da variância do sinal total em latitudes maiores do que $30^{\circ}$. O oposto ocorre na variância explicada do sinal total em relação ao sinal de meso-escala $\left(\eta_{E}\right)$, que diminui da latitude de $10^{\circ} \mathrm{S}$ até a latitude de $28^{\circ} \mathrm{S}$ e atingi o seu máximo na latitude de $40^{\circ} \mathrm{S}$. Resultados estes que corroboram os encontrados por Oliveira and Polito (2013), onde o sinal não propagante de larga escala $\left(\eta_{t}\right)$ explica a maior parte da variância explicada do sinal total ao norte de $20,5^{\circ} \mathrm{S}$. Depois de removido este sinal, os sinais com propagação para oeste são os dominantes. Ao sul de $25,5^{\circ} \mathrm{S}$ os sinais de mesoescala que não se propagam como ondas de Rossby tornam-se mais evidentes e aumentam com a latitude.

Em todas as latitudes, exceto em $28^{\circ} \mathrm{S}$, o modelo OFES subestima a amplitude do sinal sazonal da SLA em relação ao sinal encontrado no altímetro. Dentro do escopo deste trabalho podemos apenas especular quais poderiam ser os motivos para tal desempenho do modelo. No primeiro modo baroclínico a SLA é dada por $\left(\frac{-\Delta \rho}{\rho} h_{t}\right)$ onde $h_{t}$ é a anomalia da altura da 
termoclina. Se a SLA é subestimada, o movimento anual da termoclina não é tão pronunciado como deveria ser. Isso foi observado num modelo que superestima um pouco a amplitude total e muito a amplitude da onda de Rossby anual em certas latitudes. Portanto se há uma subestimativa da estratificação $\left(\frac{\Delta \rho}{\rho}\right)$ ela não é o único fator para explicar a discrepância na amplitude das ondas.

Segundo Barnier (1988) as ondas de Rossby anuais são geradas na borda leste dos oceanos pelo rotacional do vento. Esta superestimativa em $10^{\circ} \mathrm{S}$ e $15,5^{\circ} \mathrm{S}$ pode ser uma indicação de que nessa banda espectral específica o rotacional do vento forçante é exagerado, pelo menos na costa leste. Isso foi contradito por inspeção dos diagramas de Hovmoller (não mostrados), pois não se observou o esperado exagero na amplitude das ondas anuais na borda leste. Se na costa leste a amplitude não for superestimada, outra alternativa é o forçamento ressonante no interior da bacia - difícil de verificar - pois no caso de ressonância um pequeno sinal forçante causa um grande sinal de saída.

\subsubsection{Comparação com o modelo CESM}

A comparação entre o sinal total e as componentes filtradas do altímetro e do modelo CESM para a latitudede $10^{\circ} \mathrm{S}$ são apresentadas na Tabela 6. Modelo e altímetro apresentam resultados bastante próximos, com uma diferença de $11 \%$ na amplitude de $\eta_{o}$. A componente dominante no sinal total de ambos é a sazonal $\left(\eta_{t}\right)$, representando $28 \%$ da variabilidade de $\eta_{o}$ do modelo e $24 \%$ do altímetro. O segundo sinal mais energético no sinal total em ambos os dados é a componente resíduo, onde o modelo representa a amplitude desta componente com apenas $7 \%$ de diferença da amplitude do altímetro. A componente filtrada melhor representada pelo modelo quando comparada com o altímetro é a trimestral, pois nesta tanto a amplitude quanto a variância explicada diferem menos de $10 \%$ dos valores encontrados no altímetro. Apesar da representação da amplitude da componente bianual do modelo diferir em $31 \%$ da do altímetro, no quesito variância explicada do sinal total o modelo reproduz de forma satisfatória, com um $\Delta$ de apenas $6 \%$. A maior diferença entre as estimativas de amplitude do modelo e do altímetro acontece na componente de onda de Rossby com período semianual $\left(\eta_{6}\right)$, onde a amplitude desta componente dos dados do satélite é de $5 \mathrm{~mm}$, enquanto que do modelo é de 9 $\mathrm{mm}$, representando uma diferença de $80 \%$. Também nesta componente se dá a maior diferença entre as variâncias explicadas. No satélite a componente $\eta_{6}$ explica $2 \%$ da variância do sinal total e no modelo ela representa 5\%, caracterizando uma diferença de $150 \%$ entre as variâncias explicadas. Os percentuais são grandes, mas os valores absolutos são pequenos.

A Figura 15 mostra os espectrogramas do altímetro e do modelo CESM para a latitude de $10^{\circ} \mathrm{S}$. Dois picos de potência são encontrados em ambos os espectros, no período anual e semianual, sendo que o pico de potência na frequência semianual no espectro do modelo é mais energético do que o do altímetro. A variância total do sinal do altímetro é $6,5 \times 10^{2} \mathrm{~mm}^{2}$ enquanto que a do modelo é $8,1 \times 10^{2} \mathrm{~mm}^{2}$. Diferentemente do que ocorre entre o modelo OFES 
Tabela 6 - Similar à Tabela 2, para o modelo CESM.

\begin{tabular}{ccccc}
\hline Componente & Parâmetro & Altímetro & CESM & $\Delta(\%)$ \\
\hline$\eta_{o}$ & A (mm) & 36 & 40 & 11 \\
$\eta_{t}$ & A (mm) & 17 & 21 & 29 \\
& $v(\%)$ & 24 & 28 & 17 \\
$\eta_{E}$ & A (mm) & 10 & 8 & -20 \\
& $v(\%)$ & 8 & 4 & -50 \\
$\eta_{r}$ & A (mm) & 15 & 16 & 7 \\
& $v(\%)$ & 19 & 17 & -11 \\
$\eta_{24}$ & A (mm) & 13 & 17 & 31 \\
& $v(\%)$ & 16 & 17 & 6 \\
$\eta_{12}$ & A (mm) & 8 & 12 & 50 \\
& $v(\%)$ & 5 & 9 & 80 \\
$\eta_{6}$ & A (mm) & 5 & 9 & 80 \\
& $v(\%)$ & 2 & 5 & 150 \\
$\eta_{3}$ & A (mm) & 13 & 14 & 8 \\
& v (\%) & 13 & 12 & -8 \\
$\eta_{1}$ & A (mm) & 15 & 12 & -20 \\
& $v(\%)$ & 17 & 9 & -47 \\
\hline
\end{tabular}

e o altímetro na latitude de $10^{\circ} \mathrm{S}$, nesta figura vemos que o decaimento da densidade de potência no espectro do modelo nas altas frequências é similar ao do altímetro.
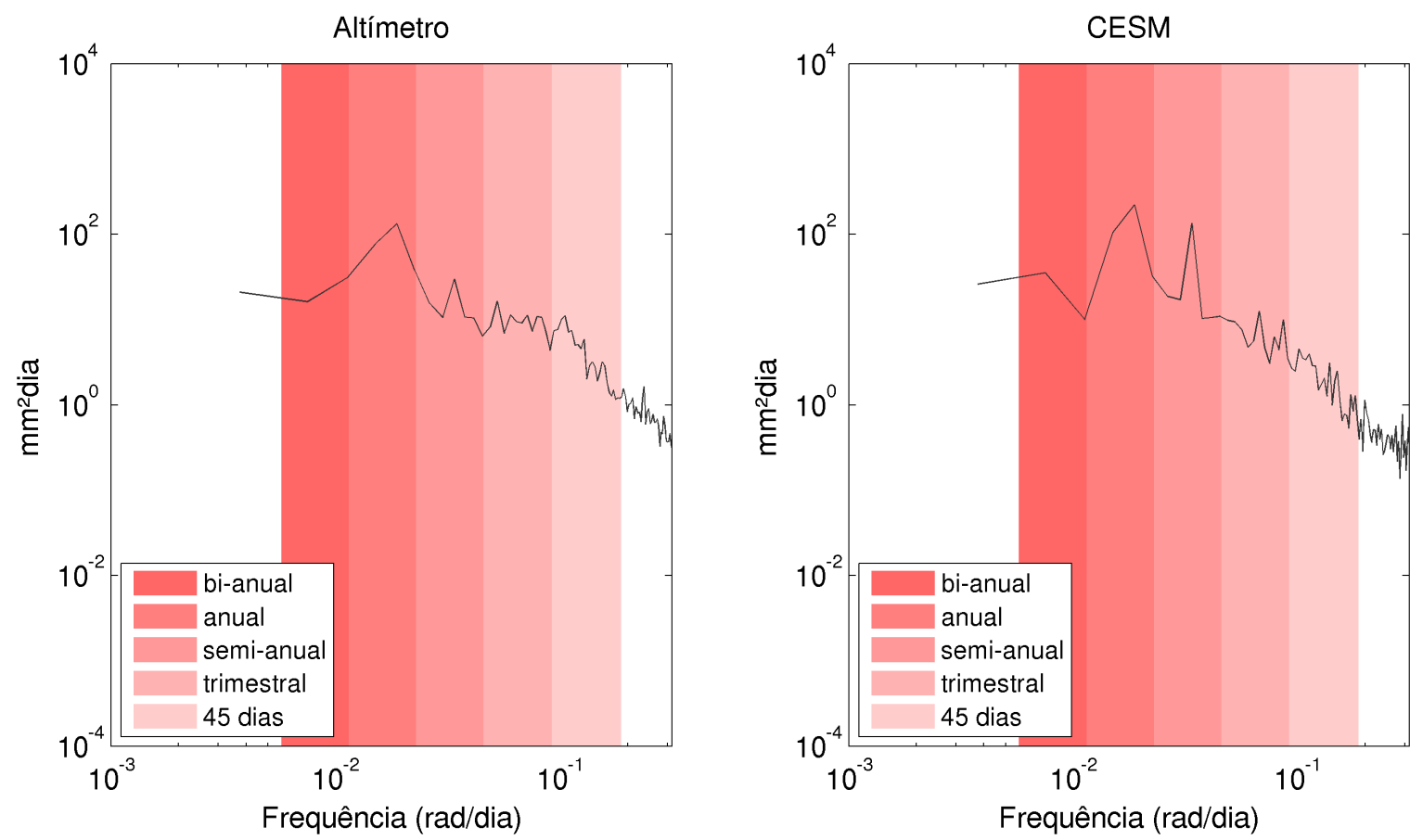

Figura 15 - Similar à Figura 11 para o modelo CESM. 
Comparando os modelos OFES e CESM na latitude de $10^{\circ} \mathrm{S}$, através das Tabelas 2 e 6 vemos que em ambos os modelos a frequência predominante no sinal total nesta latitude é $\eta_{t}$. Seguida por $\eta_{r}$ e $\eta_{24}$. No modelo OFES a quarta componente mais importante em $\eta_{o}$ é a $\eta_{12}$, seguida dos movimentos de meso-escala, ondas de Rossby com frequência sesquimensal, semestral e por último a trimestral. Já no modelo CESM, as componentes de ondas de Rossby com frequências trimestral, anual, sesquimensal e semestral apresentam, nesta ordem, uma maior influência na variância do sinal total. A componente menos influente no sinal total deste modelo em $10^{\circ} \mathrm{S}$ é a componente de meso-escala.

Confrontando a performance de reprodução de onda de Rossby dos dois modelos para a latitude de $10^{\circ} \mathrm{S}$, observamos que o modelo OFES reproduz com exatidão as ondas bianuais, enquanto que o CESM superestima-as. Nas componentes anual e semianual ambos os modelos exageram a potência das ondas e apresentam pouco sinal na frequência de 45 dias. Nessas latitudes as ondas são geradas majoritariamente na borda leste e talvez os modelos não estejam reproduzindo bem o processo de geração, que por ser na borda sugere problemas na topografia ou na composição espectral do vento.

Na latitude de $15,5^{\circ} \mathrm{S}$ (Tabela 7), assim como na latitude anterior, $\eta_{t}$ é o sinal dominante em ambos os conjuntos de dados, representando $47 \%$ do sinal total no altímetro e $54 \%$ do sinal total do modelo. A componente semianual é a componente que o modelo melhor representa a amplitude, apresentando um $\Delta=-8 \%$. Apesar da amplitude deste sinal ser bem representada pelo modelo, a variância explicada difere em $-31 \%$ entre os dados, representando $13 \%$ do sinal total do altímetro e $9 \%$ do sinal total do modelo. No caso das ondas planetárias nesta latitude, o CESM superestima os sinais anual e bianual em detrimento das frequências mais altas.

Tabela 7 - Similar à Tabela 6 para a latitude de $15,5^{\circ} \mathrm{S}$.

\begin{tabular}{ccccc}
\hline Componente & Parâmetro & Altímetro & CESM & $\Delta(\%)$ \\
\hline$\eta_{o}$ & A (mm) & 36 & 41 & 14 \\
$\eta_{t}$ & A (mm) & 25 & 30 & 20 \\
& v (\%) & 47 & 54 & 15 \\
$\eta_{E}$ & A (mm) & 9 & 8 & -11 \\
& v (\%) & 6 & 4 & -33 \\
$\eta_{r}$ & A (mm) & 12 & 14 & 17 \\
& v (\%) & 11 & 12 & 9 \\
$\eta_{24}$ & A (mm) & 9 & 13 & 44 \\
& v (\%) & 6 & 10 & 67 \\
$\eta_{12}$ & A (mm) & 8 & 10 & 25 \\
& v (\%) & 5 & 7 & 40 \\
$\eta_{6}$ & A (mm) & 13 & 12 & -8 \\
& v (\%) & 13 & 9 & -31 \\
$\eta_{3}$ & A (mm) & 13 & 11 & -15 \\
& v (\%) & 12 & 7 & -42 \\
\hline
\end{tabular}


Na Figura 16 estão representados os espectrogramas do altímetro e do modelo para a latitude de $15,5^{\circ} \mathrm{S}$. Em ambos é possível observar a presença de um pico de potência na frequência anual e um segundo pico menos relevante na frequência semianual. Nos dois espectrogramas a densidade de potência do espectro decai com o aumento da frequência; a variância total do modelo é $8,3 \times 10^{2} \mathrm{~mm}^{2}$ e do altímetro é $6,6 \times 10^{2} \mathrm{~mm}^{2}$.
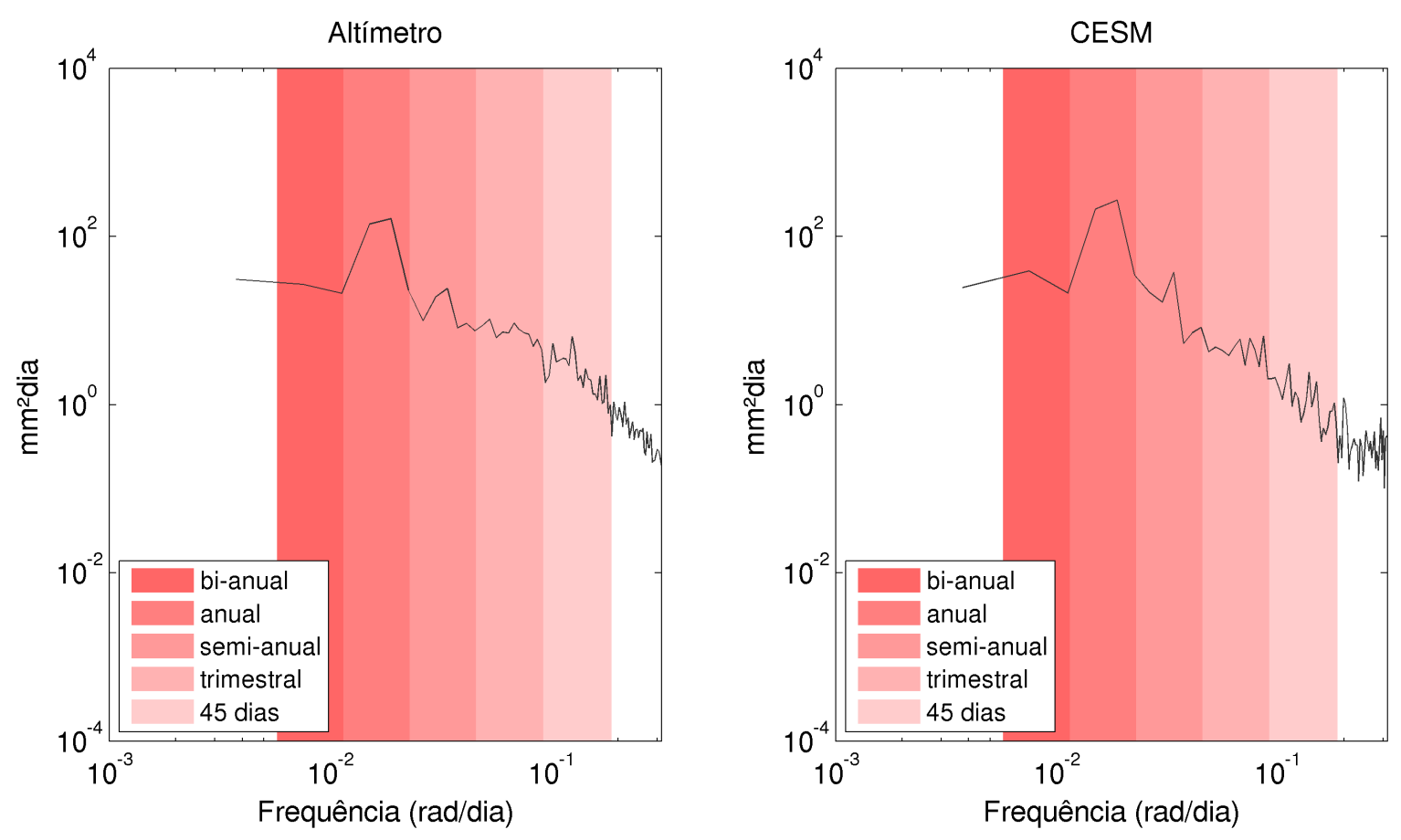

Figura 16 - Similar à Figura 12 para o modelo CESM.

Comparando a composição de $\eta_{o}$ dos modelos OFES e CESM através da variância explicada do sinal total na latitude de $15,5^{\circ} \mathrm{S}$, por meio das Tabelas 3 e 7 , notamos que apesar de $\eta_{t}$ ser o dominante no sinal total de ambos os modelos, no modelo CESM este representa mais da metade (54\%) da variância do sinal total, enquanto que no modelo OFES este sinal representa $30 \%$ da variância do sinal total. No altímetro a variância explicada pelo sinal sazonal gira em torno de 50\%, sendo assim, o modelo CESM reproduz a energia contida no sinal sazonal de forma mais adequada. Tanto em um quanto no outro modelo, o segundo sinal com maior influência na variância do sinal total é o $\eta_{r}$, seguido das diferentes componente de ondas de Rossby. A componente com menor importância no sinal total, nos dois modelos é a componente de meso-escala.

Através dos espectrogramas (Figuras 12 e 16) podemos afirmar que ambos os modelos reproduzem a energia contida na banda anual do altímetro de forma adequada. Entretanto, diferentemente do modelo CESM, o modelo OFES não consegue reproduzir a energia contida na banda semianual presente no altímetro. Essa dificuldade pode ser uma indicação de que o sinal semianual bem marcado no espectro do altímetro e no do modelo CESM seja fruto do acoplamento da atmosfera com o oceano e não apenas do vento e que este acoplamento é melhor 
resolvido no modelo CESM do que no OFES pela própria formulação do modelo. Já a energia presente na banda anual, que é bem representada por ambos os modelos, provavelmente está mais associada com o regime de ventos do que com as trocas de calor.

$\mathrm{Na}$ latitude de $28^{\circ} \mathrm{S}$ (Tabela 8 ), o $\eta_{t}$ deixa de ser o dominante na variância de $\eta_{o}$ e a componente dominante passa a ser a onda de Rossby com período semianual, tanto no modelo quanto no altímetro, representando $31 \%$ e $30 \%$ da variância explicada do sinal total, respectivamente. Essa componente é representada de forma precisa pelo modelo $(\Delta=0)$. É nesta latitude que o modelo estima com melhor precisão a amplitude do sinal total $(\Delta=-3 \%)$. A componente com menor influência no sinal total é a componente não propagante de meso-escala, representando apenas $3 \%$ da variância do sinal total em ambos os casos. Com exceção do sinal semianual, em todas as outras componentes de onda de Rossby, o modelo subestima a amplitude e a variância do sinal total explicada por essas componentes em relação ao altímetro.

Tabela 8 - Similar à Tabela 6 para a latitude de $28^{\circ} \mathrm{S}$.

\begin{tabular}{ccccc}
\hline Componente & Parâmetro & Altímetro & CESM & $\Delta(\%)$ \\
\hline$\eta_{o}$ & A (mm) & 96 & 93 & -3 \\
$\eta_{t}$ & A (mm) & 37 & 49 & 32 \\
& v (\%) & 15 & 28 & 87 \\
$\eta_{E}$ & A (mm) & 17 & 16 & -6 \\
& v (\%) & 3 & 3 & 0 \\
$\eta_{r}$ & A (mm) & 17 & 25 & 47 \\
& v (\%) & 3 & 7 & 133 \\
$\eta_{24}$ & A (mm) & 43 & 36 & -16 \\
& v (\%) & 20 & 15 & -25 \\
$\eta_{12}$ & A (mm) & 30 & 19 & -37 \\
& v (\%) & 10 & 4 & -60 \\
$\eta_{6}$ & A (mm) & 52 & 52 & 0 \\
& v (\%) & 30 & 31 & 3 \\
$\eta_{3}$ & A (mm) & 41 & 32 & -22 \\
& v (\%) & 19 & 12 & -37 \\
\hline
\end{tabular}

Os espectrogramas do altímetro e do modelo para a latitude de $28^{\circ} \mathrm{S}$ são mostrados na Figura 17. No espectro do altímetro não existe nenhum pico de densidade de potência relevante, enquanto que no do modelo existe um na frequência anual. A densidade de potência nas frequências inferiores à trimestral são iguais em ambos os espectros e nas frequências maiores o decaimento do espectro do altímetro é mais evidente do que o do modelo. A variância total do sinal do altímetro é de $4,5 \times 10^{3} \mathrm{~mm}^{2}$ enquanto que a do modelo é $5,6 \times 10^{3} \mathrm{~mm}^{2}$. 

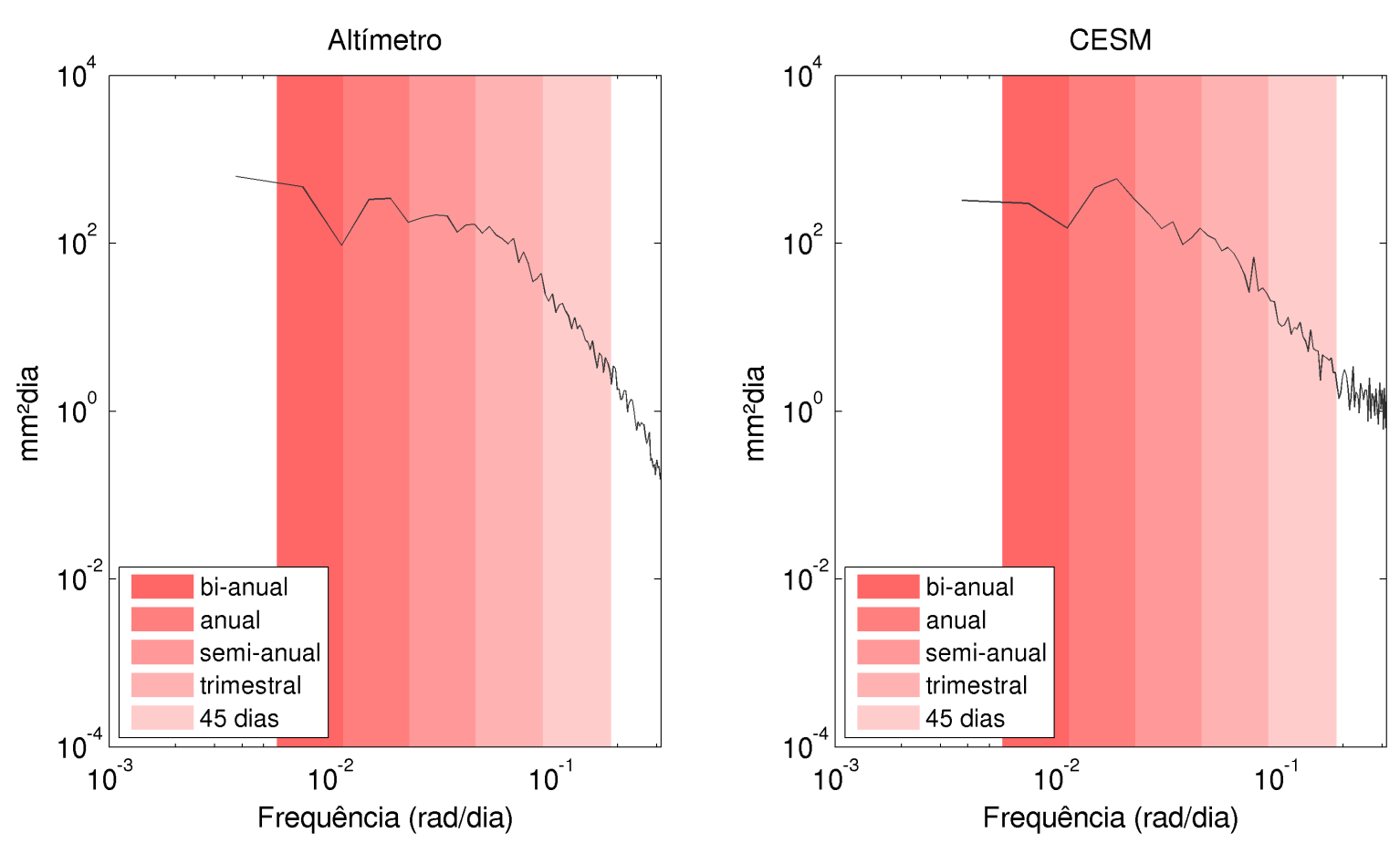

Figura 17 - Similar à Figura 13 para o modelo CESM.

Comparando o modelo CESM com o OFES na latitude de $28^{\circ} \mathrm{S}$ através das Tabelas 8 e 4 notamos que em ambos os casos o sinal de onda de Rossby com período semianual passa a ser o sinal dominante na variabilidade do sinal total. No modelo CESM, o $\eta_{t}$ é o segundo mais energético e no modelo OFES esse sinal aparece em terceiro lugar na variância do sinal total. Em ambos os modelos, os movimentos de meso-escala apresentam pouca influência na variabilidade de $\eta_{o}$, sendo a componente menos influente no modelo CESM e a segunda componente menos influente no modelo OFES, seguido da $\eta_{24}$. Em comparação às médias altimétricas há uma falta de energia nas bandas anual e bianual e um excesso no resíduo de alta frequência, tanto no OFES quanto no CESM. Ou seja, há um excesso de energia associada a processos não lineares de instabilidade em relação ao sinal determinístico e predominantemente linear forçado pelo vento.

Este sinal semianual que domina o sinal total em $28^{\circ} \mathrm{S}$ é observado claramente pelo altímetro através do diagrama de Hovmöller (não apresentado), e reproduzido de forma excelente pelo modelo CESM e razoavelmente bem pelo OFES (Tabelas 4 e 8). Embora não seja do escopo deste trabalho, a origem desse sinal está sendo investigada e está presente no sinal do bombeamento de Ekman.

Por último, na latitude de $40^{\circ} \mathrm{S}$ (Tabela 9), apenas a componente de onda de Rossby semianual é representada pelo modelo de forma discrepante das observações, com um $\Delta$ maior que $30 \%$. Em todas as outras componentes filtradas as amplitudes do modelo diferem em $17 \%$ ou menos. Sendo que apesar de a amplitude do sinal $\eta_{t}$ do modelo diferir em $17 \%$ da do altímetro, a variância do sinal total explicada por esta componente é reproduzida pelo modelo com exati- 
dão. Na componente bianual o modelo subestima a amplitude e a variância explicada enquanto que na componente anual esses parâmetros são superestimados em relação ao altímetro.

Tabela 9 - Similar à Tabela 6 para a latitude de $40^{\circ} \mathrm{S}$.

\begin{tabular}{ccccc}
\hline Componente & Parâmetro & Altímetro & CESM & $\Delta(\%)$ \\
\hline$\eta_{o}$ & A (mm) & 224 & 260 & 16 \\
$\eta_{t}$ & A (mm) & 65 & 76 & 17 \\
& v (\%) & 9 & 9 & 0 \\
$\eta_{E}$ & A (mm) & 96 & 107 & 11 \\
& v (\%) & 18 & 17 & -6 \\
$\eta_{r}$ & A (mm) & 124 & 136 & 10 \\
& v (\%) & 31 & 28 & -10 \\
$\eta_{24}$ & A (mm) & 84 & 75 & -11 \\
& v (\%) & 14 & 8 & -43 \\
$\eta_{12}$ & A (mm) & 119 & 162 & 36 \\
& v (\%) & 28 & 39 & 39
\end{tabular}

A Figura 18 mostra os espectrogramas do altímetro e do modelo para a latitude de $40^{\circ} \mathrm{S}$. A densidade de potência em ambos os espectros é maior do que nas outras latitudes estudadas. Porém, nenhum pico de energia é encontrado no espectro do altímetro e apenas um pico, não tão proeminente quanto nas outras latitudes, na frequência anual é encontrado no espectro do modelo. A variância total do sinal do modelo é de $3,4 \times 10^{3} \mathrm{~mm}^{2}$ enquanto que a do altímetro é $2,5 \times 10^{4} \mathrm{~mm}^{2}$.

Analisando as Tabelas 6 a 9 notamos que a amplitude do sinal total do altímetro e do modelo CESM aumentam com a latitude, assim como os ventos, o stress e o rotacional do vento nessa região (não mostrado). Ao longo das latitudes, os sinais com frequência anual deixam de ser a principal forma de resposta do oceano às forçantes atmosféricas e consequentemente, diminuem a contribuição para variabilidade do sinal total. Em outras palavras, dada uma forçante estocástica, cada vez menos energia mecânica absorvida pelo oceano se manifestará na forma de onda de Rossby ou sinal sazonal. Em contrapartida, cada vez mais energia será absorvida como turbulência de meso e pequena escala à medida que a latitude aumenta.

Comparando as Tabelas 5 e 9 vemos que a componente filtrada mais influente na variabilidade de $\eta_{o}$ dos dois modelos não é a mesma. No modelo OFES o sinal que explica a maior variância de $\eta_{o}$ é o $\eta_{r}$, enquanto que no modelo CESM este papel é representado por $\eta_{12}$. A segunda e terceira componentes mais influentes na variabilidade do sinal total também são diferentes entre os modelos, no OFES são $\eta_{E}$ e $\eta_{12}$, já no modelo CESM são $\eta_{r}$ seguido por $\eta_{E}$. 

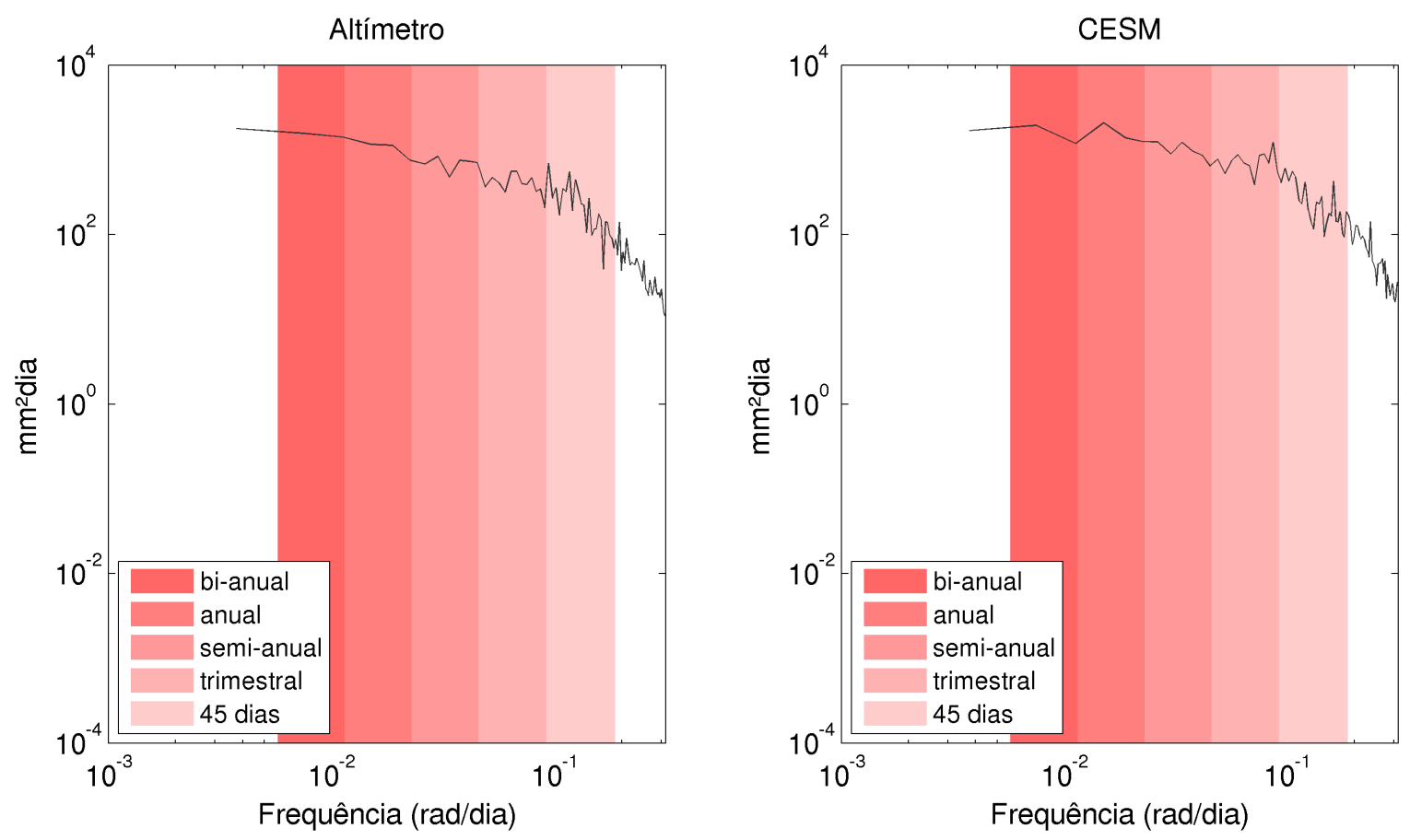

Figura 18 - Similar à Figura 14 para o modelo CESM.

As únicas componentes que são equivalentes na contribuição para a variância do sinal total são $\eta_{t}$ (explicando $9 \%$ da variância em ambos os modelos) e $\eta_{24}$ (explicando 5\% no modelo OFES e $8 \%$ no modelo CESM).

Em relação aos espectros (Figura 11 a 14 e Figuras 15 a 18) podemos afirmar que ambos os modelos reproduzem adequadamente a energia contida e a variabilidade nas baixas e médias frequências ( 2 anos a 3 meses). Entretanto, em altas frequências ambos os modelos apresentam dificuldades para reproduzir a energia observada, principalmente o modelo OFES, que exagera a energia contida no ruído, ou seja, apresenta um excesso relativo de variabilidade na borda direita dos espectrogramas. Essa é uma indicação de que este modelo apresenta um excesso de variabilidade de meso e sub-meso escala em comparação com os dados altimétricos. O motivo pelo qual supomos que o modelo OFES apresenta um excesso de energia nessas frequências e não que o altímetro apresenta uma falha na amostragem é por que o modelo CESM apresenta resultados mais parecidos com os do altímetro. 


\subsection{Comparação entre médias zonais dos parâmetros de onda}

Nesta seção, comparamos as médias zonais de amplitude, comprimento, velocidade de fase e período das ondas anuais e semianuais encontradas para cada latitude da área de estudo. As Figuras de 19 a 22 mostram a média zonal do parâmetro (azul para o satélite e vermelho para o modelo) mais ou menos um desvio padrão (sombreado) para cada latitude da área de estudo. O parâmetro da onda de Rossby com período anual é apresentado no quadro (a) e o da onda com período semianual no quadro (b). Inicialmente analisaremos as diferenças entre os resultados do altímetro e do modelo OFES e em seguida, entre os resultados do altímetro e o modelo CESM.

\subsubsection{Modelo OFES}

A Figura 19 mostra a média zonal da amplitude de onda. Na banda anual (painel a), entre as latitudes de $10^{\circ}$ e $16^{\circ} \mathrm{S}$, a diferença percentual média entre a amplitude estimada pelo modelo e a observada no altímetro é de $-36 \%$. Entre $16^{\circ}$ e $28^{\circ} \mathrm{S}$, a curva azul (vermelha) cai dentro do sombreado da curva vermelha (azul), quando isto ocorre podemos dizer que nesta latitude, o modelo e as observações são estatisticamente iguais. Isso se confirma quando olhamos para a diferença percentual média entre elas, neste caso o valor é de $-4,6 \%$. A partir de $28^{\circ} \mathrm{S}$ o modelo difere da amplitude de onda encontrada no altímetro com uma diferença percentual média de $68 \%$. O sombreamento do gráfico, nesta região, mostra que boa parte do desvio padrão do altímetro e do modelo não são coincidentes, ou seja, a diferença é estatisticamente significativa considerando-se intervalo de confiança de $68 \%$.

Na banda semianual, representada no painel (b) da Figura 19, podemos notar que em quase todas as latitudes da área de estudo as curvas são estatisticamente idênticas, com um intervalo de confiança de $68 \%$. Analisando as diferenças percentuais médias vemos que o modelo difere da amplitude do sinal semianual encontrada pelo satélite entre as latitudes de $10^{\circ}$ e $25^{\circ} \mathrm{S}$, em $\sim 19 \%$ e, entre as latitude de $25^{\circ}$ até o limite sul a diferença média é de $54 \%$. Dessa forma, podemos afirmar que a amplitude é representada adequadamente pelo modelo apenas na metade mais ao norte da área de estudo, tanto na frequência anual quanto na semianual.

A Figura 20 mostra a comparação entre os comprimentos de onda $(\lambda)$ anual (painel a) e semianual (painel b) calculados através dos dados do altímetro e do modelo. Na banda anual, podemos observar que, ao contrário da amplitude, o $\lambda$ do modelo e do altímetro diminuem com o aumento da latitude. Entre as latitudes de $10^{\circ}$ e $17^{\circ} \mathrm{S}$ o modelo apresenta uma diferença média em relação ao altímetro de $-17,3 \%$. Na região entre $17^{\circ}$ e $21^{\circ} \mathrm{S}$, as duas curvas são iguais, pois a média de uma se encontra dentro do desvio padrão da outra. Através da diferença média entre ambas $(-0,83 \%)$ confirmamos que elas são essencialmente idênticas. Entre as latitudes de $21^{\circ} \mathrm{e}$ $29^{\circ} \mathrm{S}$ encontra-se a maior diferença média do modelo em relação ao altímetro para o $\lambda$ na banda anual, apresentando uma diferença de -34 


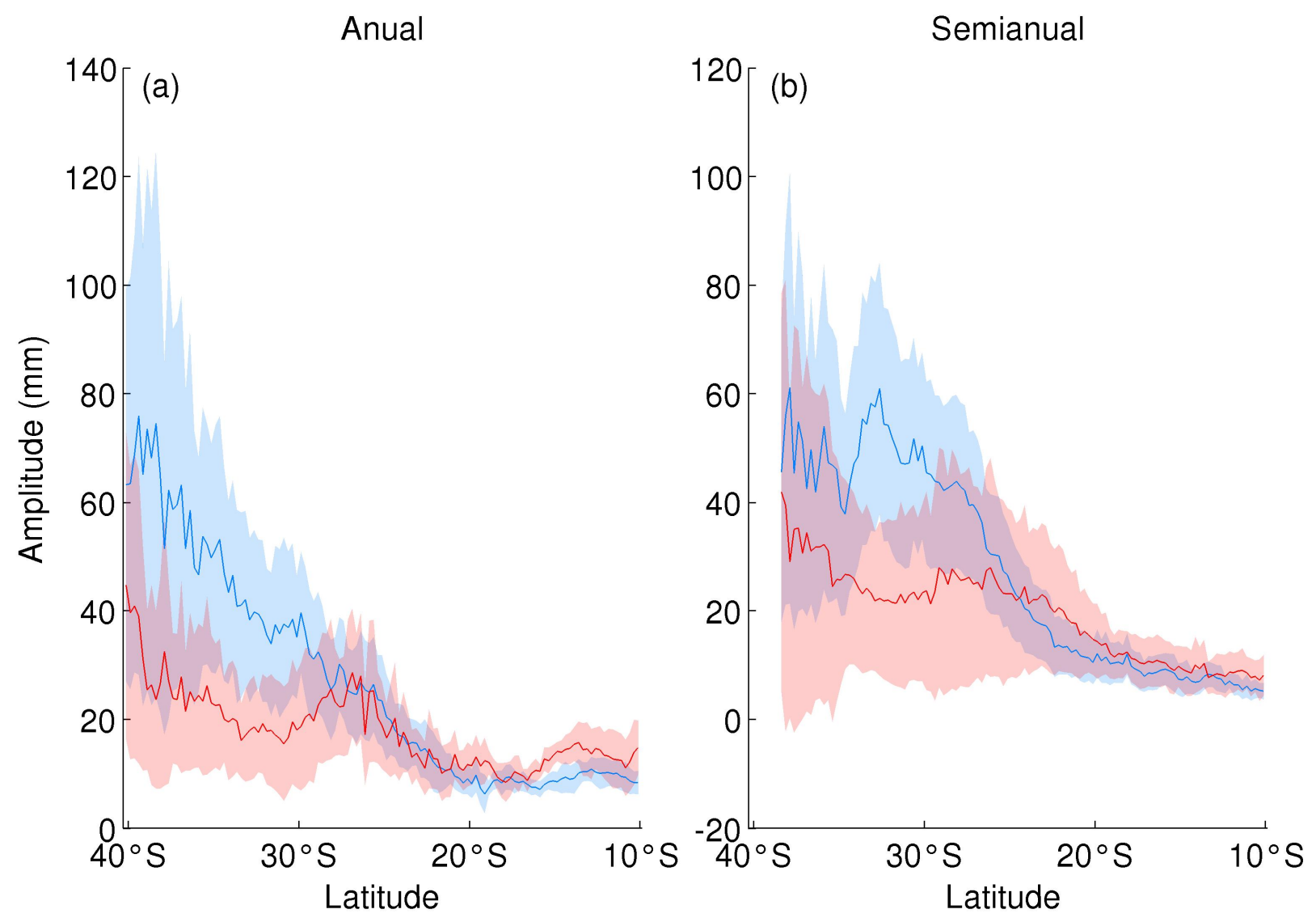

Figura 19 - Comparação entre as médias das amplitudes calculadas pelo dados do altímetro (linha escura azul) e pelo modelo OFES (linha escura vermelha) mais os respectivos desvios padrão (faixa azul claro para o desvio padrão do altímetro e vermelho claro para o desvio padrão do modelo), na banda anual (quadro a) e semianual (quadro b), ao longo das latitudes de $10^{\circ} \mathrm{S}$ e $40^{\circ} \mathrm{S}$.

O comprimento das ondas semianuais (painel b) varia menos ao longo das latitudes da área de estudo quando comparado com o das ondas anuais. Entre as latitude de $10^{\circ}$ e $15^{\circ} \mathrm{S}$ a diferença média encontrada entre modelo e altímetro é de $19 \%$, com o modelo estimando comprimentos de onda menores do que os encontrados no altímetro. Na região entre $15^{\circ}$ e $26^{\circ} \mathrm{S}$ a diferença média encontrada entre os dois conjuntos de dados foi de $-22 \%$. No intervalo de latitudes entre $26^{\circ}$ e $32^{\circ} \mathrm{S}$ foi encontrada a menor diferença média entre os $\lambda$ detectados pelo altímetro e pelo modelo, com apenas $-6 \%$ de diferença. Entre $32^{\circ}$ e $38,4^{\circ} \mathrm{S}$ foi encontrada a maior diferença média (-32\%) entre modelo e altímetro, da mesma forma que a maior diferença média entre as amplitudes do modelo e do altímetro foram encontradas em latitudes mais altas. Sendo assim, podemos alegar que apenas em algumas latitudes o modelo reproduziu adequadamente o comprimento de onda das ondas planetárias anuais e semianuais, dentro do intervalo de confiança de $68 \%$. 

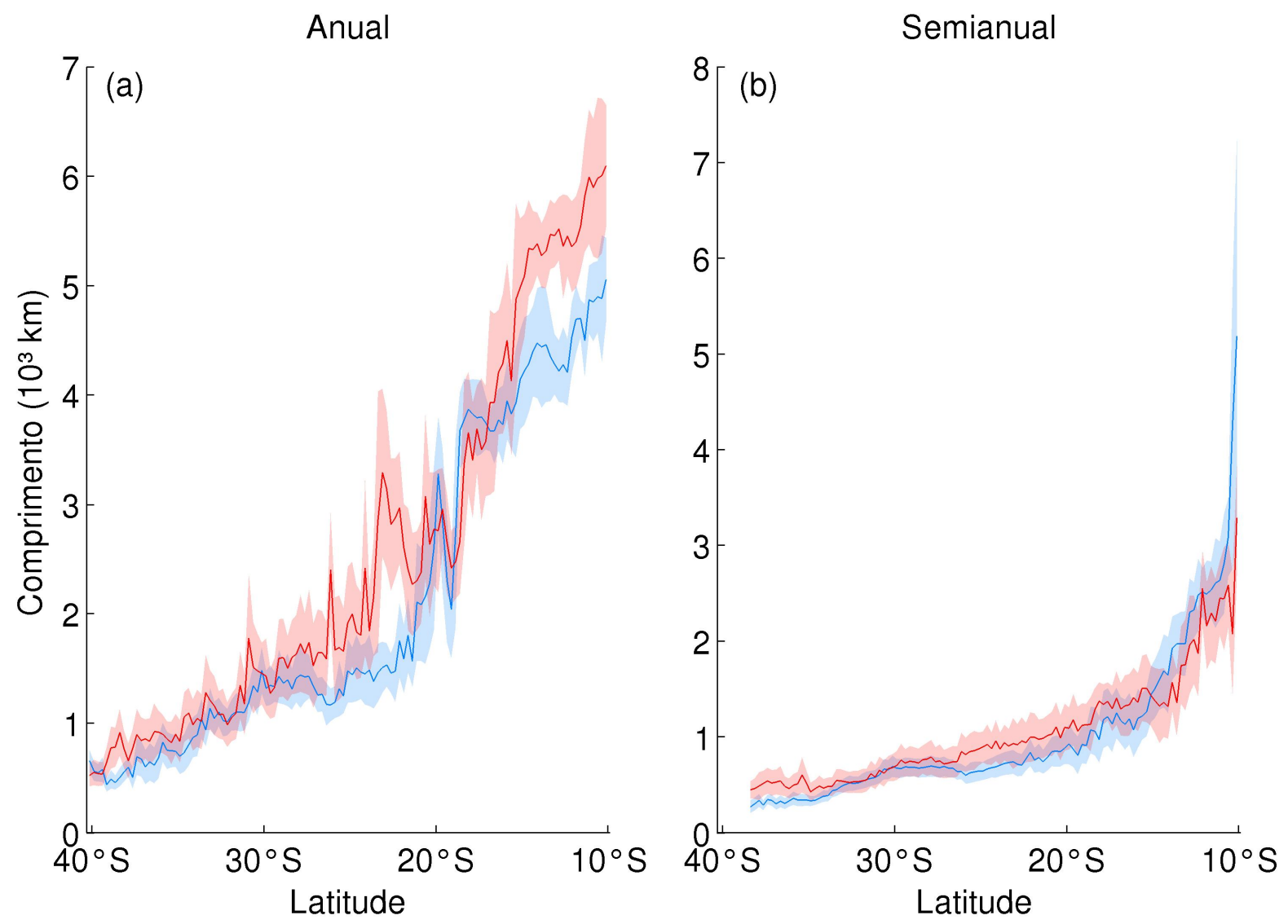

Figura 20 - Similar à Figura 19, mas para o comprimento de onda.

A Figura 21 mostra a comparação da velocidade de fase das ondas anuais (painel a) e semianuais (painel b) representadas pelo altímetro e pelo modelo. Em relação à onda anual, entre as latitudes de $10^{\circ}$ e $18^{\circ} \mathrm{S}$ as duas curvas médias são estatisticamente diferentes, apresentando uma diferença percentual média de $-16 \%$. Já entre $18^{\circ}$ e $21^{\circ} \mathrm{S}$ as curvas se tornam estatisticamente iguais, com uma diferença média de apenas $-3,8 \%$. A maior diferença entre as velocidades de fase das onda anuais se encontra entre as latitudes de $21^{\circ}$ e $28^{\circ} \mathrm{S}$, com um valor de $-27 \%$. De $28^{\circ}$ até $40^{\circ} \mathrm{S}$ as curvas são estatisticamente iguais e apresentam uma diferença média de apenas 3,8\% entre as estimativas de velocidade de fase do modelo e do altímetro.

$\mathrm{Na}$ frequência semianual (painel b) exceto pelos limites norte e sul da área de estudo, em todas as outras latitudes as curvas são estatisticamente iguais. A diferença percentual média entre modelo e altímetro entre as latitudes de $10^{\circ}$ e $15^{\circ} \mathrm{S}$ é de $22 \%$. Entre $15^{\circ}$ e $35^{\circ} \mathrm{S}$ encontra-se a menor diferença percentual média de toda a região, com um valor de apenas $-4,4 \%$. De $35^{\circ} \mathrm{S}$ até o limite sul da área de estudo a diferença média entre as estimativas da velocidade de fase é de $-38 \%$. Diante desses resultados podemos afirmar que o modelo OFES reproduz a velocidade de fase das ondas anuais de forma adequada entre $18^{\circ}$ e $21^{\circ} \mathrm{S}$ e entre $28^{\circ}$ e $40^{\circ} \mathrm{S}$, enquanto que nas ondas semianuais o modelo representa de forma adequada a velocidade de fase entre as latitudes de $15^{\circ}$ e $35^{\circ} \mathrm{S}$. 

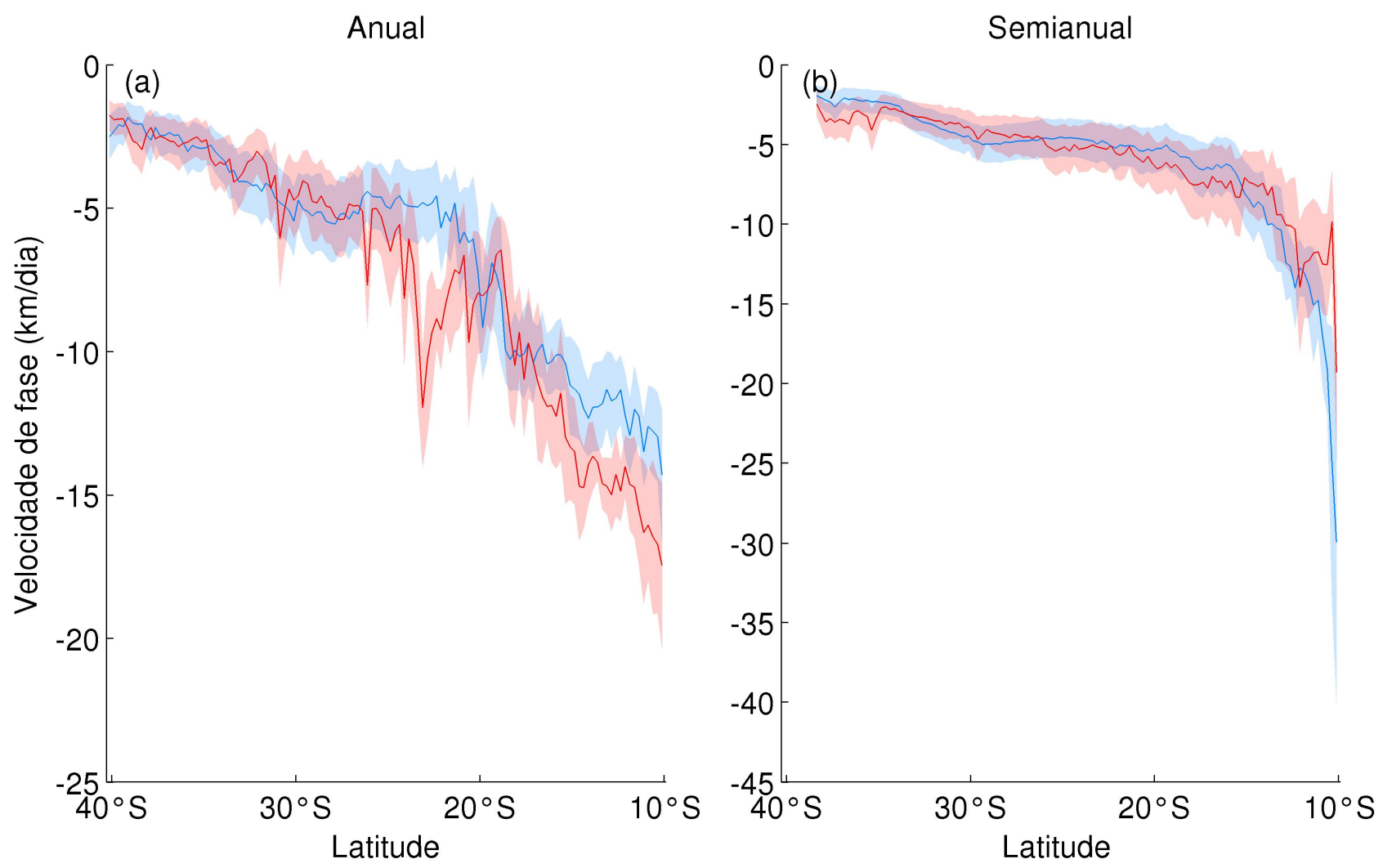

Figura 21 - Similar à Figura 19, mas para velocidade de fase.

Este é um resultado importante pois os filtros não fixam a velocidade de fase. Existe um valor inicial de $c_{p}$, escolhido através da teoria linear, e a partir desse valor inicial são feitas até 20 iterações para encontrar a velocidade que convirja para um valor estável. Ou seja, os valores da velocidade de fase poderiam ser qualquer coisa entre $c_{p} / 2$ e $2 c_{p}$. Sendo assim esses resultados estabelecem que os sinais medidos pelo altímetro e simulados pelo modelo são de ondas de Rossby do $1^{\circ}$ modo baroclínico e que os sinais de vórtices presentes no altímetro e no modelo ficam adequadamente associados a $\eta_{E}$.

De todos os parâmetros das ondas anuais e semianuais comparados até agora, o período (Figura 22) é o único que apresenta uma semelhança estatística ao longo de todas as latitudes da área de estudo. São estatisticamente indistinguíveis em todo o gráfico. Um dos motivos para isto é que os desvios padrão são maiores, pois o filtro é de banda larga, ou seja, apesar de fixarmos a frequência central, a banda é suficientemente larga para permitir as variações observadas. Porém, analisando as diferenças percentuais médias, nós conseguimos inferir quão semelhantes ou diferentes as estimativas são. Na frequência anual (painel a), a diferença média calculada entre as latitude de $10^{\circ}$ e $25^{\circ} \mathrm{S}$ é de $1,9 \%$ e, entre as latitudes de $25^{\circ}$ e $40^{\circ} \mathrm{S}$ é de $-17 \%$.

Outro ponto importante desses resultados é que na parte norte do giro subtropical do oceano Atlântico Sul os períodos das ondas anuais são um pouco maiores que 365 dias e na parte sul são bem menores, chegando a 9 meses nos dados do altímetro. O análogo acontece 


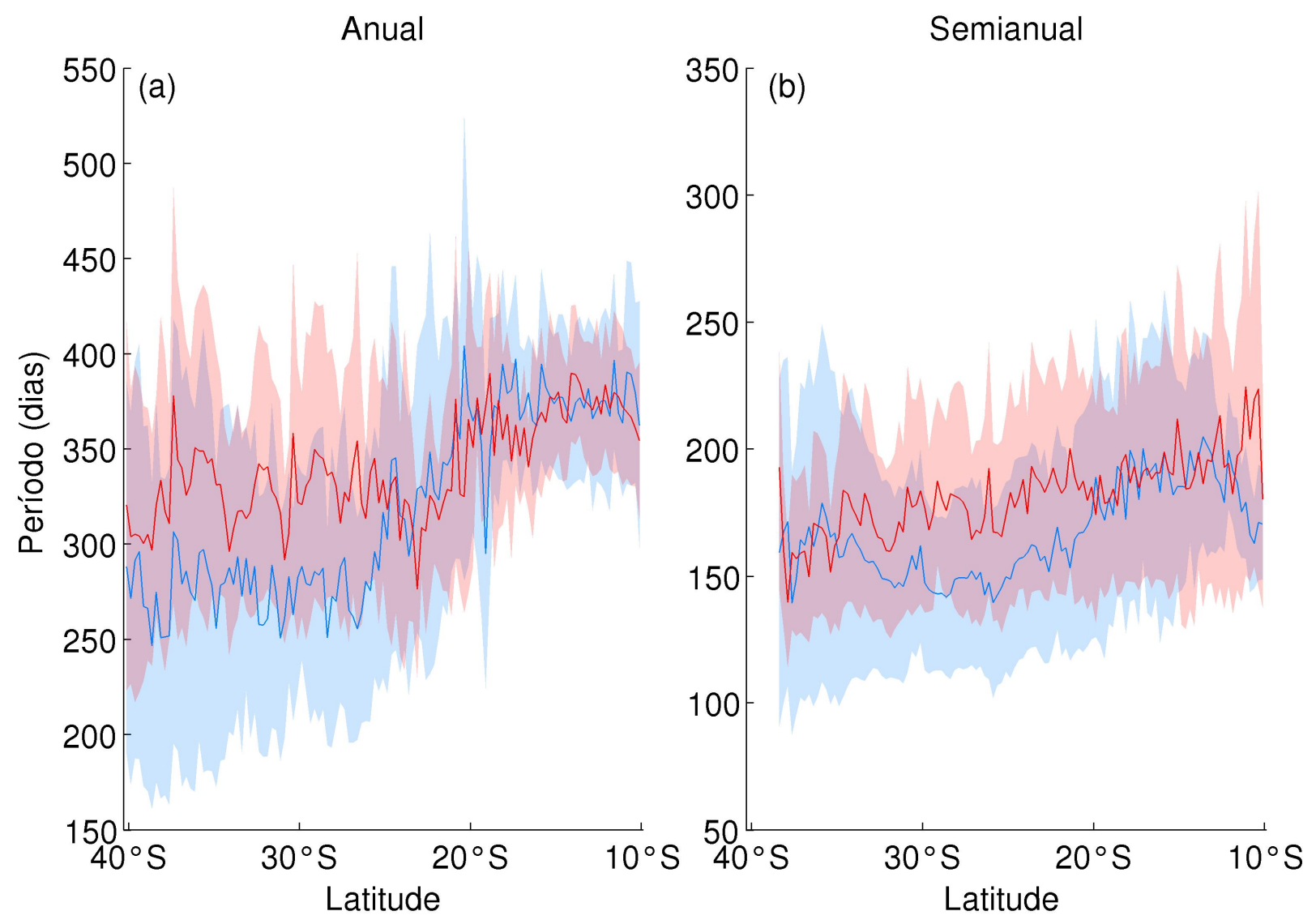

Figura 22 - Similar à Figura 19, mas para período de onda.

com o sinal semianual. Uma possível explicação para isso é o efeito Doppler; entretanto, uma investigação mais profunda não se encaixa no escopo deste trabalho, onde seria necessária uma investigação teórica através de simulações numéricas com corrente média variável para observar a influência do efeito Doppler nos períodos das ondas.

No painel b (frequência semianual), calculamos as diferenças percentuais médias para um maior número de intervalos de latitude, pois os padrões entre as curvas variam mais. Da latitude $10^{\circ}$ até a $12^{\circ} \mathrm{S}$, a diferença média entre as curvas é de $-13 \%$, enquanto que entre as latitudes de $12^{\circ}$ e $20^{\circ} \mathrm{S}$ é de apenas $-1 \%$. A maior diferença média calculada entre as curvas encontra-se entre as latitudes de $20^{\circ}$ e $35^{\circ} \mathrm{S}$, com um valor de $-14 \%$. Entre $35^{\circ} \mathrm{S}$ e a latitude mais ao sul, a diferença encontrada entre os períodos é de 1\%. Esses resultados mostram, que na banda anual na metade norte da área de estudo, o modelo reproduz com exatidão o período das ondas de Rossby e na banda semianual a reprodução é excelente entre $12^{\circ}$ e $20^{\circ} \mathrm{S}$ e entre $35^{\circ} \mathrm{S}$ e o limite sul. 


\subsubsection{Modelo CESM}

A partir de agora mostraremos as comparações entre os parâmetros de onda obtidos através das saídas do modelo CESM e pelos 4,5 anos de dados da AVISO (Figuras 23 a 26). Na Figura 23 comparamos a amplitude das ondas anuais (painel a) e semianuais (painel b). Analisando inicialmente a amplitude das ondas de Rossby com frequência anual, notamos que em praticamente todas as latitudes as curvas são estatisticamente iguais. Analisando as diferenças percentuais médias temos que entre $10^{\circ}$ e $35^{\circ} \mathrm{S}$ as curvas realmente são muito parecidas, com uma diferença de apenas $-4,9 \%$. Entre $35^{\circ}$ e $39^{\circ} \mathrm{S}$ encontra-se a maior diferença média com valor de $26 \%$. E, entre $39^{\circ}$ e $40^{\circ} \mathrm{S}$ a diferença média passa a ser de $-13 \%$.

$\mathrm{Na}$ frequência semianual notamos inicialmente que as curvas são estatisticamente iguais. Porém, ao considerar as diferenças percentuais médias constatamos que em alguns intervalos de latitude elas são realmente muito parecidas e em outros, nem tanto. Por exemplo, entre as latitudes de $10^{\circ}$ e $22^{\circ} \mathrm{S}$, a diferença média entre as curvas do modelo e do altímetro é de $-8 \%$; entre $22^{\circ}$ e $34^{\circ} \mathrm{S}$, a diferença passa a ser de $9 \%$, enquanto que entre as latitudes de $34^{\circ}$ e $37^{\circ} \mathrm{S}$ a diferença é de $-32 \%$. Entre $37^{\circ}$ e o limite sul, é de $13 \%$. Esses resultados nos permitem afirmar que o modelo CESM reproduz de forma adequada a amplitude das ondas anuais e semi-anuis na maioria das latitudes da área de estudo.

Na Figura 24 comparamos o comprimento das ondas anuais (painel a) e semianuais (painel b) calculadas através dos dados do altímetro e do modelo. No painel (a) notamos que, diferentemente do parâmetro amplitude de onda, as curvas de $\lambda$ não são estatisticamente iguais ao longo de todas as latitudes. Isso acontece em alguns trechos apenas e o motivo para isso é pequeno valor de desvio padrão, tanto para os comprimentos de onda do modelo e do altímetro. Analisando as diferenças percentuais médias notamos que entre $10^{\circ}$ e $16^{\circ} \mathrm{S}$ o modelo difere do altímetro em $13 \%$, apresentando valores de $\lambda$ menores do que os encontrados no altímetro. Já entre $16^{\circ}$ e $23^{\circ} \mathrm{S}$ essa diferença passa a ser de $-11 \%$, ou seja, o modelo apresenta valores maiores dos que os encontrados nos dados do altímetro. Entre $23^{\circ}$ e $26^{\circ} \mathrm{S}$ as curvas são estatisticamente iguais, apresentando uma diferença média de apenas $-1,8 \%$. Na região mais ao sul, entre $26^{\circ}$ e $40^{\circ} \mathrm{S}$ a diferença passa a ser de $-10 \%$.

$\mathrm{Na}$ frequência semianual (painel b) a comparação entre os comprimentos de onda ao longo das latitudes apresenta dois padrões. Entre as latitudes $10^{\circ}$ e $12^{\circ} \mathrm{S}$ as curvas são estatisticamente diferentes, apresentando uma diferença percentual média de $20 \%$. E, entre $12^{\circ} \mathrm{S}$ e o limite sul das ondas de Rossby semianuais, as curvas se tornam estatisticamente iguais, apresentando uma diferença média de apenas $-2 \%$. Dessa forma, podemos afirmar que o modelo CESM representa adequadamente o comprimento das ondas semianuais em quase toda a região estudada. Já na componente anual, o modelo apresenta mais dificuldades para reproduzir adequadamente o comprimento das ondas.

Nos gráficos do comprimento de onda (Figura 24) e da velocidade de fase (Figura 25) da componente semianual, foi removido o valor do parâmetro em $10,3^{\circ} \mathrm{S}$ por ser muito maior 

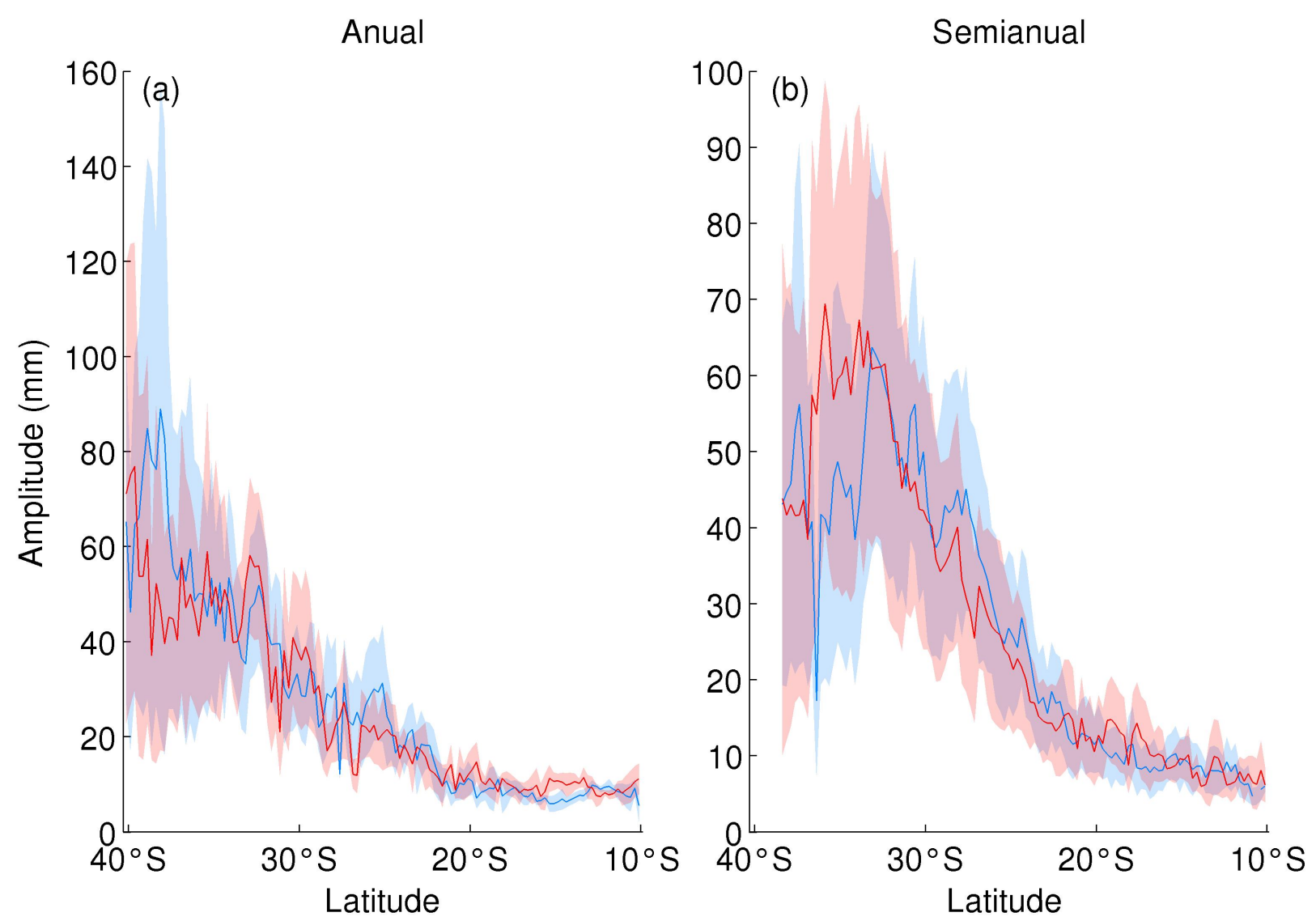

Figura 23 - Similar à Figura 19 para o modelo acoplado CESM.

(quase 3 vezes maior) do que os valores das latitudes vizinhas. O comprimento de onda é maior que a largura da bacia e o filtro não consegue resolver essa parte do espectro de forma adequada. Uma hipótese é que o filtro atribuiu parte do sinal da onda ao sinal sazonal.

A Figura 25 mostra a comparação entre velocidades de fase das ondas anuais e semianuais observadas e modeladas. No painel (a), entre as latitude de $10^{\circ}$ e $17^{\circ} \mathrm{S}$ a diferença média entre as velocidades de fase calculadas através dos dados do modelo e do altímetro é de 9,7\%. Entre as latitudes de $17^{\circ}$ e $21^{\circ} \mathrm{S}$ essa diferença passa a ser de $-17 \%$, com o modelo representando ondas mais rápidas que o altímetro. Na região mais ao sul, entre $21^{\circ}$ e $40^{\circ} \mathrm{S}$, é encontrada a menor diferença média entre as curvas de $-9 \%$. Cabe aqui ressaltar que apesar das curvas não serem estatisticamente idênticas em todas as latitudes da área de estudo, os desvios padrão encontrados nas velocidades de fase tanto do modelo CESM quanto do modelo OFES são muito menores do que as diferenças de $200 \%$ em relação à teoria linear encontradas por Chelton and Schlax (1996).

Na comparação entre as velocidades de fase das ondas de Rossby semianuais, a maior diferença média (20\%) encontra-se na região entre $10^{\circ}$ e $12^{\circ} \mathrm{S}$. Entre as latitudes de $12^{\circ}$ e $16^{\circ} \mathrm{S}$, a diferença passa a ser de $-7 \%$. Ao sul de $16^{\circ} \mathrm{S}$, as curvas são estatisticamente iguais apresentando uma diferença média de apenas $-0,5 \%$. Ou seja, o modelo representa acertadamente a velocidade 

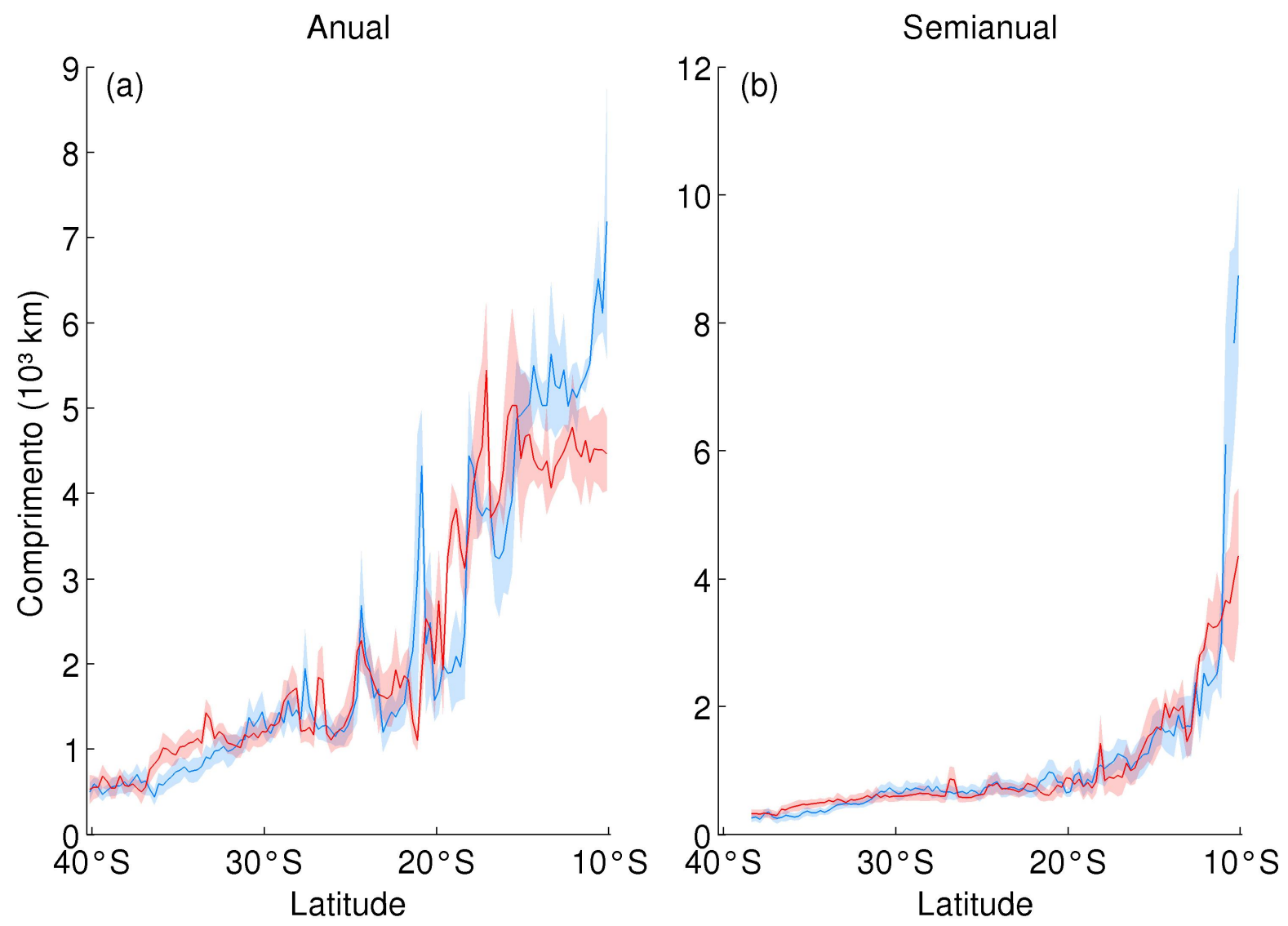

Figura 24 - Similar à Figura 20 para o modelo acoplado CESM.

de fase das ondas semianuais em praticamente todas as latitudes estudadas e reproduz de forma mais adequada a velocidade de fase das ondas anuais ao sul de $21^{\circ} \mathrm{S}$.

Na Figura 26 mostramos a comparação dos períodos calculados para as ondas de Rossby anuais e semianuais. Assim como a comparação entre os períodos de onda calculados através dos dados do altímetro e do modelo OFES, as comparações entre o altímetro e o modelo CESM também apresentam curvas estatisticamente semelhantes em toda a área de estudo. Porém, quando analisamos as diferenças médias, vemos que isto não se deve apenas ao grande valor de desvio padrão das curvas. As diferenças médias são pequenas ao longo de todas as latitudes. Na frequência anual, a diferença média entre as latitudes de $10^{\circ}$ e $16^{\circ} \mathrm{S}$ é de $-1,8 \%$. Entre $16^{\circ}$ e $21^{\circ} \mathrm{S}$ essa diferença passa a ser de $6 \%$. De $21^{\circ}$ até $25^{\circ} \mathrm{S}$ ela se torna $-7 \%$ e de $25^{\circ}$ até $40^{\circ} \mathrm{S}$ a diferença média é de apenas $3 \%$. Na frequência semianual as diferenças médias também são pequenas. Sendo apenas $0,8 \%$ entre $10^{\circ}$ e $15^{\circ} \mathrm{S},-4 \%$ entre $15^{\circ}$ e $32^{\circ} \mathrm{S}$ e $7 \%$ entre $32^{\circ} \mathrm{S}$ e o limite sul das ondas semianuais. Sendo assim, o modelo representa satisfatoriamente o período das ondas anuais e semianuais ao longo de todas as latitudes estudadas. 

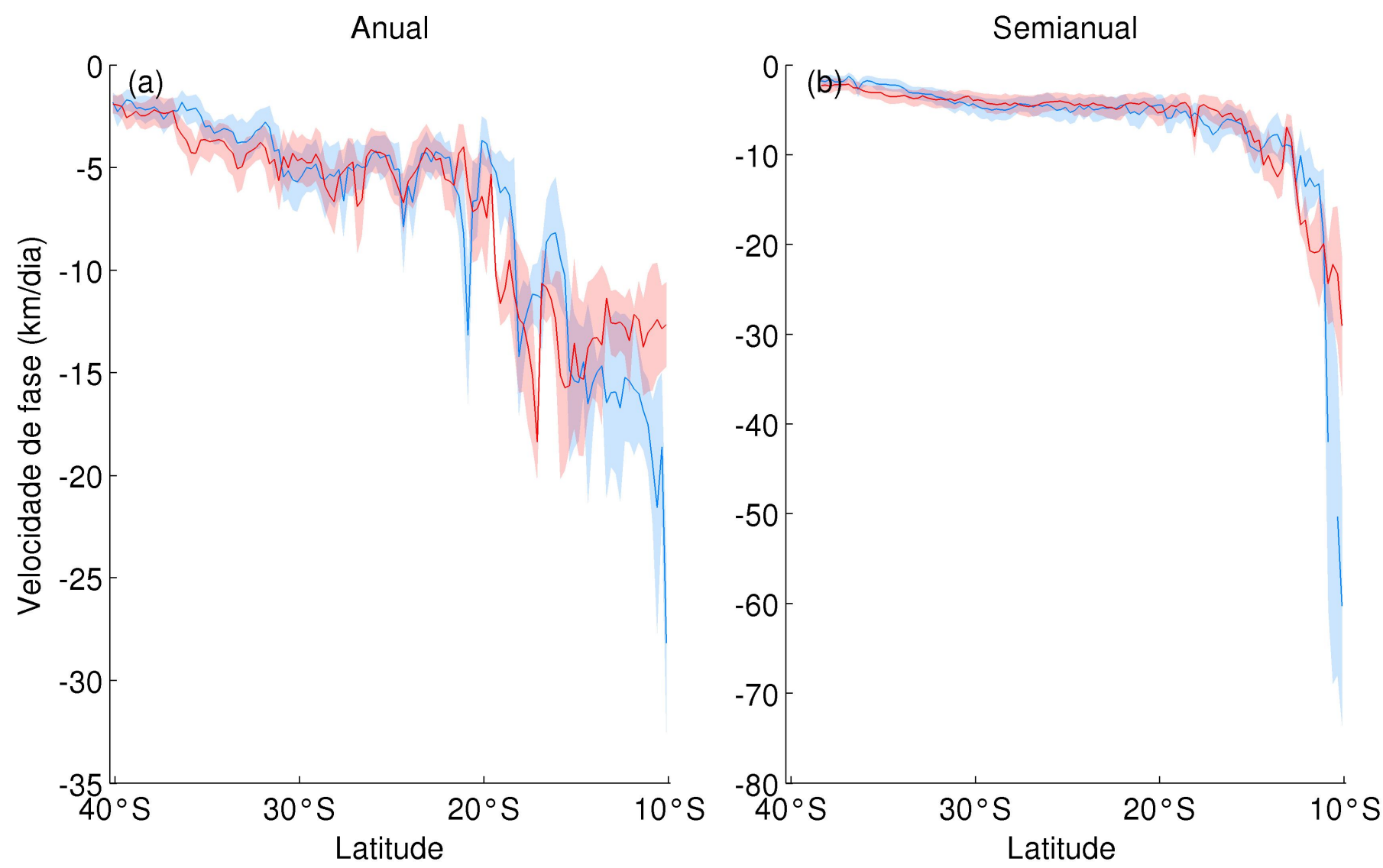

Figura 25 - Similar à Figura 21 para o modelo acoplado CESM.

Visto que os parâmetros amplitude, período e velocidade de fase foram bem simulados pelo modelo CESM, é justo dizer que a dinâmica de ondas de Rossby foi adequadamente simulada, ao menos nas bandas espectrais anual e semianual. O modelo OFES também conseguiu reproduzir os parâmetros de onda, porém não de forma tão eficiente quanto o CESM ao longo de todas as latitudes e nas duas bandas espectrais. Por adequadamente nos referimos ao fato que nas Figuras 19 a 26 o módulo das diferenças médias entre as médias zonais dos parâmetros analisados é inferior ao desvio padrão do parâmetro medido. Portanto é de se esperar que a dinâmica de larga escala decorrente da propagação e reflexão de ondas planetárias seja reproduzida de forma igualmente adequada em termos de energia mecânica.

A análise e comparação entre os comprimentos de onda, amplitudes, velocidades de fase e períodos encontrados nos resultados dos modelos e os observados pelo altímetro são de extrema importância para indicar possíveis problemas nos modelos. O comprimento e período das ondas de Rossby são ditados pela forçante, provavelmente o rotacional do vento perto da África. Já a amplitude depende da intensidade da forçante e também da diferença relativa de densidade entre as camadas $\left(\frac{\Delta \rho}{\rho}\right)$. Num modelo de camadas, este parâmetro associa o deslocamento da termoclina ao $\eta$ que o altímetro observa. $O$ ponto importante é que discrepâncias no comprimento de onda e período estão provavelmente associadas com problemas do campo 

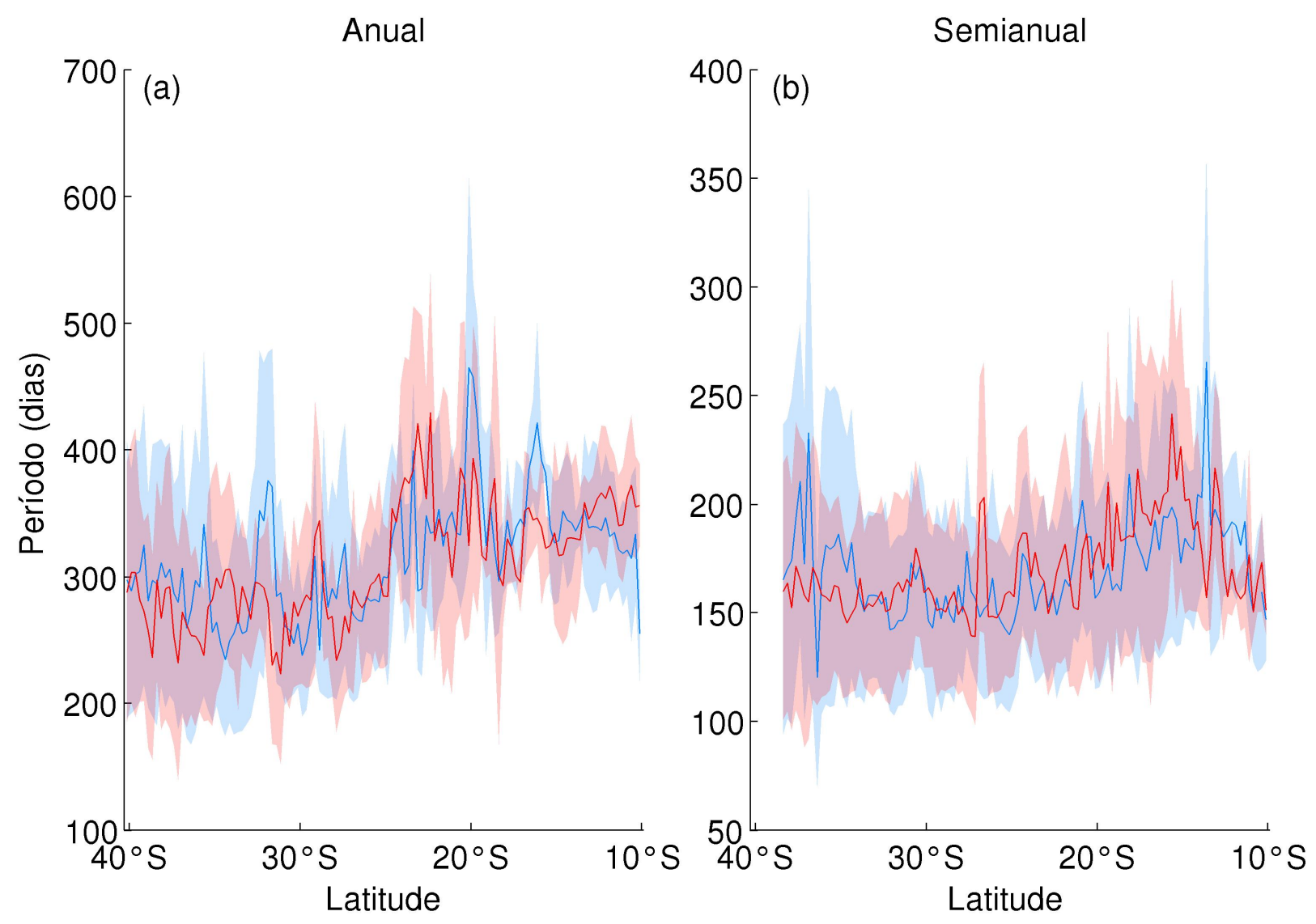

Figura 26 - Similar à Figura 22 para o modelo acoplado CESM.

forçante. Em contrapartida, diferenças de amplitude e de velocidade de fase são indicadores de problemas com a estratificação da coluna d'água.

Dessa forma, é plausível propor que o modelo OFES apresenta algum problema com a estratificação da coluna d'água ou com a intensidade da forçante ao sul $28^{\circ} \mathrm{S}$, pois subestima a amplitude das ondas anuais e semianuais. Além disso, o modelo encontra dificuldades para reproduzir o comprimento de onda e velocidade de fase anual em baixas latitudes e no centro da área de estudo. Isto pode ser encarado como um indicativo de problemas com o campo forçante e sua intensidade. Já o modelo CESM apresenta uma pequena dificuldade na reprodução das amplitudes, em aproximadamente $36^{\circ} \mathrm{S}$, indicando talvez um problema na estratificação ou na intensidade da forçante. Em relação ao comprimento e velocidade de fase das ondas anuais, este modelo também encontra alguma dificuldade em baixas latitudes e no centro da área de estudo. Porém, como um conjunto o CESM consegue reproduzir com mais precisão os parâmetros de onda. 


\subsection{Correlações com atraso de fase entre observações e simula- ções}

Nesta seção mostraremos os resultados obtidos dos cálculos de correlação e lag, como estimativa da diferença de fase entre as ondas anuais e semianuais calculadas através das observações altimétricas e as reproduzidas pelos modelos OFES e CESM. Esses resultados são apresentados nas Figuras 28, 29, 31 e 32. Porém, antes de analisarmos esses resultados mostraremos as correlações, em lag zero, entre as componentes sazonais encontradas nos dados do altímetro e nos modelos OFES (Figura 27) e o CESM (Figura 30). Usaremos esses resultados como base de comparação. Uma vez que o ciclo sazonal é a parte mais determinística do espectro, é justo esperar que este seja o limite superior de correlação entre modelo e altímetro. Em outras palavras, é justo esperar que o modelo simule ondas de Rossby com precisão menor ou igual a da simulação do ciclo sazonal.

\subsubsection{Modelo OFES}

Na Figura 27 temos, no painel à esquerda, o mapa do coeficiente de correlação em lag zero entre a componente filtrada do sinal sazonal do modelo e do altímetro. No painel à direita temos a média zonal dos coeficientes de correlação para cada latitude da área de estudo. Nesta figura podemos ver que a maior correlação entre o sinal do modelo e do altímetro ocorre a oeste de Greenwich, atingindo valores de até 0,9 , sendo que do centro da bacia para a borda leste a correlação se torna fraca (partes brancas) e em duas regiões ela chega a ser negativa. O modelo clássico de ondas de Rossby oceânicas (e.g.: Barnier (1988) propõe que estas sejam criadas pelo rotacional do stress do vento na borda leste. A correlação negativa nos diz que este modelo falha em reproduzir a fase do ciclo sazonal da altura na borda leste. Portanto, há algo errado no processo de gênese das ondas anuais. Da Figura (19) vemos que a média zonal da amplitude das ondas anuais é bem simulada entre $\approx 15^{\circ}$ e $30^{\circ} \mathrm{S}$, justamente onde a correlação é pior na borda leste. Observando o painel da direita vemos que, de modo geral, a média zonal da correlação entre o sinal do modelo e do altímetro ao longo de todas as latitudes não passa de 0,5 , exceto por alguns pontos entre as latitudes de $26^{\circ}$ e $38^{\circ} \mathrm{S}$. Apesar do sinal sazonal ser a componente principal no sinal total em latitudes menores, esta é a região onde o sinal do modelo menos se correlaciona com o do altímetro.

Na Figura 28, painel a, mostramos o mapa dos máximos coeficientes positivos da correlação cruzada entre a anomalia da altura do nível do mar das ondas de Rossby anuais obtidas através dos dados de altímetro e do modelo. No painel c mostramos os lags ou diferenças de fase em graus associados aos coeficientes de correlação do quadro superior. No painel b está a média longitudinal do mapa de correlação para cada latitude da área de estudo. Por fim, no quadro d encontram-se os coeficientes de correlação ao longo de todas as longitudes nas latitudes de $10^{\circ}, 15,5^{\circ}, 28^{\circ}$ e $40^{\circ} \mathrm{S}$. 

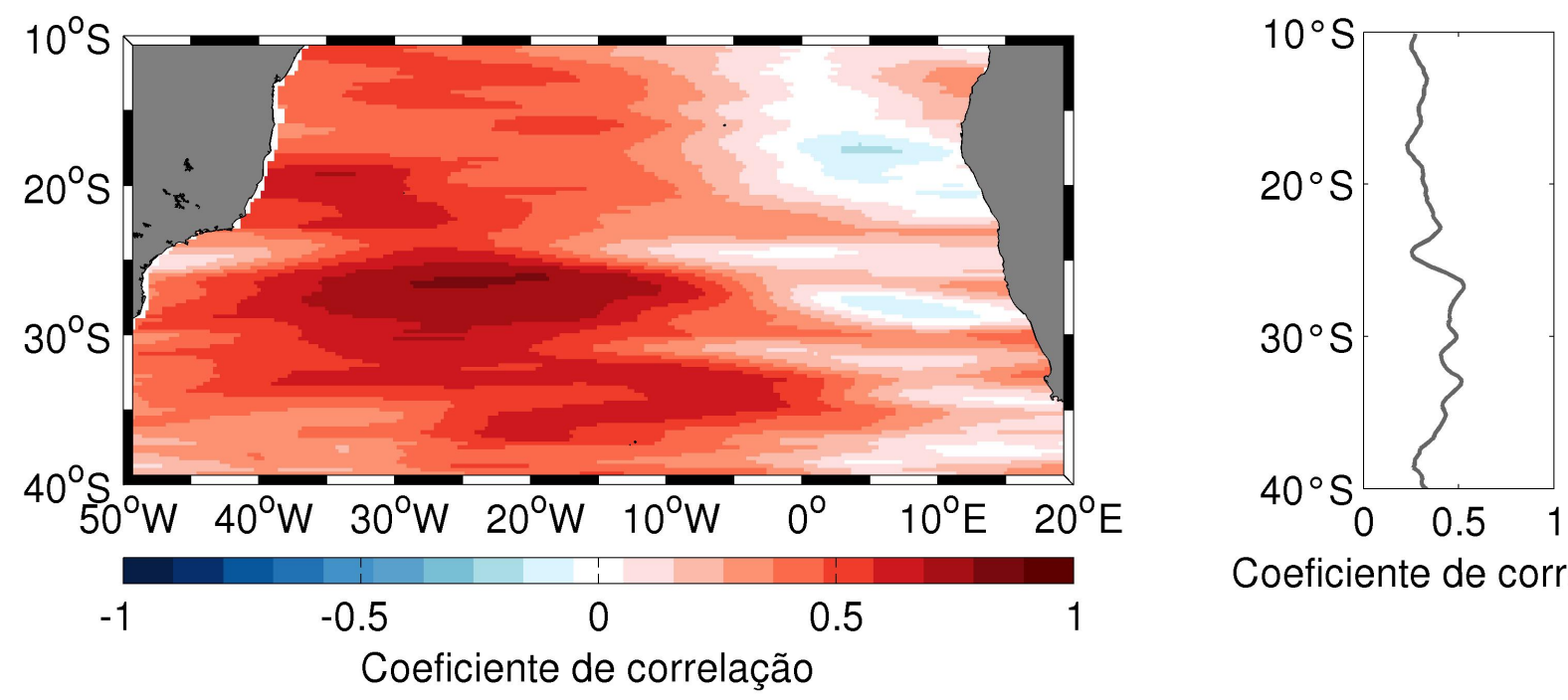

Coeficiente de correlação

Figura 27 - Mapa de correlação em lag zero entre a anomalia da altura do nível do mar calculada através dos dados do modelo OFES e do altímetro, para a componente sazonal (painel à esquerda). Média latitudinal do coeficiente de correlação (painel à direita).

Analisando o mapa dos coeficientes de correlação (painel a) vemos que as ondas reproduzidas pelo modelo melhor se correlacionam com as observadas nos dados do altímetro ao longo de toda a bacia entre as latitudes de $10^{\circ}$ a $18^{\circ} \mathrm{S}$, atingindo valores de até 0,8 para o coeficiente de correlação, sendo a média zonal da correlação para esta área superior a 0,5. Diferentemente do que esperávamos, esta correlação é maior do que a média da correlação entre os sinais sazonais analisados na Figura 27. Ao sul desta região, a média dos coeficientes de correlação cai para menos de 0,4 , mas ainda que menor, é da ordem de $50 \%$ da correlação do sinal sazonal. Analisando o mapa dos lags (painel c) observamos que nas latitudes onde a correlação é maior as diferenças de fase são mais constantes ao longo de toda a bacia, variando de $90^{\circ}$ na borda leste a $-18^{\circ}$ na borda oeste. Entre $16^{\circ}$ e $19^{\circ} \mathrm{S}$, a máxima correlação positiva entre as ondas anuais do modelo e do altímetro encontram-se em fase ao longo de quase toda a bacia oceânica. Nas latitudes maiores, os lags variam com maior frequência ao longo das longitudes, mostrando que as ondas entram e saem de fase várias vezes ao longo da bacia. Por último, analisando o painel d, fica claro que a escala espacial das variações da correlação varia com a latitude: quanto mais ao sul, maior o número de onda. Dessa forma uma pequena diferença na velocidade de fase faz com que as ondas a oeste fiquem fora de fase. Podemos comparar a escala espacial da variação da correlação com o comprimento das ondas. Quanto menor a latitude, maior o comprimento da onda anual, considerando que a velocidade de fase das ondas encontradas no altímetro e das reproduzidas pelo modelo não sejam idênticas, as ondas mais curtas entram em fase ou fora de fase mais vezes ao longo da bacia, alternando entre valores máximos e mínimos de coeficiente de correlação, como ocorre nas latitudes de $28^{\circ}$ e $40^{\circ} \mathrm{S}$. 
a)

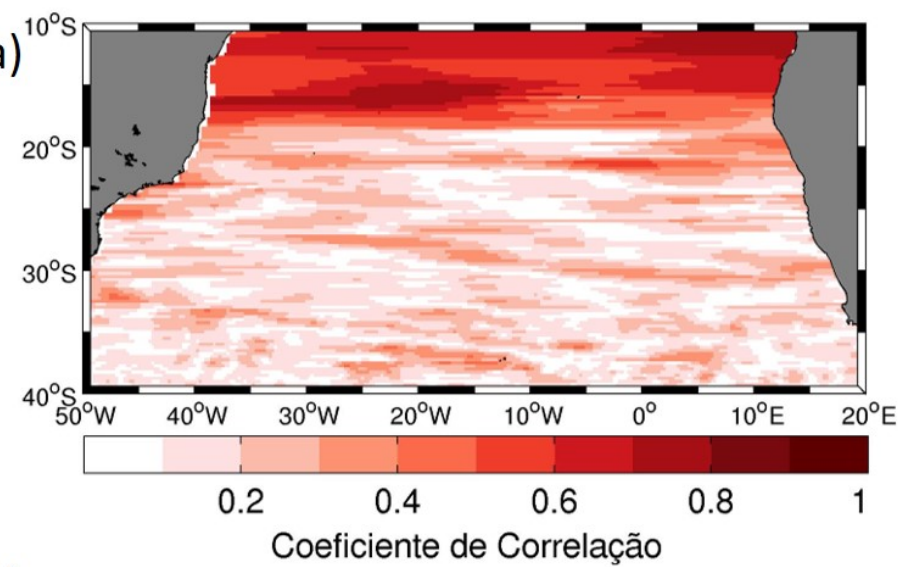

C)

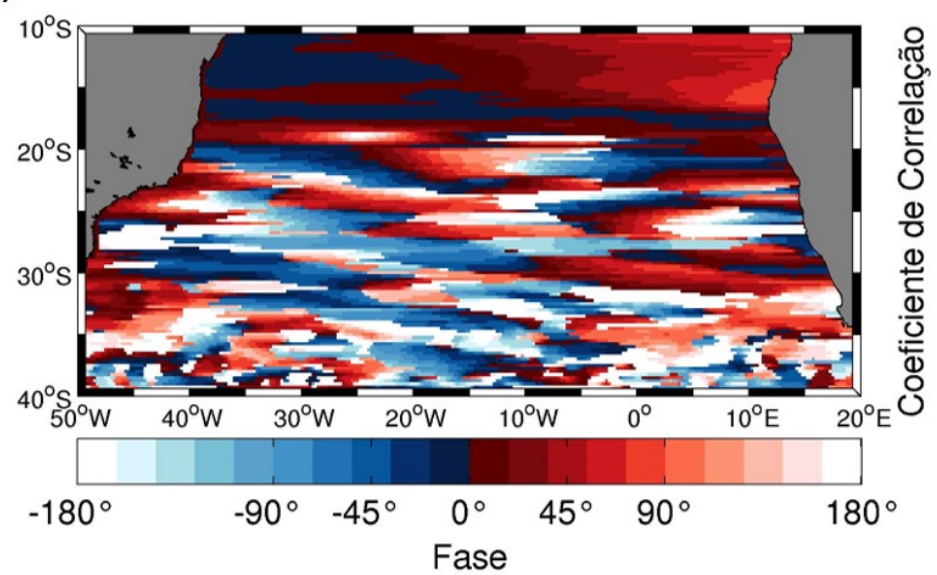

b)

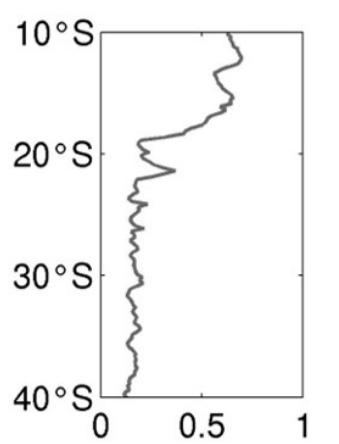

Coeficiente de correlação

d)

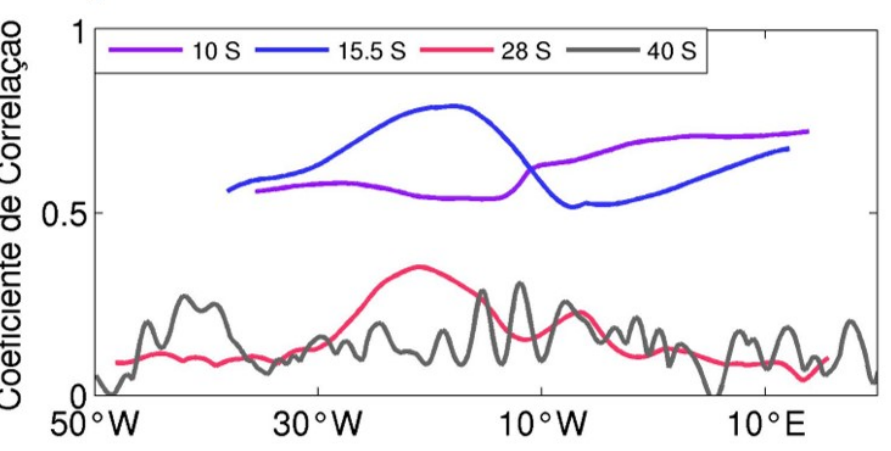

Figura 28 - Mapa dos máximos coeficientes de correlação cruzada entre a anomalia da altura do nível do mar calculada através dos dados do modelo OFES e do altímetro, para a componente anual (painel a). Média latitudinal dos coeficientes de correlação (painel b). Mapa dos lags associados aos máximos coeficientes de correlação (painel c). Gráfico dos coeficientes de correlação ao longo de todas as longitudes da área de estudo nas latitudes de $10^{\circ} \mathrm{S}$ (roxo), $15,5^{\circ} \mathrm{S}$ (azul), $28^{\circ} \mathrm{S}$ (vermelho) e $40^{\circ} \mathrm{S}$ (cinza)(painel d). 
A Figura 29 mostra os mesmos painéis da Figura 28, porém para as ondas de Rossby com frequência semianual. No painel a vemos que a correlação entre as componentes $\eta_{6}$ é bem menor do que entre as componentes $\eta_{12}$, atingindo valores máximos de 0,6 em apenas alguns pontos no limite norte da área de estudo. Exceto por essas áreas, a correlação fica em torno de 0,2 e 0,3 em toda a bacia. Associado a esses coeficientes de correlação, vemos no painel c, que os lags variam entre $-180^{\circ}$ e $180^{\circ} \mathrm{em}$ toda a bacia, exceto pela região mais ao norte onde a diferença de fase é mais constante, variando de $-10^{\circ}$ na borda leste, entrando em fase entre $10^{\circ} \mathrm{E}$ e $10^{\circ} \mathrm{W}$ e variando de $-10^{\circ}$ até $45^{\circ}$ na borda oeste. No painel b vemos que a média dos coeficientes de correlação é praticamente a mesma ao longo de todas as latitudes, exceto entre $10^{\circ}$ e $12^{\circ} \mathrm{S}$, onde o coeficiente de correlação médio chega a 0,4 , sendo maior do que o coeficiente de correlação entre os sinais sazonais. Analisando o painel d vemos que, diferentemente do que ocorre na correlação das ondas anuais, nas semianuais a escala espacial da variação da correlação não apresenta um padrão tão bem definido com o aumento da latitude. Apesar dos valores de correlação variarem em torno de 0,2 , essa magnitude é similar à metade da correlação do sinal sazonal para o lag zero da Figura 27. 


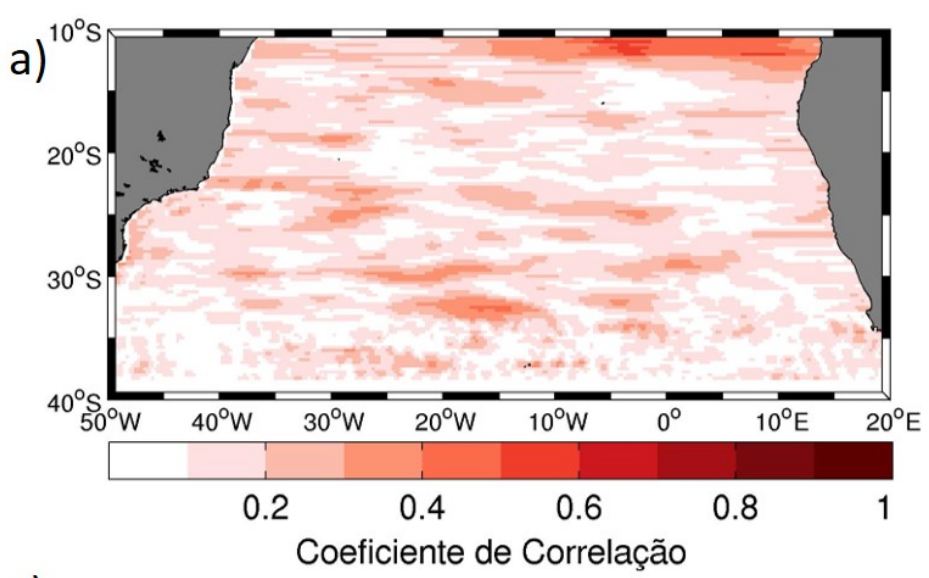

c)

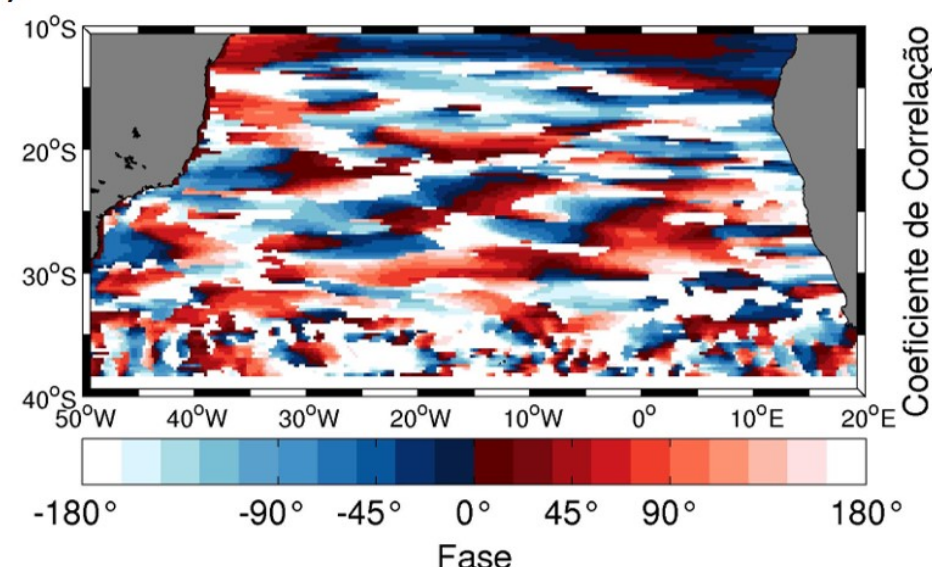

b)

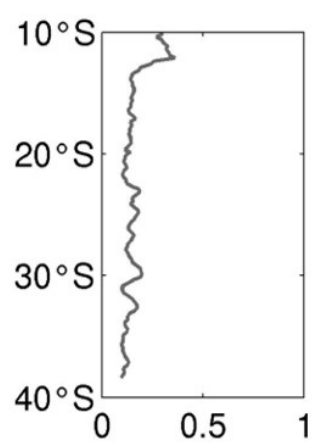

Coeficiente de correlação

d)

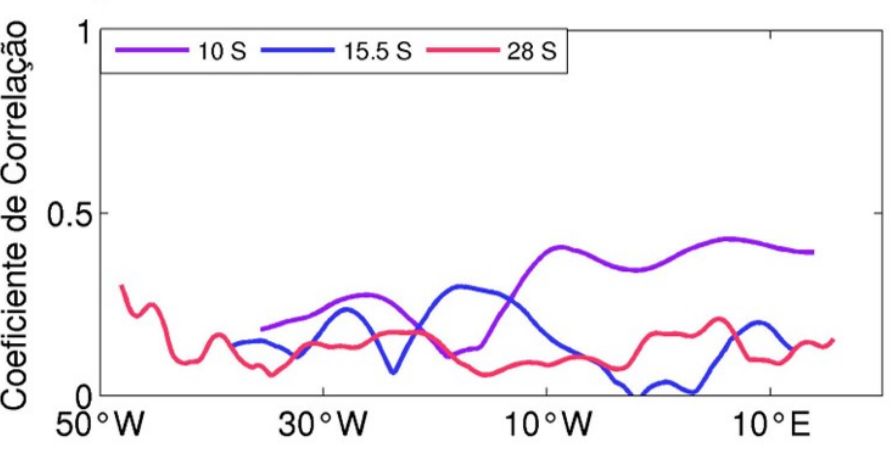

Figura 29 - Mapa dos máximos coeficientes de correlação cruzada entre a anomalia da altura do nível do mar calculada através dos dados do modelo OFES e do altímetro, para a componente semianual (painel a). Média latitudinal dos coeficientes de correlação (painel b). Mapa dos lags associados aos máximos coeficientes de correlação (painel c). Gráfico dos coeficientes de correlação ao longo de todas as longitudes da área de estudo nas latitudes de $10^{\circ} \mathrm{S}$ (roxo), $15,5^{\circ} \mathrm{S}$ (azul) e $28^{\circ} \mathrm{S}$ (vermelho) (painel d). 


\subsubsection{Modelo CESM}

A Figura 30 é similar à Figura 27 e mostra o mapa de correlação em lag zero (painel à esquerda) entre a componente filtrada do sinal sazonal do modelo CESM e do altímetro e a média zonal desses coeficientes de correlação (painel à direita). Pelo mapa dos coeficientes vemos que a correlação entre os sinais sazonais é alta em comparação com os resultados do modelo OFES (Figura 27), atingindo valor de até 0,9 em alguns locais e valores maiores que 0,5 em praticamente toda a área de estudo, exceto pela região na borda sudoeste do continente sul Africano, onde a correlação passa a ser negativa. Esta é uma área conhecida pela ressurgência costeira, devido à direção dos ventos paralelos à costa na região. Como o modelo não é forçado com ventos observados ou de reanálise e sim acoplado com um modelo atmosférico não é surpresa o fato de ele não conseguir reproduzir com tanta precisão o sinal sazonal nesta região. Analisando a média dos coeficientes de correlação ao longo das latitudes vemos que as maiores correlações se encontram entre as latitudes de $12^{\circ}$ e $28^{\circ} \mathrm{S}$, quando a correlação atinge o seu mínimo, em torno de $30^{\circ} \mathrm{S}$ e novamente se aproxima de 0,5 . Comparando a média dos coeficientes de correlação entre o altímetro e os modelos CESM e OFES (Figuras 27 e 30) constatamos que o modelo CESM apresenta uma performance significativamente melhor no que diz respeito à reprodução do sinal sazonal no oceano Atlântico sul mesmo não sendo forçado com ventos realísticos.
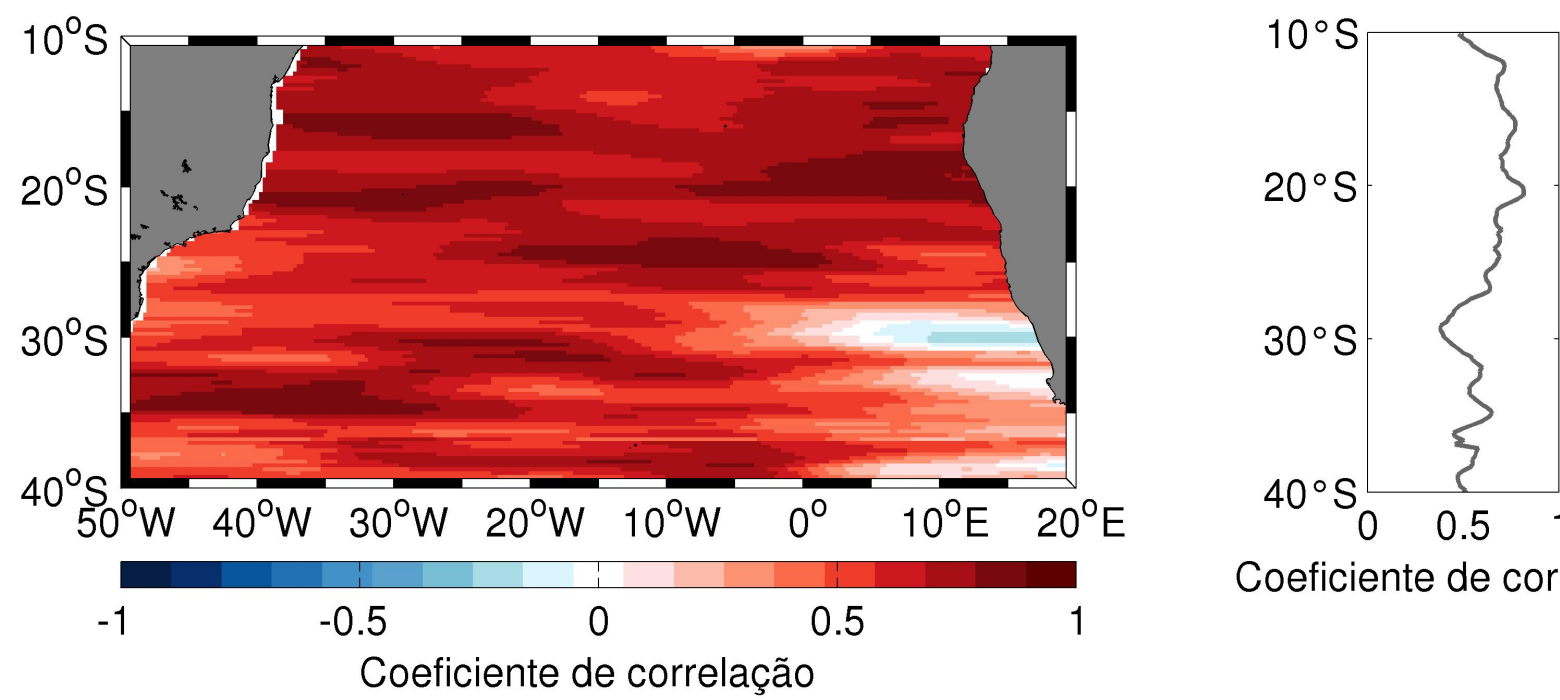

Coeficiente de correlação

Figura 30 - Similar à Figura 27 para o modelo CESM.

Assim como a Figura 28, a Figura 31 mostra os resultados da comparação entre os sinais de ondas de Rossby anual do modelo e do altímetro. Analisando inicialmente o mapa dos 
coeficientes de correlação (painel a) notamos que os maiores valores encontram-se nas latitudes menores, entre $10^{\circ}$ e $19^{\circ} \mathrm{S}$, similar ao resultado do OFES (Figura 28). Em aproximadamente $20^{\circ} \mathrm{S}$ a correlação atinge o seu mínimo. Ao sul desta latitude os coeficientes de correlação variam mais ao longo da bacia, o que pode ser constatado pelas variações entre vermelho e branco. Examinando o mapa dos lags (painel c) associados vemos que em toda a região entre $10^{\circ}$ e $19^{\circ} \mathrm{S}$ a diferença de fase é mais ou menos 20 graus, isto é, o resultado do modelo é quase perfeito pois o padrão de comparação é a correlação entre os sinais sazonais (Figura 30). Em outras palavras, o modelo CESM reproduz ondas de Rossby anuais tão bem quanto o ciclo sazonal nessa região. Em aproximadamente $20^{\circ} \mathrm{S}$, onde ocorre a mínima correlação, também ocorre a maior diferença de fase desde a costa leste. Essa diferença de fase é uma sugestão de que o problema está no processo de gênese dessas ondas, talvez no acoplamento de fluxos em condições de ressurgência de borda leste. Esta sugestão depreende do fato que em situação de ressurgência a camada limite atmosférica possui estratificação extremamente estável e isso altera o fluxo de momentum para o oceano. Através da média dos coeficientes de correlação (painel b), confirmamos que a tendência da correlação entre os sinais das ondas anuais é diminuir com o aumento da latitude, exceto pela latitude de $20^{\circ} \mathrm{S}$ onde a correlação apresenta o menor valor de toda a área de estudo. Em latitudes mais altas, as diferenças de $c_{p}$ - embora menores que as do OFES - influenciam o sincronismo das ondas e tanto a correlação quanto o lag flutuam mais. Em média, a diferença de fase na borda leste da bacia é menor do que no centro, sugerindo que as ondas são geradas próximas da costa Africana. Assim como na Figura (28), através do painel d vemos que existe uma escala espacial das variações da correlação com a latitude, sendo que em latitudes menores a correlação varia menos ao longo da bacia do que em latitudes maiores. 


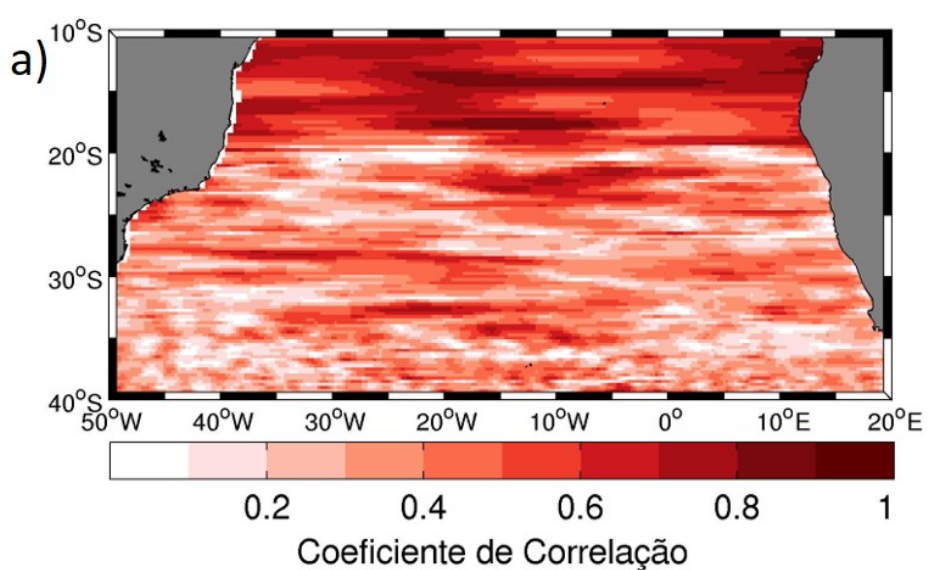

b)

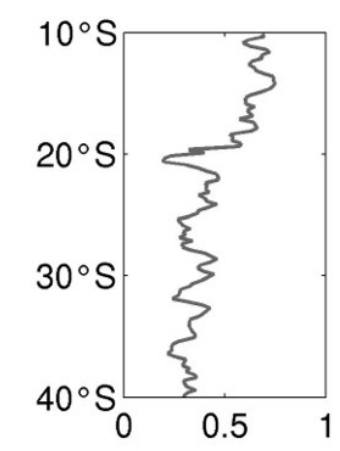

Coeficiente de correlação

c)

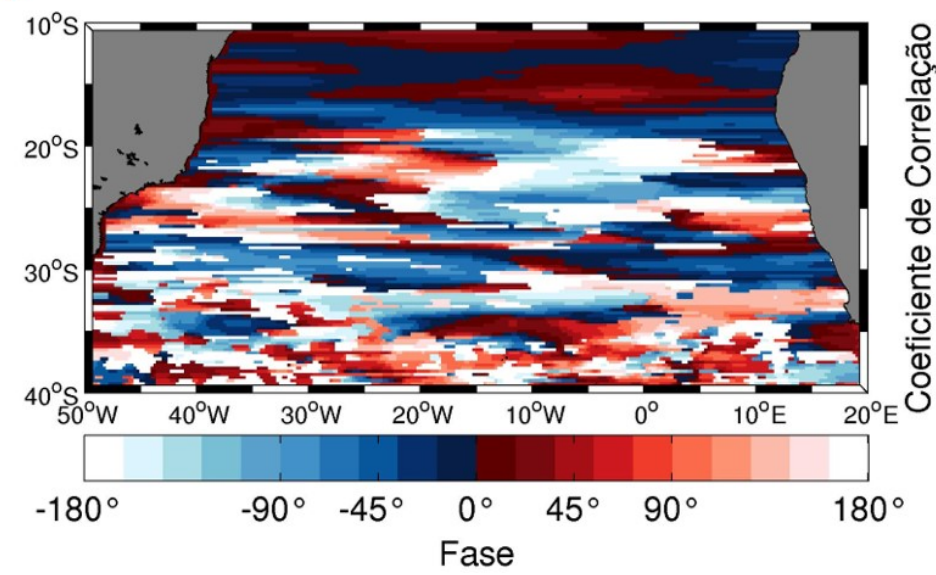

d)

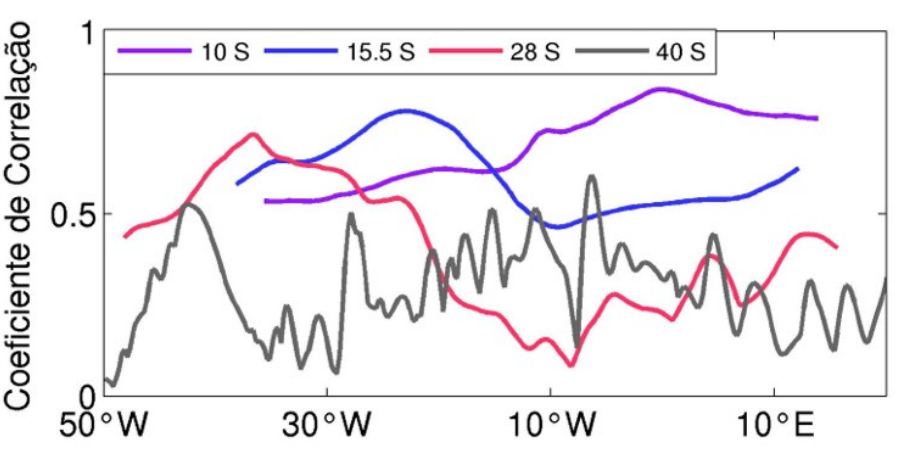

Figura 31 - Similar à Figura 28 para o modelo CESM. 
A Figura 32 mostra os mesmos painéis da Figura 31 para a componente filtrada das ondas de Rossby com período semianual encontradas no modelo e no altímetro. A análise do mapa dos coeficientes de correlação (painel a), demonstra que a correlação não é tão alta quanto nas ondas anuais e não se mostra uniforme ao longo da bacia nas latitudes menores. Neste caso, vemos que a maior correlação $(0,6)$ ocorre em alguns pontos na borda nordeste da bacia, próximo do Continente Africano. Em todas as outras regiões, a correlação varia entre 0 e 0,4. Os lags associados (painel c) apresentam uma menor variação na região onde os coeficientes mostram uma maior correlação, apresentando valores entre $0^{\circ}$ e $-45^{\circ}$. Nas outras regiões as diferenças de fase variam $-180^{\circ}$ e $180^{\circ}$; quanto mais para o sul, mais frequente é essa inversão de fase.

No painel b vemos, que a média dos coeficientes de correlação é bem menor que a média da correlação entre os sinais sazonais e os sinais anuais. Porém, assim como no sinal anual, a correlação média diminuição com o aumento da latitude. Semelhante à correlação entre as ondas semianuais do modelo OFES e do altímetro (Figura 29), vemos no painel d que em $10^{\circ} \mathrm{S}$ a correlação aumenta para leste e, em $15,5^{\circ}$ e $28^{\circ} \mathrm{S}$ não existe uma escala espacial de variação da correlação bem marcada, sendo que os máximos valores de correlação nessas latitudes são os mesmos, em torno de 0,5 . 

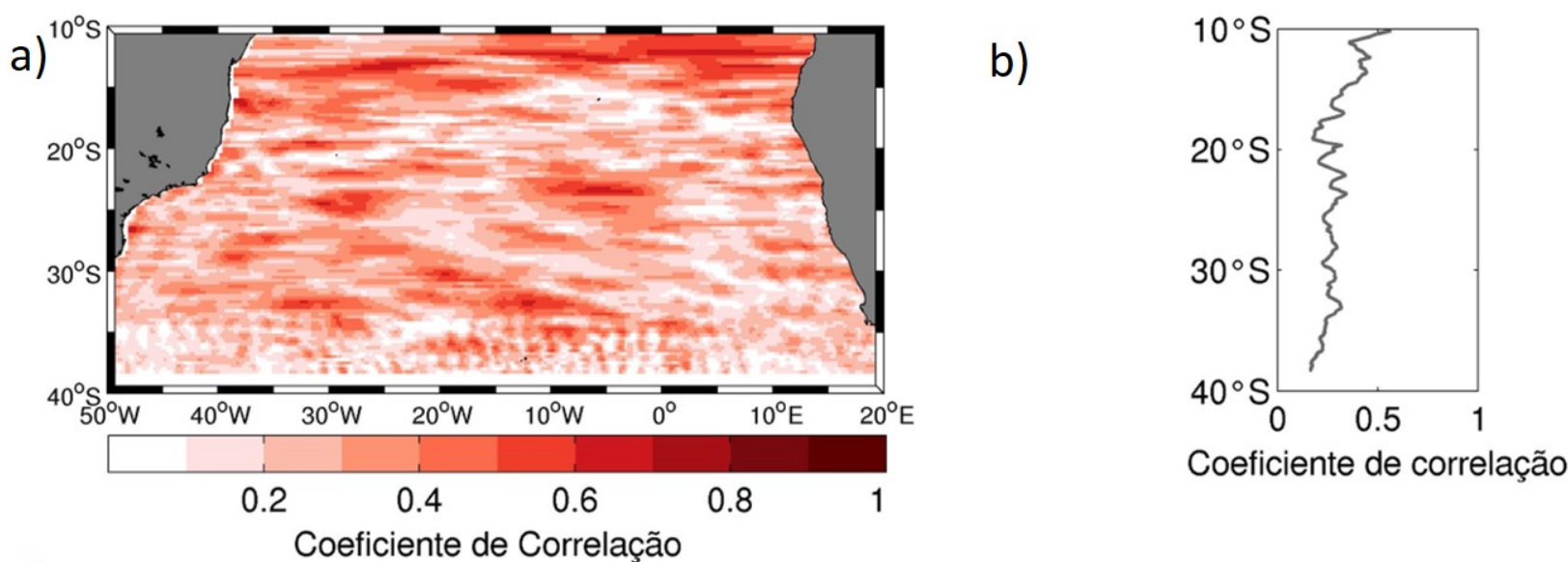

c)

d)
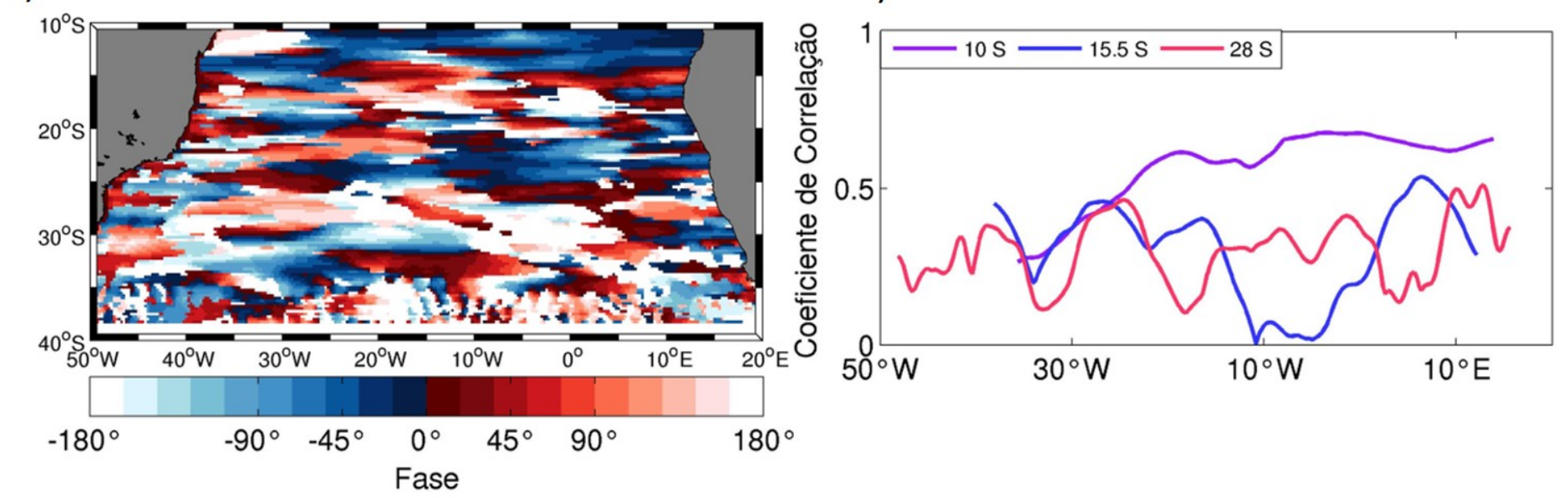

Figura 32 - Similar à Figura 29 para o modelo CESM. 


\section{Conclusões}

As análises preliminares das amplitudes do sinais originais $\left(\eta_{o}\right)$, das componentes filtradas, das variâncias explicadas por essas componentes e dos espectros de Fourier para cada uma das quatro latitudes escolhidas nos permitiram ter uma visão geral sobre a dinâmica das ondas de Rossby no altímetro e sobre a reprodução delas pelos modelos. Através desses cálculos, confirmamos que a energia contida nos espectros aumenta com a latitude e que a importância do sinal sazonal diminui com o aumento da latitude. Além disso, vimos que ao contrário do que o Chelton and Schlax (1996) encontraram, a latitude de $28^{\circ} \mathrm{S}$ é a região onde as ondas de Rossby como um todo representam a maior variância do sinal total (mais de $70 \%$ ) e que $40^{\circ} \mathrm{S}$ é a região onde as ondas menos contribuem para a variabilidade do sinal total.

Ambos os modelos conseguem reproduzir de forma adequada $(\Delta<20 \%)$ a amplitude do sinal total e o aumento de energia presente no espectro em altas latitudes. Também são capazes de retratar a diminuição da importância do sinal sazonal com o aumento da latitude e a dominância das ondas de Rossby na variabilidade do sinal total em $28^{\circ} \mathrm{S}$ (Tabelas 4 e 8 ). Além disso, os dois modelos representam adequadamente a energia contida nas baixas e médias frequências (Figuras 11 a 18). Porém, em altas frequências ambos apresentam dificuldades para reproduzir a energia associada, principalmente o modelo OFES que apresenta um excesso de variabilidade de meso e sub-mesoescala em comparação com os dados altimétricos. Além disso, o modelo OFES em todas as latitudes, exceto $28^{\circ} \mathrm{S}$, subestima a amplitude do sinal sazonal de SSHA em relação ao sinal encontrado pelo altímetro.

Em $28^{\circ} \mathrm{S}$, além do conjunto das ondas de Rossby dominarem a variância do sinal total, a onda de Rossby com período semianual explica a maior parte da variância do sinal total. Este sinal é observado claramente pelo altímetro através do Hovmöller e reproduzido de forma excelente $(\Delta=0 \%)$ pelo modelo CESM (Tabela 8) e razoavelmente bem pelo OFES $(\Delta=$ $-4 \%$ ) (Tabela 4). Apesar do modelo CESM não possuir um vento realístico, este possui as componentes espectrais necessárias para forçar uma gama de ondas de Rossby que se aproxima bastante daquilo que é observado no oceano pelo altímetro. Em todas as latitudes estudadas, os modelos apresentaram uma variância total do espectro maior do que a do altímetro e isto pode estar relacionado à menor resolução temporal do altímetro comparada com a dos modelos ou uma parametrização (e.g. viscosidade turbulenta horizontal) que incorra num exagero do termo não linear.

Para reproduzir adequadamente a dinâmica das ondas de Rossby os modelos precisam ter a dinâmica geostrófica e a quase geostrófica bem resolvidas. Através dos espectros dos modelos, concluímos que ambos são capazes de reproduzir a dinâmica dos movimentos de larga escala e baixa frequência. Conforme as escalas se aproximam de poucos períodos inerciais 
e poucos raios de deformação, os espectros dos modelos divergem mais do espectro observado. Nesta região, os dados altimétricos resolvem até escalas temporais de $\sim 10$ dias e $\sim 70 \mathrm{~km}$ e, portanto, estes valores limitam o escopo da comparação. Mesmo aquém dessas escalas há uma superestimativa da potência espectral baseada nos dados do OFES e, em menor grau, do CESM (Figuras 11 a 18).

A comparação entre as médias zonais (Figuras 19 e 23) mostrou que o modelo OFES reproduz a amplitude das ondas anuais de forma notável (diferença percentual de $-4,6 \%$ ) entre $16^{\circ}$ e $28^{\circ} \mathrm{S}$ e representou adequadamente (diferença percentual de $-19 \%$ ) a amplitude das ondas semianuais entre $10^{\circ}$ e $25^{\circ} \mathrm{S}$. Já o modelo CESM conseguiu reproduzir a amplitude das ondas de Rossby em praticamente todas as latitudes $\left(10^{\circ}\right.$ a $\left.35^{\circ} \mathrm{S}\right)$ da área de estudo com muita precisão (diferença percentual -4,9\%) e nas ondas semianuais a diferença percentual média foi de aproximadamente $9 \%$ entre as latitudes de $10^{\circ}$ e $34^{\circ} \mathrm{S}$.

Em relação à reprodução dos comprimentos de onda encontrados no altímetro o modelo CESM apresenta um melhor desempenho tanto nas ondas anuais quanto nas semianuais, reproduzindo os comprimentos com uma diferença absoluta média menor que 13\% (Figura 24) em todas as latitudes, exceto pelo intervalo entre $10^{\circ}$ e $12^{\circ} \mathrm{S}$, onde a diferença média das ondas semianuais atinge o valor de $20 \%$. Já o modelo OFES apresenta diferenças médias de até $34 \%$ (Figura 20) em relação ao comprimento de onda encontrado pelo altímetro.

Na comparação entre as velocidades de fase, novamente o modelo CESM apresenta uma performance melhor do que o OFES, representando as velocidades de fase com uma diferença absoluta média menor que $20 \%$ em todas as latitudes, sendo que entre $16^{\circ}$ e o limite sul das ondas semianuais a diferença média entre as velocidades de fase do modelo e do altímetro é de apenas 0,5\% (Figura 25), enquanto que o modelo OFES apresenta diferenças médias de até $38 \%$ na velocidade de fase das ondas semianuais e até $27 \%$ nas ondas anuais (Figura 21).

A comparação entre os períodos de onda encontrados no altímetro e nos modelos nos mostrou que os períodos não são exatamente 183 ou 365 dias e nem variações randômicas ao redor de 183 ou 365 dias. Curiosamente, as Figuras 22 e 26 mostram uma dependência dinâmica onde em baixas latitudes os períodos são mais longos e em altas latitudes os períodos são mais curtos. Como o processo de filtragem está se guiando pela velocidade de fase, isso pode ser uma consequência do efeito Doppler; porém, neste trabalho não temos elementos suficientes para investigar esta questão. Para apurar este tema teríamos que fazer experimentos com e sem corrente média nos modelos.

Os resultados das correlações entre os sinais sazonais nos mostraram que a correlação do sinal sazonal do modelo OFES com o do altímetro (Figura 27) fica muito aquém da correlação do sinal sazonal reproduzido pelo modelo CESM e o observado pelo altímetro, apesar do sinal sazonal ser a parte mais determinística do espectro e o modelo OFES ser forçado com ventos diários do NCEP. O modelo CESM (Figura 30) consegue recriar o sinal sazonal de forma excelente em praticamente toda a bacia do oceano Atlântico Sul, exceto pela latitude de $30^{\circ} \mathrm{S}$, 
próximo do continente africano, região conhecida pela ressurgência costeira, devido à direção dos ventos paralelos à costa.

Em relação as ondas anuais ambos os modelos apresentam uma maior correlação (0,8 para o OFES e 0,9 para o CESM - Figuras 28 e 31) em baixas latitudes. É nessas regiões que a diferença de fase entre altímetro e modelo é menor. Ao sul de $20^{\circ} \mathrm{S}$, a correlação das ondas anuais decai para os dois modelos e as diferenças de fase variam com maior frequência. Em $20^{\circ} \mathrm{S}$, o modelo CESM apresente a menor correlação e a maior diferença de fase desde a costa leste. Essa diferença pode ser interpretada como uma sugestão de que existe um problema na gênese dessas ondas, no processo de acoplamento de fluxos em condições de ressurgência de borda leste.

Um dos motivos possíveis para que os modelos consigam reproduzir melhor as ondas anuais em baixas latitudes é que nessas regiões temos ondas muito longas e que provavelmente são fenômenos lineares. Quando descemos em direção as altas latitudes ocorrem mais variações aleatórias da altura, ou seja, fenômenos não lineares, o que dificulta a correlação entre os sinais do modelo e do altímetro.

Nas ondas semianuais, nem o modelo OFES nem o CESM apresentam grandes correlações com as ondas observadas pelo altímetro. As diferenças de fase também são maiores e mais variáveis em toda a bacia quando comparada com as ondas anuais. Apesar das ondas semianuais não estarem diretamente correlacionadas com aquelas observadas pelo satélite, ambos os modelos foram capazes de gerar ondas que apresentam o espectro bem parecido com as do altímetro (Figuras 11 a 18). Mesmo que tenham sido geradas no local correto e pelo processo correto, como a escala espaço-temporal é menor que as anteriores, pequenas diferenças de $c_{p}, \lambda$ e $\mathrm{P}$ rapidamente fazem com que essas ondas dessincronizem com as ondas observadas, resultando em baixas correlações.

Através das análises das médias zonais dos parâmetros específicos e das correlações das ondas de Rossby observadas no altímetro e reproduzidas nos modelos, verificamos que, apesar do modelo OFES ser forçado com ventos diários do NCEP, este apresenta resultados piores que o CESM para vários parâmetros das ondas de Rossby. Isto sugere que a estratificação $\left(\frac{\partial \rho}{\partial z}\right)$ não seja bem representada no modelo, causando as subestimativas de amplitude nas ondas anuais e semianuais em altas latitudes. Outro efeito de uma estratificação inverossímil é a variação do raio de deformação de Rossby, que acarretaria variação na relação de dispersão. Além disso, o fato da forçante ser realista e mesmo assim o modelo OFES não apresentar um resultado melhor que o CESM na reprodução das ondas indica que a atmosfera atuando apenas como forçante no oceano não é o suficiente para recriar ondas de Rossby tão próximas das observadas. Este trabalho sugere fortemente que para isso é necessário um processo de acoplamento entre o oceano e a atmosfera, onde não só a atmosfera força o oceano como o oceano interfere na atmosfera. Nossos resultados favorecem o processo de acoplamento dinâmico e termodinâmico do CESM. 
Dessa forma, concluímos que ambos os modelos são capazes de reproduzir ondas de Rossby, o OFES de forma menos precisa, o CESM mais precisamente. Interpretamos esse resultado como uma indicação de que a complexidade no acoplamento oceano atmosfera, com input de água doce, fluxo de calor e principalmente a troca de momentum com a atmosfera, fazem diferença na dinâmica das ondas de Rossby. 


\section{Trabalhos futuros}

- Investigar o efeito Doppler na variação dos períodos das ondas anuais ao longo das latitudes através de simulações numéricas com corrente média variável (artificiosamente);

- Refazer o estudo de correlação das ondas anuais do modelo CESM para a costa da Namíbia, da Califórnia e do Peru/Chile com e sem restauração da temperatura para investigar se o problema na gênese dessas ondas está no acoplamento de fluxos em condições de ressurgência costeira.

- Usar uma rodado longa (secular) dos modelos e tentar associar variações interanuais do bombeamento de Ekman com a amplitude das ondas e com a intensidade dos giros.

- Investigar o papel dos fluxos de massa, calor e momentum na interface ar-mar na propagação de ondas de Rossby, variando parâmetros não do modelo em si, mas do acoplador de fluxos. 


\section{Referências}

Amante, C. and B. Eakins, 2009:. ETOPO1 1 arc-minute global relief model: procedures, data sources and analysis. NOAA Technical Memorandum NESDIS NGDC-24, 19.

Anderson, D. L. and A. Gill, 1975:. Spin-up of a stratified ocean, with applications to upwelling. Deep Sea Research 22(9), 583-596.

Anderson, D. L. and P. D. Killworth, 1977:. Spin-up of a stratified ocean, with topography. Deep Sea Research 24(8), 709-732.

Antonov, J., S. Levitus, T. Boyer, M. Conkright, T. O’Brien, and C. Stephens, 1998:. World ocean atlas 1998. Vol. 1: temperature of the Atlantic Ocean.

Barnier, B., 1988:. A numerical study on the influence of the mid-atlantic ridge on nonlinear barotropic and first-mode baroclinic rossby waves generated by seasonal winds. Journal of Physical Oceanography, 18, 417-433.

Benada, J., 1997:. PODAAC Merged GDR (TOPEX/Poseidon) Generation B User's Handbook Version 2.0. JPL D-11007, Jet Propulsion Laboratory, California Institute of Technology.

Bernstein, R. and W. White, 1974:. Time and length scales of baroclinic eddies in the central North Pacific Ocean. Journal of Physical Oceanography 4(4), 613-624.

Bernstein, R. and W. White, 1981:. Stationary and traveling mesoscale perturbations in the Kuroshio Extension current. Journal of Physical Oceanography 11(5), 692-704.

Bindoff, N. L., J. Willebrand, V. Artale, A. Cazenave, J. M. Gregory, S. Gulev, K. Hanawa, C. Le Quéré, S. Levitus, Y. Nojiri, et al., 2007:. Observations: oceanic climate change and sea level. Cambridge University Press, 747-845.

Boyer, T., S. Levitus, J. Antonov, M. Conkright, T. O’Brien, C. Stephens, and B. Trotsenko, 1998:. World ocean atlas 1998 Vol. 6: salinity of the Indian Ocean.

Bryan, K., 1969:. A numerical method for the study of the circulation of the world ocean. Journal of Computational Physics 4(3), 347-376.

Campos, E., A. Busalacchi, S. Garzoli, J. Lutjeharms, R. Matano, P. Nobre, D. Olson, A. Piola, C. Tanajura, and I. Wainer, 1999:. The South Atlantic and the climate. Contribution to the OCEAONOBS99, 1.

Chassignet, E. P. and Z. D. Garraffo, 2001:. Viscosity parameterization and the Gulf Stream separation. Technical report, DTIC Document. 
Chelton, D. B., P. Gaube, M. G. Schlax, J. J. Early, and R. M. Samelson, 2011:. The influence of nonlinear mesoscale eddies on near-surface oceanic chlorophyll. Science 334(6054), 328332.

Chelton, D. B. and M. G. Schlax, 1996:. Global observations of oceanic Rossby waves. Science, 234-243.

Chu, P., L. Ivanov, O. Melnichenko, and N. Wells, 2007:. On long baroclinic Rossby waves in the tropical North Atlantic observed from profiling floats. Journal of Geophysical Research: Oceans (1978-2012) 112(C5).

Cipollini, P., D. Cromwell, P. G. Challenor, and S. Raffaglio, 2001:. Rossby waves detected in global ocean colour data. Geophysical Research Letters 28(2), 323-326.

Cipollini, P., D. Cromwell, M. S. Jones, G. D. Quartly, and P. G. Challenor, 1997:. Concurrent altimeter and infrared observations of Rossby wave propagation near $34 \mathrm{~N}$ in the Northeast Atlantic. Geophysical Research Letters 24(8), 889-892.

Cipollini, P., D. Cromwell, and G. Quartly, 1996:. Variability of Rossby wave propagation in the North Atlantic from TOPEX/Poseidon altimetry. In Geoscience and Remote Sensing Symposium, 1996. IGARSS'96.'Remote Sensing for a Sustainable Future.', International, Volume 1, pp. 91-93. IEEE.

Cipollini, P., D. Cromwell, G. D. Quartly, and P. G. Challenor, 2000:. Remote sensing of oceanic extra-tropical Rossby waves. Elsevier Oceanography Series, 63, 99-123.

Deser, C., M. A. Alexander, and M. S. Timlin, 1999:. Evidence for a wind-driven intensification of the Kuroshio Current Extension from the 1970s to the 1980s. Journal of Climate 12(6), 1697-1706.

Douglas, B. C., 2001:. Sea level change in the era of the recording tide gauge. International Geophysics, 75, 37-64.

Duacs/AVISO, 2014:. A new version of SSALTO/Duacs produts available in April 2014. CNES.

Emery, W. and R. Thomson, 2001:. Data Analysis Methods in Physical Oceanography. Elsevier.

Gangopadhyay, A., P. Cornillon, and D. R. Watts, 1992:. A test of the Parsons-Veronis hypothesis on the separation of the Gulf Stream. Journal of Physical Oceanography 22(11), 1286-1301.

Gent, P. R., G. Danabasoglu, L. J. Donner, M. M. Holland, E. C. Hunke, S. R. Jayne, D. M. Lawrence, R. B. Neale, P. J. Rasch, M. Vertenstein, et al., 2011:. The community climate system model version 4. Journal of Climate 24(19), 4973-4991. 
Gent, P. R., S. G. Yeager, R. B. Neale, S. Levis, and D. A. Bailey, 2010:. Improvements in a half degree atmosphere/land version of the CCSM. Climate Dynamics 34(6), 819-833.

Gill, A., 1980:. Some simple solutions for heat-induced tropical circulation. Quarterly Journal of the Royal Meteorological Society 106(449), 447-462.

Gill, A. E., 1982:. Atmosphere-ocean dynamics, Volume 30. Academic press.

Gouretski, V. and K. P. Koltermann, 2004:. WOCE global hydrographic climatology. Technical Report 35, Berichte des BSH.

Hill, K. L., I. S. Robinson, and P. Cipollini, 2000:. Propagation characteristics of extratropical planetary waves observed in the ATSR global sea surface temperature record. Journal of Geophysical Research: Oceans (1978-2012) 105(C9), 21927-21945.

Holton, J. R., R. Dmowska, and S. G. Philander, 1989:. El Niño, La Niña, and the southern oscillation, Volume 46. Academic Press.

Hughes, C., 1995: Rossby waves in the Southern Ocean: A comparison of TOPEX/Poseidon altimetry with model. Journal of Geophysical Research 100(C8), 15,933-15,950.

Hunke, E. and W. Lipscomb, 2008:. CICE: The Los Alamos sea ice model, documentation and software, version 4.0, Los Alamos National Laboratory Tech. Rep. Technical report, LA-CC-06-012.

Hurlburt, H. E. and P. J. Hogan, 2000:. Impact of 1/8 to 1/64 resolution on Gulf Stream modeldata comparisons in basin-scale subtropical Atlantic Ocean models. Dynamics of Atmospheres and Oceans 32(3), 283-329.

Hurrell, J. W., M. M. Holland, P. R. Gent, S. Ghan, J. E. Kay, P. Kushner, J.-F. Lamarque, W. G. Large, D. Lawrence, K. Lindsay, et al., 2013:. The community earth system model: A framework for collaborative research. Bulletin of the American Meteorological Society 94(9), 1339-1360.

Jacobs, G., W. Emery, and G. Born, 1993:. Rossby waves in the Pacific Ocean extracted from Geosat altimeter data. Journal of Physical Oceanography 23(6), 1155-1175.

Jacobs, G. A., H. E. Hurlburt, J. C. Kindle, E. J. Metzger, J. L. Mitchell, W. J. Teague, and A. J. Wallcraft, 1994:. Decade-scale trans-Pacific propagation and warming effects of an El Nino anomaly. Nature 370(6488), 360-363.

Kalnay, E., M. Kanamitsu, R. Kistler, W. Collins, D. Deaven, L. Gandin, M. Iredell, S. Saha, G. White, J. Woollen, et al., 1996:. The NCEP/NCAR 40-year reanalysis project. Bulletin of the American Meteorological Society 77(3), 437-471. 
Kang, Y. Q. and L. Magaard, 1979:. Stable and unstable rossby waves in the north pacific current as inferred from the mean stratification. Dynamics of Atmospheres and Oceans 3(1), $1-14$.

Kawamiya, M. and A. Oschlies, 2001:. Formation of a basin-scale surface chlorophyll pattern by Rossby waves. Geophysical Research Letters 28(21), 4139-4142.

Killworth, P. D., D. B. Chelton, and R. A. de Szoeke, 1997:. The speed of observed and theoretical long extratropical planetary waves. Journal of Physical Oceanography 27(9), 1946-1966.

Killworth, P. D., P. Cipollini, B. M. Uz, and J. R. Blundell, 2004:. Physical and biological mechanisms for planetary waves observed in satellite-derived chlorophyll. Journal of Geophysical Research: Oceans (1978-2012) 109(C7).

Kirtman, B. P., C. Bitz, F. Bryan, W. Collins, J. Dennis, N. Hearn, J. L. Kinter III, R. Loft, C. Rousset, L. Siqueira, et al., 2012:. Impact of ocean model resolution on CCSM climate simulations. Climate Dynamics 39(6), 1303-1328.

Large, W. and G. Danabasoglu, 2006:. Attribution and impacts of upper-ocean biases in CCSM3. Journal of Climate 19(11), 2325-2346.

Large, W. and S. Yeager, 2009:. The global climatology of an interannually varying air-sea flux data set. Climate Dynamics 33(2-3), 341-364.

Lawrence, D. M., K. W. Oleson, M. G. Flanner, P. E. Thornton, S. C. Swenson, P. J. Lawrence, X. Zeng, Z.-L. Yang, S. Levis, K. Sakaguchi, et al., 2011:. Parameterization improvements and functional and structural advances in version 4 of the Community Land Model. Journal of Advances in Modeling Earth Systems 3(1).

Le Traon, P.-Y. and J.-F. Minster, 1993:. Sea level variability and semiannual Rossby waves in the South Atlantic subtropical gyre. Journal of Geophysical Research: Oceans (19782012) 98(C7), 12315-12326.

Lecointre, A., T. Penduff, P. Cipollini, R. Tailleux, and B. Barnier, 2008:. Depth dependence of westward-propagating north atlantic features diagnosed from altimetry and a numerical 1/6 model. Ocean Science Discussions 4(6), 817-853.

Lim, J. S., 1990:. Two-dimensional signal and image processing. Englewood Cliffs, NJ, Prentice Hall, 1.

Machu, E., B. Ferret, and V. Garçon, 1999:. Phytoplankton pigment distribution from SeaWiFS data in the subtropical convergence zone south of Africa: A wavelet analysis. Geophysical Research Letters 26(10), 1469-1472.

Maltrud, M. E. and J. L. McClean, 2005:. An eddy resolving global 1/10 ocean simulation. Ocean Modelling 8(1), 31-54. 
Masumoto, Y., H. Sasaki, T. Kagimoto, N. Komori, A. Ishida, Y. Sasai, T. Miyama, T. Motoi, H. Mitsudera, K. Takahashi, et al., 2004:. A fifty-year eddy-resolving simulation of the world ocean: Preliminary outcomes of OFES (OGCM for the Earth Simulator). Journal of the Earth Simulator, 1, 35-56.

Matthews, P. E., M. A. Johnson, and J. J. O’Brien, 1992:. Observation of mesoscale ocean features in the northeast Pacific using Geosat radar altimetry data. Journal of Geophysical Research: Oceans (1978-2012) 97(C11), 17829-17840.

McClean, J. L., D. C. Bader, F. O. Bryan, M. E. Maltrud, J. M. Dennis, A. A. Mirin, P. W. Jones, Y. Y. Kim, D. P. Ivanova, M. Vertenstein, et al., 2011:. A prototype two-decade fully-coupled fine-resolution CCSM simulation. Ocean Modelling 39(1), 10-30.

McClean, J. L., P.-M. Poulain, J. W. Pelton, and M. E. Maltrud, 2002:. Eulerian and Lagrangian statistics from surface drifters and a high-resolution POP simulation in the North Atlantic. Journal of Physical Oceanography 32(9), 2472-2491.

McCreary, J., 1976:. Eastern tropical ocean response to changing wind systems: With application to El Niño. Journal of Physical Oceanography 6(5), 632-645.

McWilliams, J. C. and G. R. Flierl, 1976:. Optimal, quasi-geostrophic wave analyses of mode array data. 23(4), 285-300.

Menezes, V. V., M. L. Vianna, and H. E. Phillips, 2014:. Aquarius sea surface salinity in the South Indian Ocean: Revealing annual-period planetary waves. Journal of Geophysical Research: Oceans 119(6), 3883-3908.

Milne, G. A., W. R. Gehrels, C. W. Hughes, and M. E. Tamisiea, 2009:. Identifying the causes of sea-level change. Nature Geoscience 2(7), 471-478.

Munk, W. H., 1950:. On the wind-driven ocean circulation. Journal of meteorology 7(2), 80-93.

Neale, R. B., J. H. Richter, A. J. Conley, S. Park, P. H. Lauritzen, A. Gettelman, and D. L. Williamson, 2010:. Description of the NCAR community atmosphere model (CAM 4.0). NCAR Tech. Note NCAR/TN-485+STR.

Nicholls, R. J. and A. Cazenave, 2010:. Sea-level rise and its impact on coastal zones. Science 328(5985), 1517-1520.

Nicholls, R. J., P. P. Wong, V. Burkett, J. Codignotto, J. Hay, R. McLean, S. Ragoonaden, C. D. Woodroffe, P. Abuodha, J. Arblaster, et al., 2007:. Coastal systems and low-lying areas. In Climate Change 2007: Impacts, Adaptation and Vulnerability. Contribution of Working Group II to the Fourth Assessment Report of the Intergovernmental Panel on Climate Change (M. L. Parry et al. ed.)., Cambridge Univ. Press, Cambridge, U. K, pp. 315-356. 
Nonaka, M., H. Nakamura, Y. Tanimoto, T. Kagimoto, and H. Sasaki, 2006:. Decadal variability in the Kuroshio-Oyashio Extension simulated in an eddy-resolving OGCM. Journal of Climate 19(10), 1970-1989.

Oliveira, F. S. and P. S. Polito, 2013:. Characterization of westward propagating signals in the South Atlantic from altimeter and radiometer records. Remote Sensing of Environment, 134, 367-376.

Osychny, V. and P. Cornillon, 2004:. Properties of Rossby waves in the North Atlantic estimated from satellite data. Journal of physical oceanography 34(1), 61-76.

Pacanowski, R. and S. Griffies, 2000:. MOM 3.0 User Manual.

Pedlosky, J., 1987:. Geophysical Fluid Dynamics. Springer-Verlag, New York.

Peterson, R. G. and L. Stramma, 1991: Upper-level circulation in the south atlantic ocean. Progress in oceanography 26(1), 1-73.

Polito, P., O. Sato, and I. Wainer, 2008:. Height variability from the MIROC-IPCC model for the 20th century compared to that of the TOPEX/Poseidon altimeter. Ocean Modelling 24(3), 73-91.

Polito, P. S. and P. Cornillon, 1997:. Long baroclinic Rossby waves detected by TOPEX/Poseidon. Journal of Geophysical Research: Oceans (1978-2012) 102(C2), 32153235 .

Polito, P. S. and W. T. Liu, 2003:. Global characterization of Rossby waves at several spectral bands. Journal of Geophysical Research: Oceans (1978-2012) 108(C1).

Polito, P. S. and O. Sato, 2003:. Patterns of sea surface height and heat storage associated to intraseasonal rossby waves in the tropics. Journal of Geophysical Research: Oceans (19782012) 108(C12).

Polito, P. S. and O. T. Sato, 2008:. Global interannual trends and amplitude modulations of the sea surface height anomaly from the TOPEX/Jason-1 altimeters. Journal of Climate 21(12), 2824-2834.

Polito, P. S. and O. T. Sato, 2015:. Do eddies ride on Rossby waves? Journal of Geophysical Research: Oceans 120(8), 5417-5435.

Qiu, B. and S. Chen, 2006:. Decadal variability in the large-scale sea surface height field of the South Pacific Ocean: Observations and causes. Journal of Physical Oceanography 36(9), $1751-1762$. 
Quartly, G. D., P. Cipollini, D. Cromwell, and P. G. Challenor, 2003:. Rossby waves: Synergy in action. Philosophical Transactions of the Royal Society of London. Series A: Mathematical, Physical and Engineering Sciences 361(1802), 57-63.

Rosati, A. and K. Miyakoda, 1988:. A general circulation model for upper ocean simulation. Journal of Physical Oceanography 18(11), 1601-1626.

Rossby, C.-G. et al., 1939:. Relation between variations in the intensity of the zonal circulation of the atmosphere and the displacements of the semi-permanent centers of action. Journal of Marine Research 2(1), 38-55.

Ryan, J. P., P. S. Polito, P. G. Strutton, and F. P. Chavez, 2002:. Unusual large-scale phytoplankton blooms in the equatorial pacific. Progress in Oceanography 55(3), 263-285.

Sasaki, H., Y. Sasai, M. Nonaka, Y. Masumoto, and S. Kawahara, 2006:. An eddy-resolving simulation of the quasi-global ocean driven by satellite-observed wind field. Journal of the Earth Simulator, 6, 35-49.

Sasaki, Y. N., S. Minobe, N. Schneider, T. Kagimoto, M. Nonaka, and H. Sasaki, 2008:. Decadal sea level variability in the South Pacific in a global eddy-resolving ocean model hindcast. Journal of Physical Oceanography 38(8), 1731-1747.

Sato, O., P. Polito, and W. Timothy Liu, 2002:. Intra-decadal variability in the ekman heat flux from scatterometer winds. Geophysical research letters 29(17), 12-1.

Sato, O. T. and P. S. Polito, 2005:. Comparison of the global meridional ekman heat flux estimated from four wind sources. Journal of physical oceanography 35(1), 94-108.

Sato, O. T. and T. Rossby, 2000:. Seasonal and low-frequency variability of the meridional heat flux at $36^{\circ} \mathrm{N}$ in the North Atlantic. Journal of Physical Oceanography, 30, 600-621.

Schlax, M. G. and D. B. Chelton, 1994:. Aliased tidal errors in TOPEX/Poseidon sea surface height data. Journal of Geophysical Research: Oceans (1978-2012) 99(C12), 24761-24775.

Semtner, A. J. and R. M. Chervin, 1992:. Ocean general circulation from a global eddyresolving model. Journal of Geophysical Research: Oceans (1978-2012) 97(C4), 54935550 .

Semtner Jr., A., 1986:. Finite-difference formulation of a world ocean model. Springer.

Slangen, A., C. Katsman, R. Van de Wal, L. Vermeersen, and R. Riva, 2012:. Towards regional projections of twenty-first century sea-level change based on IPCC SRES scenarios. Climate Dynamics 38(5-6), 1191-1209. 
Smith, R., P. Jones, B. Briegleb, F. Bryan, G. Danabasoglu, J. Dennis, J. Dukowicz, C. Eden, B. Fox-Kemper, P. Gent, et al., 2010:. The Parallel Ocean Program (POP) reference manual: Ocean component of the Community Climate System Model (CCSM). Los Alamos National Laboratory, LAUR-10-01853.

Smith, R. D., M. E. Maltrud, F. O. Bryan, and M. W. Hecht, 2000:. Numerical simulation of the North Atlantic Ocean at 1/10. Journal of Physical Oceanography 30(7), 1532-1561.

Smith, W. and P. Wessel, 1990:. Gridding with continuous curvature splines in tension. Geophysics 55(3), 293-305.

Stommel, H., 1948:. The westward intensification of wind-driven ocean currents. Eos, Transactions American Geophysical Union 29(2), 202-206.

Stramma, L. and R. G. Peterson, 1990:. The South Atlantic Current. Journal of Physical Oceanography 20(6), 846-859.

Stumpf, H. G. and R. V. Legeckis, 1977:. Satellite observations of mesoscale eddy dynamics in the eastern tropical Pacific Ocean. Journal of Physical Oceanography 7(5), 648-658.

Subrahmanyam, B., D. M. Heffner, D. Cromwell, and J. F. Shriver, 2009:. Detection of Rossby waves in multi-parameters in multi-mission satellite observations and HYCOM simulations in the Indian Ocean. Remote Sensing of Environment 113(6), 1293-1303.

Sverdrup, H. U., 1947:. Wind-driven currents in a baroclinic ocean; with application to the equatorial currents of the eastern Pacific. Proceedings of the National Academy of Sciences of the United States of America 33(11), 318.

Taguchi, B., S.-P. Xie, H. Mitsudera, and A. Kubokawa, 2005:. Response of the Kuroshio extension to Rossby waves associated with the 1970s climate regime shift in a high-resolution ocean model. Journal of Climate 18(15), 2979-2995.

Taguchi, B., S.-P. Xie, N. Schneider, M. Nonaka, H. Sasaki, and Y. Sasai, 2007:. Decadal variability of the kuroshio extension: Observations and an eddy-resolving model hindcast*. Journal of Climate 20(11), 2357-2377.

Talley, L. D., G. L. Pickard, W. J. Emery, and J. H. Swift, 2011:. Descriptive physical oceanography: an introduction. Academic press.

Uz, B. M., J. A. Yoder, and V. Osychny, 2001:. Pumping of nutrients to ocean surface waters by the action of propagating planetary waves. Nature 409(6820), 597-600.

Vaid, B., C. Gnanaseelan, P. Polito, and P. Salvekar, 2007:. Influence of Pacific on southern Indian Ocean Rossby waves. In Atmospheric and Oceanic, pp. 1765-1785. Springer. 
Webb, D. J., 2000:. Evidence for shallow zonal jets in the South Equatorial Current region of the southwest Pacific. Journal of Physical Oceanography 30(4), 706-720.

Wessel, P. and D. Bercovici, 1998:. Interpolation with splines in tension: a Green's function approach. Mathematical Geology 30(1), 77-93.

White, W. B., 1977: Annual forcing of baroclinic long waves in the tropical North Pacific Ocean. Journal of Physical Oceanography 7(1), 50-61.

White, W. B., 1982:. Traveling wave-like mesoscale perturbations in the North Pacific Current. Journal of Physical Oceanography 12(3), 231-243.

White, W. B., 1983:. Westward propagation of short-term climatic anomalies in the western North Pacific Ocean from 1964-1974. Journal of Marine Research 41(1), 113-125. 